\author{
Universidade de São Paulo \\ Instituto de Física
}

\title{
Excitação de Ondas de Helicon e de Alfvén no Tokamak TCABR
}

\author{
Paulo Giovane Paschoali Pereira Puglia
}

Orientador: Prof. Dr. Artour Elfimov

Dissertação de Mestrado apresentada ao Instituto de Física para a obtenção do título de Mestre em Ciências

Comissão examinadora:

Prof. Dr. Artour Elfimov (IFUSP)

Prof. Dr. Edson Del Bosco (INPE)

Prof. Dr. Ruy Pepe da Silva (IFUSP)

São Paulo

2011 
FICHA CATALOGRÁFICA

Preparada pelo Serviço de Biblioteca e Informação do Instituto de Física da Universidade de São Paulo

\begin{tabular}{|l|}
\hline Puglia, Paulo Giovane Paschoali Pereira \\
Excitação de Ondas de Helicon e de Alfvéns no \\
Tokamak \\
TCABR. - São Paulo, 2011. \\
Dissertação (Mestrado) - Universidade de São Paulo. \\
Instituto de Física - Depto. de Física Aplicada \\
Orientador: Prof. Dr. Artour Efimov \\
Área de Concentração: Física de Plasma \\
Unitermos:1. Física; 2. Eletromagnetismo; 3.Física \\
Experimental. \\
USP/IF/SBI-029/2011
\end{tabular}




\section{Resumo}

O objetivo do trabalho é a investigação da excitação de ondas no plasma com o uso de uma antena externa e fazer uma análise das ressonâncias de Alfvén encontradas. O sistema de antenas de Alfvén no tokamak TCABR foi desenhado para aquecimento do plasma por meio de ressonâncias. Além do aquecimento, é possível usar a detecção de ondas excitadas com o uso da antena para objetivos de diagnóstico do plasma, encontrando o valor do perfil de segurança e massa efetiva dos íons.

Por causa de uma falha nos diodos do campo toroidal usamos o regime de disparos de limpeza, com campo magnético toroidal mais fraco que de disparos típicos do TCABR, para os testes do método de excitação e identificação de ressonâncias no plasma. Com o uso do circuito demodulador foram medidas ondas de helicon excitadas com a antena de Alfvén no plasma de limpeza usando as sondas magnéticas e de Langmuir. Com simulação foi possível identificas as ondas medidas. Há disponível um gerador de frequência variável que foi utilizado junto desse experimento. Ambos os equipamentos se encontram preparados para uso, sendo a próxima etapa usar o plasma típico de disparo do TCABR, que tem maior densidade que o plasma de limpeza. As medidas realizadas foram um teste para o circuito demodulador e gerador de frequência variável, que teve seu comportamento comparado com os dados de um osciloscópio de alta frequência de amostragem.

Os equipamentos do TCABR usados nos experimentos, as antenas e sondas magnéticas, um gerador de baixa potência com frequência variável, um circuito demodulador, sonda de Langmuir e o reflectômetro, que tem alta taxa de amostragem $(200 M H z)$ e varredura de frequência na banda de $18-40 G H z$. São todos descritos na dissertação.

Para modelagem das ressonâncias de Alfvén foi feito o cálculo do tensor dielétrico do plasma para o modelo cinético e para o limite magnetohidrodinâmico. Por meio de simulação computacional e cálculos considerando plasma como um fluido de 2 componentes, no caso prótons e elétrons, é possível determinar alguns tipos de onda que podem ser excitadas no plasma e sua relação de dispersão, foram calculadas a onda magnetossônica rápida e a onda global de Alfvén. Determinamos radialmente a posição dos campos eletromagnéticos no plasma.

Usando o reflectômetro foram medidas as ressonâncias das ondas de Alfvén na borda do plasma induzidas pelas antenas, com o plasma típico do tokamak, com densidade mais alta e o gerador de alta potência com frequência fixa. O método para achar as ressonâncias nos dados do reflectômetro foi com o uso de sidebands que aparecem em torno da frequência da ressonância no sinal do reflectômetro, que é a frequência do gerador. As sidebands foram 
analisadas com um espectrograma dos dados. As ondas excitadas na borda do plasma puderam ser identificadas também nas simulações.

Os resultados da análise mostram que foi possível medir as ondas no plasma que foram excitadas com o uso das antenas e tanto o circuito demodulador com o uso de sondas magnéticas como o reflectômetro são adequados para se achar ressonâncias no plasma. 


\section{Abstract}

The objective of this work is to investigate the excitation of waves in a plasma using an antenna and to analyse the Alfvén resonances found. The Alfvén antenna heating system of the TCABR tokamak was designed to heat the plasma due to resonances.

As the diodes of the toroidal field had burned down we used cleaning discharges, with low toroidal magnetic field, to test the excitation method and the identification of plasma resonances. With the demodulator circuit we measured helicon waves excited with the Alfvén antenna in the cleaning plasma using Langmuir and magnetic probes. With computational simulation we found the measured waves. A generator of variable frequency was used in this experiment. Both equipments are prepared for future experiments with the typical plasma of the TCABR, which has higher density than the cleaning plasma. This work was aimed to test to the demodulator circuit and the variable frequency generator, the data obtained were compared to that of a high sampling frequency oscilloscope.

It is presented the description of the TCABR equipments used, antenna, magnetic probe, variable frequency generator of low power, demodulator circuit, Langmuir probe and a reflectometer which has a high sampling frequency $(200 \mathrm{MHZ}$ ) and frequency scanning in the range $18-40 \mathrm{GHz}$, and was built in Portugal.

In order to have a model of Alfvén resonances we calculated the plasma dieletric tensor both in the kinetic and magnetohydrodynamic limits. With computational simulation and using a two fluid model, protons and electrons, it is possible to find some of the excited waves in the plasma and its dispersion relation, we calculated the fast magnetosonic wave and the global Alfvén wave. We found the radial position of the electromagnetic fields in the plasma.

With the reflectometer we measured resonances of Alfvén waves induced by the antenna at the plasma border in a typical TCABR tokamak plasma discharge, with higher density and a high power fixed frequency generator. We used sidebands as a method to find out the resonances in the reflectometer data. These sidebands are localized around the resonance frequency, which is the Alfvén wave generator frequency. The sidebands were analysed with spectrograms of the data. The waves excited at the plasma border were also found in the simulation.

The analysis results show that we could detect the plasma waves excited with the antennas. The demodulator circuit along with magnetic probes and the reflectometer can be used to find plasma resonances. 


\section{Agradecimentos}

Agradeço primeiramente a meu pai, minha mãe, minha família e meus amigos, pessoas que sem o incentivo não teria completado este projeto.

Especialmente ao Prof. Dr. Artour Elfimov e ao Dr. Leonid Ruchcko, pela orientação, disponibilidade e a amizade e convívio por 4 anos, sem o qual o apoio não teria sido possível realizar este projeto. Agradeço também todos os membros do TCABR pelo suporte e apoio em todos os momentos. Nestes 4 anos que estou no laboratório todos foram essenciais.

Por fim, agradeço a FAPESP (Fundação de Amparo a Pesquisa do Estado de São Paulo) pelo apoio financeiro a este projeto. 


\section{Sumário}

1 Introdução 1

1.1 Fusão termonuclear controlada . . . . . . . . . . . . . . . . . . 1

1.2 Tokamaks . . . . . . . . . . . . . . . . 3

1.3 Métodos de aquecimento do plasma . . . . . . . . . . 5

1.3.1 Aquecimento por radio frequência $(\mathrm{RF}) \ldots \ldots$

1.3.2 Injeção de partículas neutras . . . . . . . . . . . 7

1.4 TCABR ....................... 7

1.5 Ondas de Alfvén . . . . . . . . . . . . . . . . . . . 8

1.6 Proposta da dissertação . . . . . . . . . . . . . . . . . . . 10

1.7 Estrutura da dissertação . . . . . . . . . . . . . . . . . . . 10

2 Modelo do plasma e cálculos analíticos 11

2.1 Calculo do tensor dielétrico . . . . . . . . . . . . . . . . . 12

2.2 Cálculo do tensor dielétrico no limite MHD com rotação . . . 17

2.3 Ondas globais de Alfvén . . . . . . . . . . . . . . . . . . . . 19

3 Cálculos Computacionais $\quad 25$

4 Descrição dos equipamentos $\quad 31$

4.1 Antenas e sondas magnéticas . . . . . . . . . . . . . . . . . . . . . . . . . . 32

4.2 Sonda de Langmuir . . . . . . . . . . . . . . . . . . . 35

4.3 Circuito demodulador . . . . . . . . . . . . . . 36

4.4 Reflectômetro . . . . . . . . . . . . . . . . . 40

4.5 Gerador RF com varredura de frequência . . . . . . . . . . . . 42

5 Teste de excitação de ondas de RF no TCABR no modo de limpeza - Helicon 43

5.1 Sumário do capítulo . . . . . . . . . . . . . . . . . . . . 48 
6 Medidas de perturbações de densidade por ondas de Alfvén com reflectômetro

6.1 Metodologia . . . . . . . . . . . . . . . 49

6.2 Resultados e análise . . . . . . . . . . . . . . . . . . 50

6.3 Simulações . . . . . . . . . . . . . . . . . . . . 57

6.4 Sumário do capítulo . . . . . . . . . . . . . . . . 58

7 Conclusão $\quad 59$

8 Sugestão para trabalhos futuros $\quad 61$

A Código do Matlab usado para análise dos dados do reflectômetro

Referências bibliográficas 


\section{Capítulo 1}

\section{Introdução}

\subsection{Fusão termonuclear controlada}

Há no mundo uma necessidade cada vez maior de energia, sendo cada vez maior o consumo de energia elétrica conforme há avanços tecnológicos, junto com o aumento da população humana e da atividade econômica que propicia esses avanços. Para suprir essa demanda são necessárias fontes de energia. A mais usada atualmente, vem da queima de combustíveis fósseis e tem causado desagrado pois é uma fonte de energia não renovável, cuja previsão de esgotamento das reservas fósseis é da ordem de 100 anos, e além disso coloca dejetos na atmosfera que são causadores do aquecimento global, principalmente o $\mathrm{CO}_{2}[1]$.

No Brasil há um grande uso de usinas hidroelétricas, mas sua construção é cara e depende muito da geografia da região e da disponibilidade de rios. Além de sua construção causar impacto ambiental, alagando regiões e alterando a ecologia do local. A energia eólica não tem o potencial de suprir as necessidades energéticas disponíveis e seu impacto no ambiente ainda é motivo de discussão[2].

Alternativas a estas fontes são a energia solar e a energia nuclear, a primeira é muito cara no momento, não sendo viável economicamente pois a produção de células fotovoltaicas é cara, além deste modo há a possibilidade de usar um sistema de espelhos para aquecer água e fazer vapor para produzir energia elétrica, mas este último ocupa um espaço grande e funciona só em dias ensolarados. Outro empecilho é que se fica a disposição do clima, prolongados períodos de chuva ou muitas nuvens poderia causar falta de energia e é necessário armazenar energia para a noite, pois apenas há produção de energia de dia.

Já a energia nuclear é uma fonte economicamente e ecologicamente viável. 
Apesar de apresentar resíduos radioativos, se estes forem bem manuseados e estocados em lugar próprio e inóspito não devem causar problemas. É uma fonte de energia aparentemente segura, mas no passado já houve um acidente, Chernobyl[3, 4, 5], que deixou uma área de um raio de $30 \mathrm{~km}$ que não poderá ser utilizada plenamente por 60-200 anos após a data do acidente. Além deste acidente houve outro em Tree Mile Island tmisland, mas de proporções menores. Pode-se argumentar que foi um evento raro, um acidente, com baixa chance de ocorrer. Mas conforme se proliferam usinas nucleares as chances de algum acidente ocorrer são maiores, com milhares de usinas funcionando, basta algum pequeno problema em uma delas pode causar um acidente de grandes proporções.

Por isso, seria desejável uma alternativa que não tivesse esse perigo em potencial, uma destas é a fusão nuclear, que ao contrário das usinas nucleares que trabalham com a fissão nuclear, que é a quebra de um núcleo atômico pesado, se baseia no processo inverso, que é juntar dois núcleos leves. Para isso é necessário vencer a força elétrica que repele os núcleos colocando-os muito próximos, fazendo-os colidir com energia suficiente para que a força nuclear forte se manifeste e junte-os.

Foram pensados diversos dispositivos para se atingir fusão termonuclear, o que teve maior avançado foi o tokamak. Este dispositivo confina o plasma em um campo magnético toroidal. Outra característica é seu regime de operação ser pulsado. Neste trabalho foi usado o plasma produzido por uma maquina deste tipo.

Além do tokamak, há outra maquina com confinamento magnético chamada de stellarators, parecidas com os tokamaks. Mas apresentam uma corrente contínua e o campo de confinamento tem uma geometria complexa. Nos stellarators ainda não se consegue atingir densidades tão altas quanto nos tokamaks devido há turbulência e movimentos caóticos. Resta ainda avanços para serem feitos em seu confinamento, para atingirem a mesma condição de confinamento do plasma dos tokamaks.

Há também o confinamento inercial, que é atingido com lasers muito potentes, que energizam as partículas e estas podem realizar fusão. Por causa do uso militar deste sistema as pesquisas são confidenciais e não há projetos de pesquisa no Brasil.

A reação pretendida para se gerar energia é de trítio e deutério, pois é a mais vantajosa, já que a seção de choque desta é maior para energias mais baixas. O produto dessa reação é um núcleo de hélio e um nêutron com energia cinética, a partir dai o processo para gerar energia é análogo ao de uma usina nuclear, que também envolve nêutrons energéticos. A reação é exotérmica, havendo a ignição ela pode continuar sendo auto-sustentável. 


\subsection{Tokamaks}

Como mencionado, os melhores resultados para se atingir a fusão nuclear foram atingidos por tokamaks, que são máquinas toroidais de confinamento magnético. A maquina foi idealizada na antiga União Soviética pelos físicos A. D. Sakharov e I. E. Tamm nos anos 1950 [6, 7, 8]. Ainda na década de 50 um laboratório russo, chefiado por L. A. Artsimovich no Instituto Kurchatov em Moscow começou a fazer pesquisas com tokamaks. No começo, projetos sobre fusão nuclear e plasma eram confidenciais, estando ligado a pesquisa nuclear e de armas [9]. Depois que a possibilidade para produzir energia elétrica foi descoberta, aos poucos os trabalhos deixaram de ser confidenciais. Hoje há um esforço de diversas nações para se chegar a fusão termonuclear controlada.

Desde esses primeiros passos houve grandes avanços no confinamento de plasmas em tokamaks. Um dos critérios para se determinar a condição necessária para a fusão é conhecido como critério de Lawson [10]

$$
\hat{n} \tau_{e} \hat{T}>5 \times 10^{21} \mathrm{~m}^{-3} \text { skeV, }
$$

onde $\hat{n}$ é a densidade no centro do plasma, $\hat{T}$ é a temperatura no centro do plasma e $\tau_{e}$ é o tempo de confinamento de energia, que é

$$
\tau_{e}=\frac{\int \frac{3 n}{2}\left(T_{i}+T_{e}\right) d V}{P}
$$

Sendo $\mathrm{P}$ a potência total depositada no plasma, vemos que $\tau_{e}$ é a razão da energia térmica do plasma pela potência necessária para manter essa energia. Esse fator aumenta com o tamanho do tokamak. Quanto maior o volume se tem um melhor confinamento.

A equação 1.1 apresenta um grande progresso ao longo dos anos, sendo comparável com a evolução do processamento dos computadores até o começo da década de 90, quando parou de se fazer tokamaks maiores. Agora se tem o projeto para um protótipo de reator.

Nos tokamaks há 2 campos principais para o confinamento, um é um campo toroidal criado por bobinas colocadas em volta do toróide, o outro é um campo poloidal, criado pela corrente do próprio plasma. Assim se tem linhas de campo com trajetórias helicoidais em torno do toroide. Na figura 1.1 podemos ver uma ilustração dos principais componentes de um tokamak.

No tokamak o plasma pode ser criado por um disparo ôhmico, que consiste de uma descarga elétrica realizada na parte central, na direção ao longo do toroide. Isso gera uma mudança de fluxo magnético, de modo a criar o plasma. Que é aquecido até uma temperatura que não é suficiente para atingir fusão nuclear, poucos $k e V$, por aquecimento ôhmico. Como é necessário 


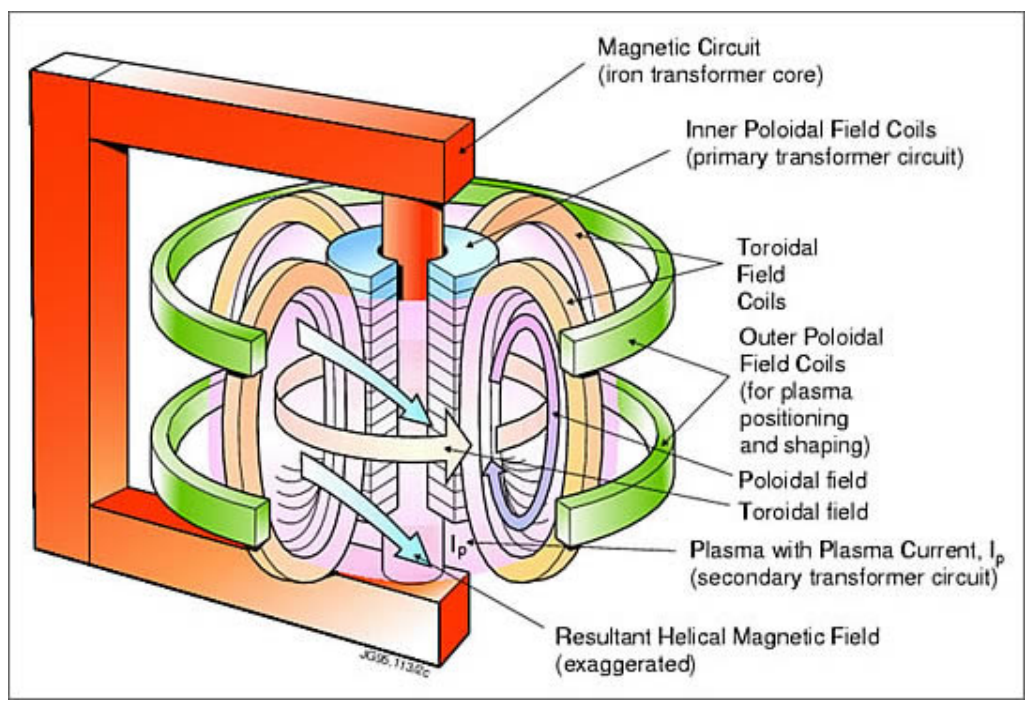

Figura 1.1: Esquema representativo de um tokamak, como o JET [11].

uma corrente variável em apenas uma direção para se ter esse disparo, ele não pode ser muito longo, por limitações tecnológicas, por isso os tokamaks funcionam em regime pulsado. Não é algo muito motivador neste aspecto, pois envolve alta potência, e é necessária manutenção constante pois como é pulsado há mais chances de dano aos equipamentos.

Não é possível aquecer o plasma à uma temperatura alta que é suficiente para gerar fusão pelo apenas regime ôhmico pois a resistência do plasma diminui com a temperatura na forma $T^{-3 / 2}[12]$, a temperatura estimada é de $10 \mathrm{keV}\left(\sim 10^{8} \mathrm{~K}\right)$ [13]. Ou seja é necessário um método auxiliar de aquecimento para continuar a aquecer o plasma.

Alem destes problemas, o plasma é altamente instável, havendo problemas e fenômenos que não são inteiramente compreendidos, fazendo com que o plasma acabe, ou seja, o disparo não dura muito tempo por instabilidades do próprio plasma, que é um sistema complexo e caótico. Fazendo com que o confinamento do plasma seja algo totalmente não trivial.

No JET Joint European Torus, localizado na Inglaterra e maior tokamak em operação hoje, já foi realizada fusão nuclear [14], mas de modo modesto, não suficiente para se produzir energia, sendo que a energia liberada era menor que a usada para produzi-la, foram produzidos $16 M W$ por fusão nuclear. O JET está em operação desde a década de 80 e é um projeto europeu, mas com colaborações internacionais. Já são usados deutério e trítio como componentes para o plasma e para fazer pesquisas diretamente ligadas ao funcionamento de um reator nuclear. Atualmente está em operação de modo a ser semelhante a um protótipo de um reator nuclear. 
O protótipo do reator nuclear é o ITER (International Thermonuclear Experimental Reactor) [15], que deve ser construído na França, é uma cooperativa internacional. A expectativa é que o ITER produza $500 M W$ de potência por fusão nuclear, sendo necessário $50 \mathrm{MW}$ para manter o plasma, o disparo deve durar por $1000 \mathrm{~s}$. Será usado $0,5 \mathrm{~g}$ de deutério e trítio para a reação de fusão, que formahélio e libera um nêutron energético.

\subsection{Métodos de aquecimento do plasma}

Como mencionado, é necessário algum método auxiliar de aquecimento além do aquecimento ôhmico do próprio disparo, já que a resistividade do plasma diminui com a temperatura

$$
\eta=0,51 \frac{m_{e}^{1 / 2} e^{2} \ln \Lambda}{3 \epsilon_{0}^{2}\left(2 \pi T_{e}\right)^{3 / 2}} .
$$

Como podemos notar, é inversamente proporcional à temperatura na potência $3 / 2$. É necessário métodos alternativos para se aquecer o plasma. Alguns dos métodos são brevemente descritos a seguir.

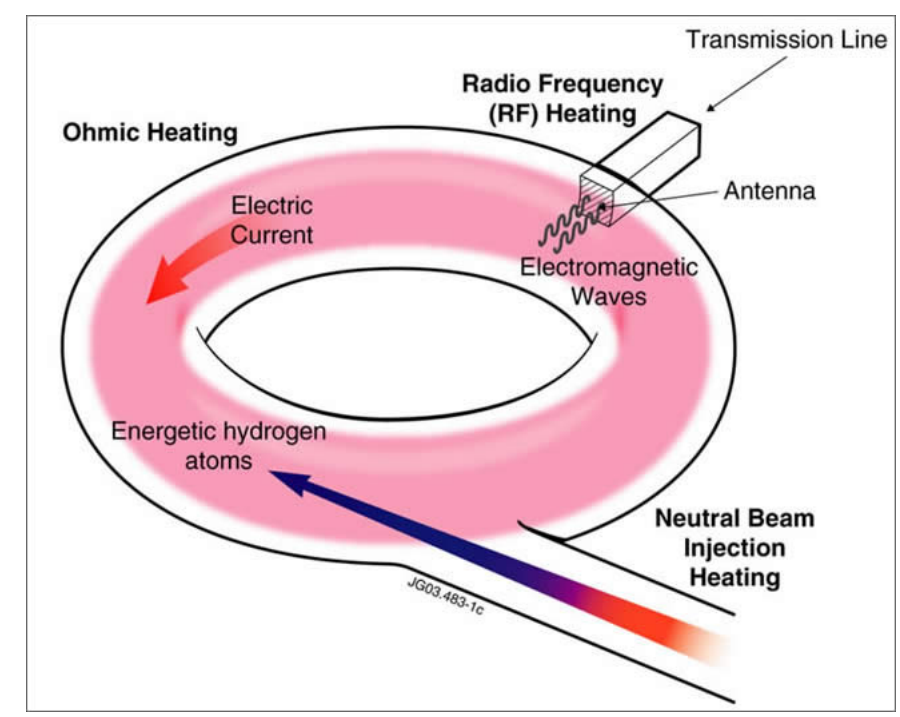

Figura 1.2: Esquema das formas de aquecimento auxiliar para o plasma [11].

\subsubsection{Aquecimento por radio frequência $(\mathrm{RF})$}

Usando ondas de RF é possível aquecer o plasma por colisões, que é semelhante ao aquecimento ôhmico e não serve para altas temperaturas, mas tam- 
bém há absorção cinética ressonante de Landau das ondas eletromagnéticas pelo plasma, através de algumas frequências específicas, que são frequências com alguma ressonância no plasma [16]. Por amortecimento de Landau é possível aquecer o plasma com estas ressonâncias [17, 18], chegando a temperaturas mais altas, que são necessárias para a fusão. As ondas utilizadas são listadas a seguir, as frequências mostradas são de valores aproximados para o plasma de fusão em tokamaks, sendo que os valores são completamente diferentes para diferentes tipos de plasma, como a ionosfera:

- Ondas de Alfvén, que são estudadas neste trabalho são usadas no tokamak TCABR do Instituto de Física da USP. Mas não tem um projeto para serem utilizadas para aquecimento do ITER. Busca-se usar ondas globais que aqueceriam o plasma como um todo, uma região larga, mas sendo mais intensa na parte central do plasma. Não sendo desejável excitar a borda da coluna de plasma. Com a frequência dos geradores na banda de rádio frequência é possível excitar ondas de Alfvén, que é o que propõe este trabalho. A sua vantagem é que já há muitos equipamentos prontos que atuam nessa banda de frequência, que é da ordem de poucos $\mathrm{MHz}$, e são muito bem conhecidos. Alem de terem um custo mais baixo.

- Onda ciclotrônica de íons (ICRH) tem frequência de $\sim 10-50 \mathrm{MHz}$, dependendo do campo magnético. Excita diretamente os íons e é possível determinar o local onde excitar as ondas no plasma por ajuste de frequência que depende do campo magnético toroidal do tokamak. O campo magnético toroidal é proporcional a $R^{-1}$ o inverso da distância ao eixo central do tokamak. Este método pode causar superaquecimento de íons, que produz instabilidades no plasma.

- Onda ciclotrônica eletrônica (ECRH), que tem frequência mais altas, $100-200 \mathrm{GHz}$, aquece apenas os elétrons e estes transmitem energia aos íons por colisões. Mas conforme se aumenta a densidade do plasma essas ondas não se propagam, pois ficam com uma frequência semelhante a frequência de plasma. O preço para esta forma de aquecimento é muito cara, pois se usa muita energia para se ter alta potência em uma frequência muito alta.

- Lower Hybrid Ressonance, tem uma frequência entre as duas anteriores, entre $1-10 G H z$, são usadas ondas de mesmo nome. Tem como vantagem se propagar muito bem nos guias de onda. A idéia é usar esta ressonância para excitar os íons. Um problema para este método é que apresenta limitações de densidade, funciona melhor com plasma de baixa densidade. 


\subsubsection{Injeção de partículas neutras}

Consiste em injetar átomos neutros no plasma, estes acabam se ionizando por colisão com o plasma e através de colisões elétron-íon transmitem energia ao plasma. Os átomos são lançados no plasma como um feixe energético. É necessário ter alta energia cinética para depois transmiti-la ao plasma.

É um método mais caro que aquecimento por RF. Precisa-se de um equipamento que é maior que o tokamak em si para se produzir as partículas energéticas. É um acelerador de partículas do lado do tokamak.

\subsection{TCABR}

O TCABR é o tokamak que se encontra na USP, no final da década de 1990 foi trazido para a São Paulo. Primeiramente ele foi utilizado em Lausanne na Suíça para experimentos de excitação de ondas de Alfvén [19, 20], porém não foi obtido o sucesso esperado no aquecimento do plasma [21]. Seu objetivo de construção é investigar ondas de Alfvén e como elas podem ser utilizadas para aquecer o plasma, através de antenas instaladas na câmara de vácuo [22] com as quais é possível excitar tais ondas. A única forma de aquecimento auxiliar disponível no TCABR são as antenas de Alfvén. Alguns parâmetros do TCABR estão apresentados na tabela 1.1.

Tabela 1.1: Parâmetros do TCABR

\begin{tabular}{|c|c|}
\hline \hline raio maior & $61,5 \mathrm{~cm}$ \\
\hline raio menor & $18,0 \mathrm{~cm}$ \\
\hline raio da parede do vaso & $24,0 \mathrm{~cm}$ \\
\hline raio da antena & $20 \mathrm{~cm}$ \\
\hline campo magnético toroidal & $1,11 \mathrm{~T}$ \\
\hline fator de segurança na borda & 3,5 \\
\hline densidade no centro do plasma & $\leq 3 \times 10^{13} \mathrm{~cm}^{-3}$ \\
\hline densidade na borda do plasma & $1 \times 10^{11} \mathrm{~cm}^{-3}$ \\
\hline temperatura no centro do plasma & $\leq 500 \mathrm{eV}$ \\
\hline temperatura na borda do plasma & $\sim 15 \mathrm{eV}$ \\
\hline corrente de plasma & $60-100 \mathrm{kA}$ \\
\hline duração do disparo & $\sim 100-150 \mathrm{~ms}$ \\
\hline
\end{tabular}

É um tokamak pequeno, que apresenta vantagens pois pode ser usado para treinamento de pessoal e é mais simples fazer algum teste novo do que em tokamaks maiores. É mais fácil instalar algum equipamento novo e realizar 
diversos disparos, pois o tempo de funcionamento de máquina é mais barato, além de haver mais acesso a máquina em si.

No TCABR se tem como diagnósticos de temperatura de elétrons os detectores de emissão ciclotrônica de elétrons (ECE) e espalhamento Thompson. Para medidas de densidade da linha há um interferômetro e um reflectômetro para densidade local. Outros equipamentos de diagnósticos são: medições de emissão de raio-X mole, medidas de linhas espectrais óticas, bobinas de Mirnov, sondas eletrostáticas e sondas magnéticas, para medida do campo excitado com a antena de Alfvén.

\subsection{Ondas de Alfvén}

Em um gás ideal apenas há a oscilação de ondas de pressão, que são ondas sonoras, a única força restauradora presente é a pressão térmica. Em um fluido magnetizado como o plasma, na presença de um campo magnético há mais duas forças de restauração das perturbações de pressão, a tensão associada as linhas de força do campo magnético e a pressão associada a densidade de energia do campo magnético. Por causa disso, na teoria magnetohidrodinâmica (MHD), ao invés de haver um único tipo de onda, há três, magnetossônica (rápida e lenta) e Alfvén [23].

A onda de Alfvén é incompressível, sendo assim é pouco afetada pela pressão de plasma. Já as outras duas envolvem compressão e o campo magnético, sendo chamadas de ondas magnetossônica rápida e lenta, devido a suas velocidades em relação a velocidade da onda de Alfvén, que é intermediária. A frequência da onda de Alfvén é baixa se comparada à frequência de ciclotron dos íons. Essas ondas MHD envolvem movimento conjunto de íons e elétrons, sendo que a frequência de plasma, possui uma frequência muito mais alta e envolve apenas o movimento dos elétrons, que tem uma inércia menor.

As ondas de Alfvén foram propostas por Hannes Alfvén, físico sueco ao qual devem seu nome, num artigo de 1942 onde trata-se ondas aplicadas a física solar [24]. No mesmo trabalho ele também introduziu a teoria MHD. Este trabalho lhe rendeu um prêmio Nobel de física, até hoje o único Nobel referente a física de plasma.

Ondas de Alfvén ocorrem quando o campo magnético sofre uma oscilação $[13,25,26]$. A velocidade da oscilação do plasma é perpendicular a propagação, por isto este tipo de onda também recebe o nome shear Alfvén wave, pois tem esse movimento paralelo de duas camadas do plasma. A força restauradora é produzida pelo campo magnético, o movimento das partículas do plasma faz com que o campo magnético oscile junto, a curvatura da os- 
cilação cria uma força de tensão magnética $\vec{B} \cdot \vec{\nabla} B$ na direção oposta a do movimento do plasma.

Para derivar uma expressão para a relação de dispersão das ondas de Alfvén podemos tomar o campo magnético de equilíbrio na direção $z$. O vetor de onda $\vec{k}$ é tomado no plano $z x$. Assim, a movimentação do plasma se dá na direção $y$.

Tomamos quantidades na forma $A=A_{0}+A_{1} e^{i\left(-\omega t+k_{x} x+k_{z} z\right)}$, onde $A_{1}$ é uma perturbação, sendo muito menor que $A_{0}$, o parâmetro de equilíbrio.

Temos a equação de força de Lorentz, sem campo elétrico.

$$
\rho \partial_{t} \vec{v}=\frac{1}{c} \vec{j} \times \vec{B} \quad \rightarrow \quad-\frac{1}{c} i \rho \omega v_{y 1}=-j_{x 1} B_{0}
$$

E as equações de Maxwell:

$$
\begin{array}{r}
\frac{4 \pi}{c} \vec{j}=\vec{\nabla} \times \vec{B} \quad \rightarrow \quad \frac{4 \pi}{c} j_{x 1}=-i k_{z} B_{y 1} \\
\frac{1}{c} \partial_{t} \vec{B}=-\vec{\nabla} \times \vec{E} \quad \rightarrow \quad-\frac{1}{c} i \omega B_{y 1}=-k_{z} E_{x 1}+k_{x} E_{z 1} \\
\vec{E}=-\frac{1}{c} \vec{v} \times \vec{B} \quad \rightarrow \quad E_{z 1}=0 \quad, \quad E_{x 1}=\frac{1}{c} v_{y 1} B_{0}
\end{array}
$$

Combinando estas fórmulas chegamos a relação de dispersão

$$
\frac{\omega}{k_{z}}=V_{A}=\frac{B_{0}}{\sqrt{4 \pi \rho}}
$$

A velocidade $V_{A}$ é chamada de velocidade de Alfvén, que é independente do valor de $k_{\perp}$, só dependendo da componente $k_{x}$, que é paralela ao campo magnético.

Se forem usadas coordenadas cilíndricas, que é uma aproximação para o tokamak, teremos

$$
\omega_{A}=\frac{V_{A}}{R_{0}}\left(N+\frac{M}{q}\right)
$$

onde $N$ é o número de onda toroidal, $R_{0}$ o raio maior do tokamak e $M$ o número de onda poloidal e $q=\frac{r B_{0}}{R_{0} B_{0 \theta}}$ é o fator de segurança.

As medidas das ondas de Alfvén podem ser usadas para se fazer diagnósticos no plasma. Sendo possível medir a composição de isótopos nos plasmas de fusão e o perfil do $q(r)$ nos tokamaks [27]. 


\subsection{Proposta da dissertação}

O objetivo deste trabalho é realizar um estudo das ondas Alfvén que podem ser excitadas no TCABR com o uso de geradores na banda de radiofrequência de $\sim 1-6 \mathrm{MHz}$. Que podem excitar ondas de Alfvén no plasma do tokamak TCABR. É feito um estudo dos tipos de ressonância que podem ocorrer com a excitação de ondas no plasma, por uma antena externa que há no TCABR, com o uso de cálculos do tensor dielétrico do plasma e simulações computacionais com código ALTOK. Temos a possibilidade de excitar a onda global de Alfvén, que pode aquecer o plasma na parte central. Também é possível excitar ondas de Alfvén locais, que podem ser usadas para diagnóstico do plasma [27].

Como trabalho experimental foi feito a reestruturação de um circuito demodulador com o intuito de medir a amplitude e a frequência das ondas de Alfvén sondas magnéticas. Foram feitos testes com este circuito que pode ser usado para medidas de ondas de Alfvén excitadas pela antena.

Foi estudado um método de uso de um reflectômetro [28] para determinar a densidade e a posição onde pode haver perturbações de densidade causadas por ressonâncias locais de Alfvén no plasma.

\subsection{Estrutura da dissertação}

O capítulo 2 apresenta cálculos do tensor dielétrico do plasma, usando o modelo cinético e também no limite MHD. São feitos cálculos teóricos para se chegar aos tipos de onda que são propagadas no plasma. No capítulo 3 são feitas simulações do plasma do TCABR com código ALTOK cilíndrico disponível no laboratório, que é comparado com os cálculos teóricos.

O capítulo 4 apresenta uma descrição dos equipamentos experimentais disponíveis no TCABR que foram usados nessa dissertação. No capítulo 5 são apresentadas medidas do plasma de limpeza com um gerador de frequência variável com o circuito demodulador. No capítulo 5 estão as medidas feitas com o reflectômetro e o método para se achar ressonâncias.

No capítulo 6 apresentamos o sumário da dissertação. E no capítulo 7 sugestões para trabalhos futuros. 


\section{Capítulo 2}

\section{Modelo do plasma e cálculos analíticos}

Neste capítulo fazemos derivação do tensor dielétrico para o plasma e posteriormente são apresentados cálculos feitos a partir dele analiticamente. No capítulo seguinte são feitos cálculos com simulação computacional usando código [29] disponível no laboratório.

O estudo foi baseado nas equações de Maxwell em unidades de Gauss (cgs) na seguinte forma:

$$
\begin{gathered}
\vec{\nabla} \times \vec{B}=-i \frac{\omega}{c} \overleftrightarrow{\epsilon} \vec{E} \\
\vec{\nabla} \times \vec{E}=-i \frac{\omega}{c} \vec{B}
\end{gathered}
$$

Onde usamos $4 \pi j_{i}=i \Omega\left(\delta_{i j}-\epsilon_{i j}\right) E_{j}$. As equações levam a uma combinação:

$$
\vec{\nabla} \times \vec{\nabla} \times \vec{E}=\frac{\omega^{2}}{c^{2}} \overleftrightarrow{\epsilon} \vec{E}
$$

Para se calcular o rotacional são usadas coordenadas ligadas a direção do campo magnético, equação (2.25). Na direção paralela o campo elétrico é desconsiderado por ser muito pequeno. O rotacional na direção radial e perpendicular fica:

$$
(\vec{\nabla} \times \vec{\nabla} \times \vec{E})_{r}=\left(k_{\perp}^{2}+k_{\|}^{2}\right) E_{r}+\frac{i k_{\perp}}{r} \frac{\partial}{\partial r}\left(r E_{\perp}\right)-i k_{\|} r E_{\perp} \frac{\partial}{\partial r}\left(\frac{1}{r} \frac{B_{0_{\theta}}}{B_{0}}\right)
$$




$$
(\vec{\nabla} \times \vec{\nabla} \times \vec{E})_{\perp}=k_{\|}^{2} E_{\perp}-\frac{\partial}{\partial r}\left(i k_{\perp} E_{r}+\frac{1}{r} \frac{\partial}{\partial r}\left(r E_{\perp}\right)\right)+i k_{\|} r E_{r} \frac{\partial}{\partial r}\left(\frac{1}{r} \frac{B_{0_{\theta}}}{B_{0}}\right)
$$

Apresentamos as equações para a corrente oscilatória via componentes do tensor dielétrico

$$
\frac{\omega^{2}}{c^{2}} \overleftrightarrow{\epsilon} \vec{E}=\frac{\omega^{2}}{c^{2}}\left[\epsilon_{11} \vec{E}+\epsilon_{12}\left(\hat{e_{\|}} \times \vec{E}\right)+\frac{i c}{\omega} \frac{\left(\nabla \times B_{0}\right)_{\|}}{B_{0}}\left(\vec{B}-\vec{B}_{\|}\right)\right]
$$

\subsection{Calculo do tensor dielétrico}

Os cálculos do tensor são apresentados como os da referência [30] e os detalhes dos cálculos estão na referência [31]. Para modelarmos o aquecimento de um plasma colisional por radiofrequência usamos o modelo cinético de plasma $[32,17]$. No TCABR usamos a frequência da colisão elétron-íon $(\sim 100 k H z)$ como muito menor que a frequência da onda de Alfvén $(2-5 \mathrm{MHz})$, usada ou para aquecimento do plasma ou para diagnósticos. O comprimento de onda paralelo às linhas de campo magnético é menor que o livre caminho médio dos elétrons, ou seja, o plasma é pouco colisional. Sendo assim partimos da equação de Vlasov colisional com campo eletromagnético e das equações de Maxwell no sistema de unidades de Gauss (cgs):

$$
\frac{\partial F_{\alpha}}{\partial t}+\vec{v} \frac{\partial F_{\alpha}}{\partial \vec{r}}+\frac{e_{\alpha}}{m_{\alpha}}\left[\vec{E}+\frac{\vec{v}}{c} \times \vec{B}\right] \frac{\partial F_{\alpha}}{\partial \vec{v}}=\hat{S} t\left\{F_{\alpha}\right\},
$$

onde $F_{\alpha}$ é a função de distribuição, $e_{\alpha}$ é a carga e $m_{\alpha}$ a massa das partículas de determinada espécie $\alpha .(\vec{r}, \vec{v})$ é a posição no espaço de fase. $\vec{E}, \vec{B}$ e $\vec{J}$ são os campos elétrico, magnético e a corrente respectivamente. Não aparece a carga livre pois temos que o plasma é neutro para as distâncias consideradas nas equações. $\hat{S} t\left\{F_{\alpha}\right\}$ é o operador colisional na forma de Landau, e $c$ é a velocidade da luz.

Introduzimos coordenadas cilíndricas para o espaço de posição $(r, \theta, z)$ e de velocidade $\left(v_{r}, v_{\theta}, v_{z}\right)$, afim de deixar os cálculos mais simples e parecidos com a geometria espacial cilíndrica $(r, \theta, z)$, sendo o eixo z paralelo ao eixo to-

roidal do tokamak. Neste caso apresentamos perturbações do campo elétrico e magnético $\sim e^{i\left(m \theta+k_{z} z-\omega t\right)}$, como um modo do vetro de onda de oscilação.

$$
k_{\theta}=\frac{m}{r}, \quad k_{z}=\frac{N}{R},
$$


sendo $m$ o número do modo poloidal, $N$ o número do modo toroidal e $R$ o raio maior do tokamak. Apresentamos as componentes do campo eletromagnético como radial, binormal ou paralela em realação às linhas do campo magnético. A seguir temos as componentes paralela e binormal, sendo a componente radial a mesma que era antes da mudança para coordenadas magnéticas.

$$
\begin{gathered}
k_{b}=k_{\theta} h_{z}-k_{z} h_{\theta}, \quad k_{\|}=k_{z} h_{z}+k_{\theta} h_{\theta} \\
h_{z, \theta}=\frac{B_{z, \theta}}{B}, \quad B=\sqrt{B_{z}^{2}+B_{\theta}^{2}}
\end{gathered}
$$

O $h_{z, \theta}$ é a componente do versor unitário. Qualquer vetor que tivermos pode ser apresentado desta forma, no caso foi apenas apresentado para $\vec{k}$, mas vale para o campo elétrico e magnético.

Faremos então uma mudança das coordenadas de velocidade com relação ao campo magnético de equilíbrio, que está na direção $z$, ao longo do toróide, temos:

$$
v_{3}=v_{\|}, \quad v_{1}=v_{\perp} \cos \sigma, \quad v_{2}=v_{\perp} \sin \sigma
$$

Fazendo essas substituições em (2.7) e aproximando $\omega<\omega_{c i} \approx \frac{B_{z} e_{i}}{c m_{i}}$ chegase a:

$$
\begin{gathered}
\frac{\partial F_{\alpha}}{\partial t}+v_{\perp} \cos \sigma \frac{\partial F_{\alpha}}{\partial r}+\frac{v_{\perp}}{r} \sin \sigma \frac{\partial F_{\alpha}}{\partial r}+v_{\|} \frac{\partial F_{\alpha}}{\partial z}-\left(\frac{v_{\perp}}{r} \sin \sigma+\omega_{c}\right) \frac{\partial F_{\alpha}}{\partial \sigma}+ \\
\frac{e_{\alpha}}{m_{\alpha}}\left[\left(E_{r}-\frac{v_{\|}}{c} B \theta\right) \cos \sigma+\left(E_{\theta}+\frac{v_{\|}}{c} B_{r}\right) \sin \sigma\right] \frac{\partial F_{\alpha}}{\partial v_{\perp}}+ \\
\frac{e_{\alpha}}{m_{\alpha}}\left[\frac{v_{\perp}}{c}\left(B_{\theta} \cos \sigma-B_{r} \sin \sigma\right)+E_{z}\right] \frac{\partial F_{\alpha}}{\partial v_{\|}}+ \\
\frac{e_{\alpha}}{m_{\alpha}}\left[\left(E_{\theta}+\frac{v_{\|}}{c} B_{r}\right) \cos \sigma-\left(E_{r}-\frac{v_{\|}}{c} B_{\theta}\right) \sin \sigma\right] \frac{1}{v_{\perp}} \frac{\partial F_{\alpha}}{\partial \sigma}=\hat{S} t\left\{F_{\alpha}\right\}
\end{gathered}
$$

Vamos fazer uma expansão da perturbação da função de distribuição como uma série de Fourier:

$F=F_{M}+F_{b} \sin \sigma+F_{r} \cos \sigma+\left(f_{0}+\sum_{l \neq 0}\left[f_{r, l} \cos (l \sigma)+f_{b, l} \sin (l \sigma)\right]\right) e^{i\left(m \theta+k_{z} z-\omega t\right)}$ 
onde $F_{M}$ é uma distribuição maxwelliana, $F_{b}$ é a perturbação em primeira ordem na direção binormal e $F_{r}$ na direção radial, como primeiro passo resolvemos a equação do equilibrio. Tomaremos apenas termos com $l=1$ na equação (2.11). Os três primeiros termos da equação 2.11 representam uma solução estacionária para a equação de Vlasov, sem colisão e sem os campos eletromagnéticos. Substituindo estes termos na equação, com a ausência dos campos eletromagnéticos e sem colisões conclui-se que $F_{r}$ é nulo.

Supomos o operador colisional na forma de Krook [33, 34]:

$$
\hat{S} t\left\{F_{\alpha}\right\}=\nu_{e} F_{e}=\nu_{e} f_{0}
$$

Sendo assim, temos uma substituição de $\omega \rightarrow \Omega-i \nu_{e}$. Fazendo estas substituições para a perturbação em (2.10) e supondo que o raio de Larmor é muito menor que as inomogeneidades na direção radial, chega-se que:

$$
\begin{gathered}
i\left(k_{\|} v_{\|}-\omega\right) f_{0}+\frac{v_{\perp}}{2}\left(\frac{\partial f_{r}}{\partial r}+\frac{f_{r}}{r}+i \frac{m}{r} f_{b}\right)= \\
-\frac{e_{\alpha}}{m_{\alpha}}\left[E_{z} \frac{\partial F_{M \alpha}}{\partial v_{\|}}+\frac{E_{\theta}}{\omega_{c}} \frac{\partial}{\partial r}\left(\frac{F_{M \alpha}}{2}+\frac{v_{\perp}}{2} \frac{\partial F_{M \alpha}}{\partial v_{\perp}}\right)+\frac{v_{\|}}{2 c v_{\perp}} B_{r} F_{b}\right] \\
\omega_{c} f_{b}=-i\left(\omega-k_{\|} v_{\|}\right) f_{r}+v_{\perp} \frac{\partial f_{0}}{\partial r}+\frac{e_{\alpha}}{m_{\alpha}}\left(E_{r} \frac{\partial F_{M \alpha}}{\partial v_{\perp}}+\frac{B_{\theta}}{c} \frac{v_{\perp} v_{0}}{v_{T}^{2}} F_{M \alpha}\right) \\
\omega_{c} f_{r}=i\left(\omega-k_{\|} v_{\|}\right) f_{b}-i k_{b} v_{\perp} f_{0}-\frac{e_{\alpha}}{m_{\alpha}}\left(E_{\theta} \frac{\partial F_{M \alpha}}{\partial v_{\perp}}+E_{z} \frac{\partial F_{b}}{\partial v_{\|}}\right)
\end{gathered}
$$

A grandeza $v_{T}=\left(T_{\alpha} / m_{\alpha}\right)^{1 / 2}$ é a velocidade térmica da distribuição maxwelliana. Temos que a densidade de corrente oscilatória no plasma é dada pelas expressões:

$j_{r}=\sum_{\alpha} e_{\alpha} \int_{0}^{2 \pi} d \sigma \cos \sigma \int_{-\infty}^{\infty} d v_{\|} \int_{0}^{\infty} v_{\perp}^{2} \tilde{f}_{\alpha} d v_{\perp}=\pi \sum_{\alpha} e_{\alpha} \int_{-\infty}^{\infty} d v_{\|} \int_{0}^{\infty} v_{\perp}^{2} f_{r}^{\alpha} d v_{\perp}$

$j_{\theta}=\sum_{\alpha} e_{\alpha} \int_{0}^{2 \pi} d \sigma \sin \sigma \int_{-\infty}^{\infty} d v_{\|} \int_{0}^{\infty} v_{\perp}^{2} \tilde{f}_{\alpha} d v_{\perp}=\pi \sum_{\alpha} e_{\alpha} \int_{-\infty}^{\infty} d v_{\|} \int_{0}^{\infty} v_{\perp}^{2} f_{b}^{\alpha} d v_{\perp}$ 


$$
j_{z}=\sum_{\alpha} e_{\alpha} \int_{0}^{2 \pi} d \sigma \int_{-\infty}^{\infty} v_{\|} d v_{\|} \int_{0}^{\infty} v_{\perp} \tilde{f}_{\alpha} d v_{\perp}=2 \pi \sum_{\alpha} e_{\alpha} \int_{-\infty}^{\infty} v_{\|} d v_{\|} \int_{0}^{\infty} v_{\perp} f_{0}^{\alpha} d v_{\perp}
$$

E podemos determinar o tensor dielétrico a partir da relação [35]:

$$
4 \pi j_{i}=i \Omega\left(\delta_{i j}-\epsilon_{i j}\right) E_{j}
$$

Pegando termos em primeira ordem em relação a $\omega_{c}$ e sem considerar a parte relacionada a $F_{b}$, que esta relacionada a deriva, chegamos que:

$$
\begin{gathered}
\epsilon_{11}=\epsilon_{22}=1+\sum_{\alpha} \frac{\omega_{p \alpha}^{2}}{\omega_{c \alpha}^{2}}\left[1-\frac{\omega^{2}}{\omega_{c \alpha}^{2}}\right]^{-1}\left[1+\frac{v_{0 \alpha} k_{\|}}{\omega}\right]^{2} \\
\epsilon_{12}=-\epsilon_{21}=\sum_{\alpha} \frac{i \omega_{p \alpha}^{2}}{\omega_{c \alpha} \omega}\left[1-\frac{\omega^{2}}{\omega_{c \alpha}^{2}}\right]^{-1}\left[1+\frac{v_{0 \alpha} k_{\|}}{\omega}\right] \\
\epsilon_{33}=1+\sum_{\alpha} \frac{\omega_{p \alpha}^{2}}{k_{\|}^{2} v_{T \alpha}^{2}}, \Lambda_{\alpha}
\end{gathered}
$$

onde negligenciamos os termos $\epsilon_{i 3}$ e $\epsilon_{3 i}$ que são responsáveis pelo movimento de deriva, que não é importante para determinarmos as ressonâncias de Alfvén. Os números 1, 2 e 3 representam as direções radial, binormal e paralela, respectivamente. Temos ainda que:

$$
\Lambda_{\alpha}=1+i \sqrt{\pi} z_{\alpha} W\left(z_{\alpha}\right) \quad, \quad z_{\alpha}=\frac{w}{\sqrt{2} k_{\|} v_{T \alpha}}
$$

onde

$$
W\left(z_{\alpha}\right)=-\frac{i}{\pi} \int_{-\infty}^{\infty} \frac{\exp \left(-t^{2}\right) d t}{t-z_{\alpha}}
$$

é a função de Kramp, que é proporcional a função de dispersão do plasma [34], diferenciada apenas por uma constante, dado por:

$$
Z\left(z_{\alpha}\right)=i \sqrt{\pi} W\left(z_{\alpha}\right)
$$

sendo que $Z\left(z_{\alpha}\right)$ é a função de dispersão do plasma. No limite MHD, temos $\frac{\omega}{k_{\|}}>>v_{T i}, v_{T e}$, assim, assumimos a forma assintótica de $Z\left(z_{\alpha}\right)$ dada por: 


$$
Z\left(z_{\alpha}\right)=-\frac{1}{z_{\alpha}}-\frac{1}{2 z_{\alpha}^{2}}
$$

e obtemos o componente paralelo do tensor na aproximação de plasma frio

$$
\epsilon_{33} \approx 1-\sum_{\alpha} \frac{\omega_{p \alpha}^{2}}{\omega_{\alpha}^{2}}
$$




\subsection{Cálculo do tensor dielétrico no limite MHD com rotação}

Pretende-se calcular o tensor dielétrico pelo tensor de condutividade para um plasma magnetizado. Chegaremos no resultado apresentado na seção anterior mas sem a parte colisional e de dissipação, mas é possível incluir a rotação toroidal, pois este é um modelo mais simples que o cinético. O limite MHD, como já comentado na seção anterior, tem a aproximação $\frac{\omega}{k_{\|}}>>$ $v_{T i}, v_{T e}$. A rotação é importante na análise das ressonâncias causadas por causa do efeito Doppler.

Primeiramente se escreve a equação de força de Lorentz para os elétrons e íons, usando-se coordenadas relativas ao campo magnético, transformadas de coordenadas cilíndricas. $B_{0}$ é o módulo do campo magnético, principalmente paralelo à direção $z$ que é aplicado pelas bobinas externas ao plasma. Também inserimos a rotação toroidal nas equações. As coordenadas seguem com a transformação:

$$
\begin{gathered}
\vec{e}_{r}=\vec{e}_{r}, \\
\vec{e}_{b}=\vec{e}_{\theta}-\frac{B_{\theta}}{B_{0}} \vec{e}_{z}, \\
\vec{e}_{\|}=\frac{B_{\theta}}{B_{0}} \vec{e}_{\theta}+\vec{e}_{z}
\end{gathered}
$$

Podemos escrever a equação da continuidade e a partir dela determinar a equação da força de Lorentz, tendo um movimento de rotação na direção toroidal, que corresponde a componente paralela.

$$
n=-i \frac{n_{0}}{\bar{\omega}} \vec{\nabla} \cdot \vec{v}
$$

sendo $n$ a perturbação na densidade que é da forma

$$
n \sim e^{i\left(m \theta+k_{z} z-\omega t\right)}
$$

onde $n_{0}$ é a densidade não perturbada, $\vec{v}$ a perturbação da velocidade de plasma e definimos

$$
\bar{\omega} \equiv \omega-v_{0 \alpha} k_{\|},
$$

onde $v_{0}$ é a velocidade não perturbada, sendo na direção paralela ao campo magnético, que representa o movimento toroidal. Todas as quantidades perturbadas são da forma da equação (2.27), ou seja $E \propto B \propto v \propto n$. A força de Lorentz fica: 


$$
-i \bar{\omega} \vec{v}=\frac{e}{m} \vec{E}+\frac{e}{m c}\left(\vec{v} \times \overrightarrow{B_{0}}+\overrightarrow{v_{0}} \times \vec{B}\right) .
$$

Utilizando a equação de Maxwell:

$$
\begin{gathered}
B_{r}=\frac{c}{w}\left(k_{b} E_{\|}-k_{\|} E_{b}\right), \\
B_{b}=\frac{c}{w}\left(k_{\|} E_{r}+i \frac{\partial E_{\|}}{\partial r}\right),
\end{gathered}
$$

podemos eliminar a dependência em relação ao campo magnético e usando $\omega_{c}=\frac{e B_{0}}{m}$, temos para a equação (2.29) as componentes

$$
\begin{gathered}
v_{r}=\frac{e}{m\left(\omega_{c}^{2}-\bar{\omega}^{2}\right)}\left[-i \bar{\omega}\left(1-\frac{v_{0 \alpha} k_{\|}}{\omega}\right) E_{r}+\omega_{c} E_{b}\left(1-\frac{v_{0 \alpha} k_{\|}}{\omega}\right)+\ldots E_{\|}\right], \\
v_{b}=\frac{e}{m\left(\omega_{c}^{2}-\bar{\omega}^{2}\right)}\left[-i \bar{\omega}\left(1-\frac{v_{0 \alpha} k_{\|}}{\omega}\right) E_{r}-\omega_{c} E_{b}\left(1-\frac{v_{0 \alpha} k_{\|}}{\omega}\right)+\ldots E_{\|}\right], \\
v_{\|}=\frac{i e}{\bar{\omega} m} E_{\|} .
\end{gathered}
$$

Agora podemos determinar a densidade de corrente no plasma com

$$
j_{i}=q n_{0} v_{i}
$$

sendo $q$ a carga da partícula. O tensor dielétrico é dado pela mesma relação que foi usada anteriormente, equação 2.19 .

Lembrando que $\omega_{p}=\sqrt{\frac{4 \pi n_{0} e^{2}}{m}}$, sendo que temos íons e elétrons no plasma, somamos para as duas espécies de partículas, podemos escrever o tensor dielétrico como:

$$
\begin{gathered}
\epsilon_{11}=\epsilon_{22}=1+\sum_{\alpha} \frac{\omega_{p \alpha}^{2}}{\omega_{c \alpha}^{2}} \frac{\bar{\omega}_{\alpha}^{2}}{\omega^{2}}\left[1-\frac{\bar{\omega}_{\alpha}^{2}}{\omega_{c \alpha}^{2}}\right]^{-1} \\
\epsilon_{12}=-\epsilon_{21}=\sum_{\alpha} \frac{i \omega_{p \alpha}^{2}}{\omega_{c \alpha} \bar{\omega}_{\alpha}} \frac{\bar{\omega}^{2}}{\omega^{2}}\left[1-\frac{\bar{\omega}_{\alpha}^{2}}{\omega_{c \alpha}^{2}}\right]^{-1} \\
\epsilon_{33}=1-\sum_{\alpha} \frac{\omega_{p \alpha}^{2}}{\bar{\omega}_{\alpha}^{2}}
\end{gathered}
$$


Onde negligenciamos termos $\epsilon_{i 3}$ e $\epsilon_{3 i}$ que são responsáveis pelo movimento de deriva, que não é importante para determinarmos as ressonâncias de Alfvén. Tem que se somar em $\bar{\omega}$ pois a velocidade $v_{0}$ é diferente para as espécies, como há uma corrente no plasma, os íons vão para um lado e os eletróns para o outro.

Podemos notar que temos o mesmo resultado para o $\epsilon_{33}$ que no limite MHD feito na seção anterior, equação (2.24).

\subsection{Ondas globais de Alfvén}

As ondas globais de Alfvén (GAW) se caracterizam pelo campo eletromagnético distribuído na maior parte do raio do plasma, não sendo localizadas em alguma região específica. Como as ondas de superfície, que se concentram na borda do plasma, ou outros tipos de ondas. Para se fazer um estudo das GAW, se considera o tensor dielétrico calculado no modelo MHD, eq. $(2.35,2.36,2.37)[36,37]$.

Eliminando-se $E_{r}$ do sistema de equações 2.4 e 2.5 e usando-se a equação 2.2, chegamos que:

$$
\begin{gathered}
\frac{A}{r} \frac{d}{d r}\left(r E_{\perp}\right)=k_{\perp} G E_{\perp}+\frac{i \omega}{c}\left(A-k_{\perp}^{2}\right) B_{\|}, \\
\frac{i \omega}{c} A \frac{d B_{\|}}{d r}=\left(G^{2}-A^{2}\right) E_{\perp}-\frac{i \omega}{c} k_{\perp} G B_{\|},
\end{gathered}
$$

sendo

$$
A=\frac{\omega^{2}}{c^{2}} \epsilon_{11}-k_{\|}^{2} \quad, \quad G=-\frac{\omega^{2}}{i c^{2}} \epsilon_{12}-\frac{2 k_{\|}}{r}\left(\frac{B_{0_{\theta}}}{B_{0}}\right) .
$$

Se supormos que as densidades de íons e elétrons são constantes e que há uma corrente uniforme $J_{0 z}$, de modo que $\frac{2 \pi}{c} J_{0 z}=B_{0 \theta} / r$. Assim $A, G$ e $k_{\|}$são constantes. Multiplicando-se a eq. 2.39 por $\frac{d}{d r}\left(r\left(G^{2}-A^{2}\right)^{-1}\right)$ e eliminando $E_{\perp}$, se chega a uma equação parecida com a de Bessel, que é a equação para um plasma cilíndrico homogêneo. Nesta análise tomamos todas as quantidades de equilíbrio como constantes, assumimos que $\overrightarrow{v_{0}} \overrightarrow{k_{\|}} \ll \omega$ e desprezando-se termos da ordem de $\left(\frac{B_{0_{\theta}}}{B_{0}}\right)^{2}$. A direção paralela se torna a direção z, sendo assim temos uma eq. de Bessel:

$$
\frac{1}{r} \frac{d}{d r}\left(r \frac{d B_{z}}{d r}\right)+\left[k_{r}^{2}-\frac{m^{2}}{r^{2}}\right] B_{z}=0
$$




$$
k_{r}^{2} \equiv \frac{A^{2}-G^{2}}{A} .
$$

Têm-se como condições de contorno a regularidade e a continuidade do campo na interface entre o plasma e o vácuo, nesta aproximação não se consideram a antena, pois buscamos resolver o problema de autovalores. $\mathrm{Na}$ câmara de vácuo do tokamak $\frac{d B_{z}}{d r}\left(r=r_{S}\right)=0$.

A solução no plasma tem a forma:

$$
B_{z}(r)=C_{1} Z_{m}\left(\left|k_{r}\right| r\right)= \begin{cases}C_{1} J_{m}\left(\left|k_{r}\right| r\right) & k_{r}^{2}>0 \\ C_{1} I_{m}\left(\left|k_{r}\right| r\right) & k_{r}^{2}<0\end{cases}
$$

E no vácuo:

$$
B_{z}(r)=C_{2} I_{m}(k r)+C_{3} K_{m}(k r)
$$

Resolvendo-se o problema para as constantes, usando-se condições de contorno, se chega a relação de dispersão com valores normalizados, o raio do plasma sendo 1. Para simplificar podemos tomar o raio da casca metálica do tokamak, como 1, assim não há solução no vácuo, e temos que a derivada de $Z_{m}\left(\left|k_{r}\right| r\right)$ deve ser nula na borda do plasma. Podemos ignorar $I_{m}$, pois tem uma dependência exponencial e sua derivada não se anula na borda do plasma.

Assim, temos que $k_{r}$ deve ser um zero da derivada da função de Bessel $J_{m}$, experiências mostram que no TCABR o modo $m=1$ é o mais razoável de ser tratado, pois os outros modos não são excitados. É possível assim, escrever a eq. (2.42) como uma equação de quarto grau para $k_{\|}$. Vamos ultilizar o fator de segurança $q=\frac{r B_{0}}{r_{S} B_{0 \theta}}$ para escrever as equações de modo mais conveniente:

$$
k_{\|}^{4}+k_{\|}^{2}\left(-2 \tilde{\epsilon_{11}}-\frac{4}{R^{2} q^{2}}+k_{r}^{2}\right)+k_{\|}\left(\frac{4}{R q} \tilde{\epsilon_{12}}\right)+\left(\tilde{\epsilon}_{11}^{2}-\tilde{\epsilon}^{2}-k_{r}^{2} \tilde{\epsilon_{11}}\right)=0,
$$

onde

$$
\tilde{\epsilon_{11}}=\frac{\omega^{2}}{c^{2}} \epsilon_{11} \quad, \quad \tilde{\epsilon_{12}}=\frac{\omega^{2}}{i c^{2}} \epsilon_{12}
$$

Para prosseguir nos cálculos vamos desconsiderar termos da ordem de $\omega_{c e}^{-1}$ ou menores. Tomamos certo cuidado com a soma de $\epsilon_{12}$, por a equação $\frac{\omega_{p e}^{2}}{\omega_{c e}}=$ $\frac{\omega_{p i}^{2}}{\omega_{c i}}$. Convém usarmos grandezas adimensionais, normalizando as distâncias 
pelo raio do plasma $r$ (adimensional $)=r / r_{p}$. Nas equações irá aparecer $\tilde{\omega_{c i}}=\left(\frac{\omega_{c i} r_{p}}{v_{A}}\right)^{2}$. E definimos $x=\frac{\omega}{\omega_{c i}}$. Assim, redefinimos $\tilde{\epsilon_{1 i}}$ :

$$
\tilde{\epsilon_{11}}=\tilde{\omega}_{c i} \frac{x^{2}}{1-x^{2}} \quad, \quad \tilde{\epsilon_{12}}=\tilde{\omega}_{c i} \frac{x^{3}}{1-x^{2}} .
$$

Para resolver a equação (2.45) foi utilizado um método numérico, o resultado está apresentado na figura (2.1) para o primeiro modo radial, $k_{r}=1,84$. São apresentadas as partes reais das soluções encontradas. Como parâmetros foi usado $q=3, n_{0}=2 \times 10^{13} \mathrm{~cm}^{-3}, r_{p}=18 \mathrm{~cm}$, que nos dá $\tilde{\omega_{c i}}=3,54$.

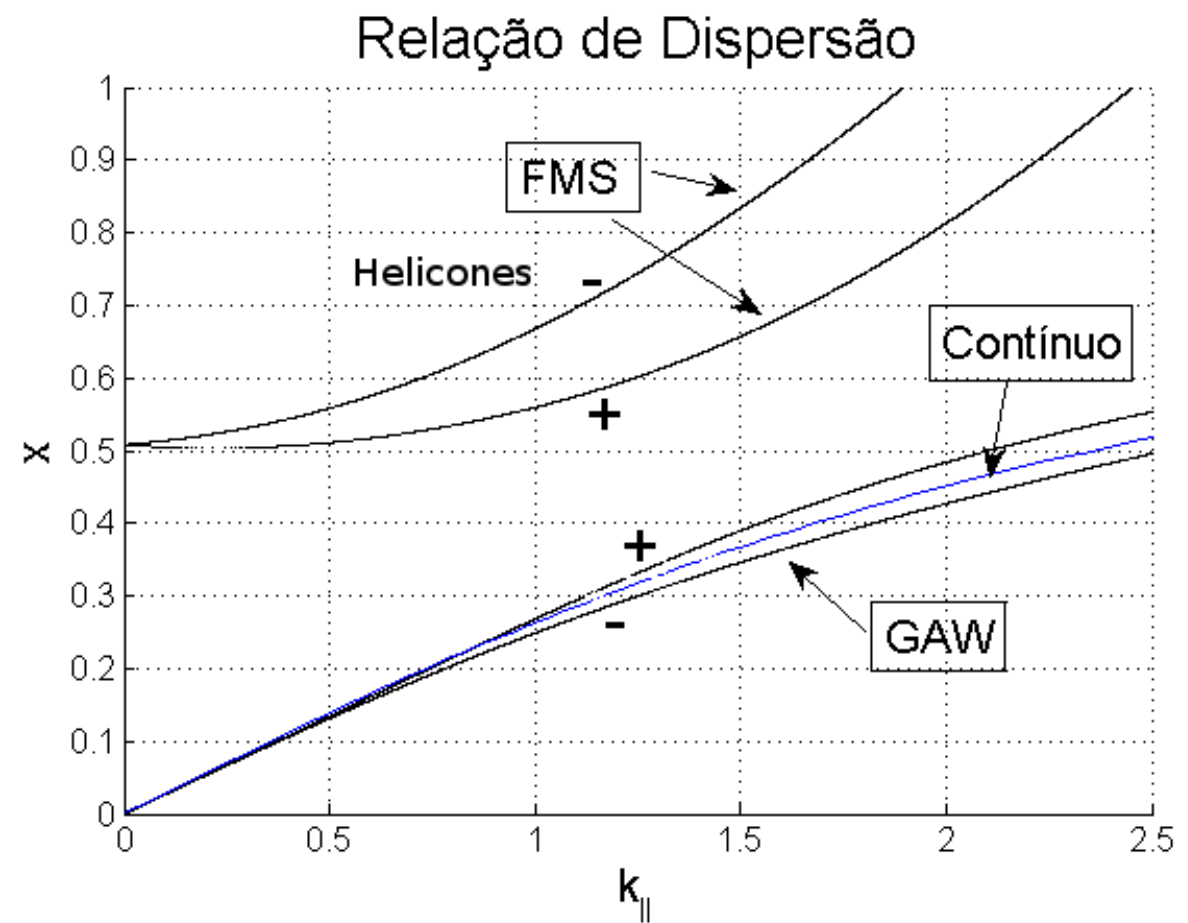

Figura 2.1: Relação de dispersão para as ondas de Alfvén para o primeiro modo radial. $x=\omega / \omega_{c i}$ e $k_{\|}=N c /\left(\omega_{p} R\right)$ sendo $N$ o número do modo toroidal, no caso foi considerado um contínuo de modo toroidais, para se ter uma imagem da relação de dispersão, mas no caso real, temos valores discretos de $k_{\|}$, para cada valor de $N= \pm 1, \pm 2, \pm 3 \ldots$, foram apresentadas as partes reais das soluções encontradas.

Os ramos da parte superior do gráfico representam a onda magnetossônica rápida (FMS) e os ramos inferiores a onda global de Alfvén (GAW), o ramo negativo da FMS também é conhecido como ondas de helicon ou whistler [38]. Os sinais mostram o sinal da parte real da onda, podemos ver que os 
ramos com sinal negativo são mais extremos. Também foi colocado no gráfico o contínuo de Alfvén, que corresponde a relação

$$
k_{\|}^{2}=\tilde{\epsilon_{11}}
$$

Há um modo análítico mais fácil de se chegar nestas curvas, se desconsiderarmos o termo proporcional a $k_{\|}$em $G$, equação 2.40 , isso pode ser feito para valores de $x$ próximos de 1 , teremos no lugar da equãção (2.45) uma equação biquadrática, cuja solução é:

$$
k_{\|}^{2}=\tilde{\epsilon_{11}}-\frac{k_{r}^{2}}{2}\left(1 \pm \sqrt{1+\frac{4 \tilde{\epsilon}_{12}^{2}}{k_{r}^{4}}}\right)
$$

O sinal positivo é a FMS e o sinal negativo é a GAW. Se considerar$\operatorname{mos} \tilde{\epsilon}_{12}^{2} \ll k_{r}^{4}$ podemos considerar o termo que o envolve uma perturbação. Temos então para o sinal positivo:

$$
k_{\|}^{2} \approx \tilde{\epsilon}_{11}-k_{r}^{2}
$$

Que é a solução clássica para FMS. Para o sinal negativo temos:

$$
k_{\|}^{2} \approx \tilde{\epsilon_{11}}+\frac{\epsilon_{12}}{k_{r}^{2}}
$$

que é a relação de dispersão para GAW.

Facilmente podemos identificar os perfis radiais dos modos do campo $B_{z}$, figura 2.2. Sendo que já temos $k_{r}$ determinado.
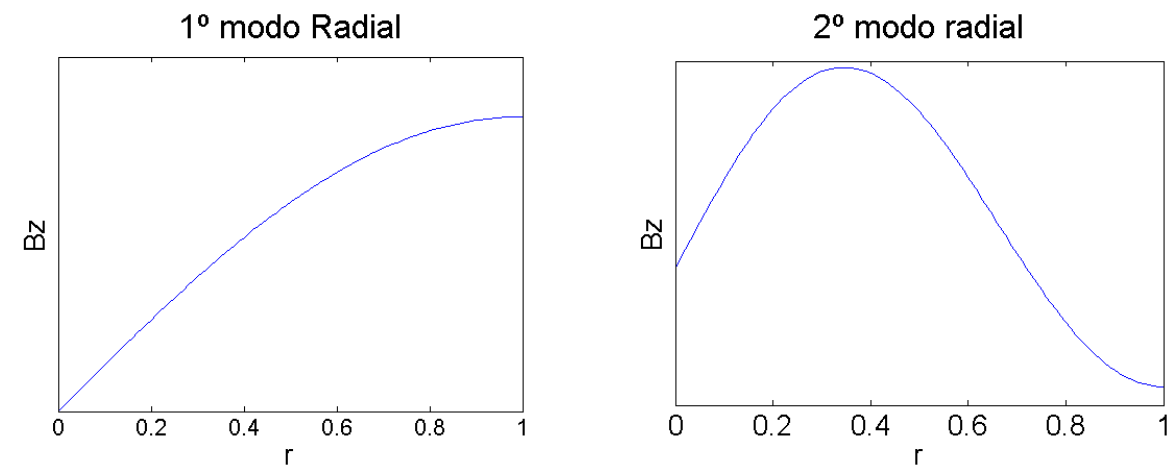

Figura 2.2: Perfil radial do campo $B_{z}$ para os dois primeiros modos radiais, estão mostrados os modos com $m=1$, para $m=-1$ só muda o sinal, pois $J_{1}$ é impar. O sinal de $k_{\|}$deve influenciar na magnitude do campo, não na forma da função. 
É possível notar que os campos representados representam modos globais, pois tem seu valor máximo dentro do plasma. Se estivéssemos tratando o problema de forma mais detalhada, teríamos também como solução $I_{m}$ que tem um caráter exponencial, e assim iria ser responsável por uma onda na superfície do plasma, por isso chamadas ondas de superfície. Simulações numéricas são feitas no próximo capítulo com o uso de um código desenvolvido no laboratório e apresentado na ref. [39]. 


\section{Capítulo 3}

\section{Cálculos Computacionais}

Neste capítulo são apresentados cálculos numéricos feitos utilizando o código cilíndrico disponível no laboratório [40], que leva em conta o tensor dielétrico já calculado para o modelo cilíndrico do plasma. O código é baseado nos resultados apresentados nas referências [41, 29]. Foi resolvido o sistema de equações de Maxwell-Vlasov como um problema de contorno, de modo semelhante a outros códigos [32, 42]

Os parâmetros de entrada para o código são os dados dos perfis radiais de equilíbrio do plasma, os parâmetros do tokamak, no caso o TCABR e os harmônicos do campo eletromagnético excitados. Como resposta temos os perfis radiais dos campos, a impedância da antena, ambos mostrados nesse capítulo, além da densidade de potência absorvida no plasma.

Com o código podemos fazer uma varredura da frequência e calcular a impedância da antena para cada frequência. As ressonâncias dos modos globais de Alfvén, que são de interesse, aparecem como picos na impedância, isto representa um depósito de energia maior no plasma. Os modos globais apresentam este pico, posteriormente podemos analisar os campos eletromagnéticos para uma dada frequência e verificar se estes são concentrados na parte central do plasma, e não na borda, caracterizando um modo global.

O código resolve as equações para os campos, e depois é calculada a impedância da antena

$$
Z_{A}=\frac{W}{J_{A}^{2}}=\frac{\operatorname{Re}\left(\vec{J} \cdot \overrightarrow{E^{*}}\right)}{2 J_{A}^{2}},
$$

sendo $J_{A}$ a corrente na antena.

O código considera um modelo mais real de plasma, com um perfil de densidade e corrente não homogênea, ao contrario do caso tratado na no capítulo anterior, que era homogêneo, porém os resultados são semelhantes. 
No capítulo anterior foi usado um valor para a densidade correspondente a densidade de linha, que é fazer uma integral do perfil de densidade e retirar um valor representativo para a densidade, no caso temos $2 / 3$ da densidade no centro do TCABR, que vale $3 \times 10^{13} \mathrm{~cm}^{-3}$, pois o perfil é quadrático.

Um problema numérico de singularidade nas equações pode ser contornado com o uso das colisões no plasma, que evita instabilidades numéricas. A seguir temos um gráfico da impedância para o modo $m=-1$ e $N=-4$, só foram usados valores negativos de $m$ e $N$, pois, do contrário, ondas globais não são excitadas e não há boa absorção no plasma [17]. Os valores negativos representam que a polarização das ondas é contrária a do movimento de ciclotron dos prótons no plasma.

Ainda na figura 3.1 notamos a importância das colisões, pois as oscilações presentes para frequências altas no gráfico $b$ não é algo físico, e sim problema numérico que pode ser contornado com aumento da frequência de colisões.

Foram usados 2 valores diferentes do parâmetro de colisões para ilustrar as instabilidades numéricas que aparecem, além de mostrar como há um pico forte na frequência $5,35 \mathrm{MHz}$, que é um modo global de Alfvén [17].
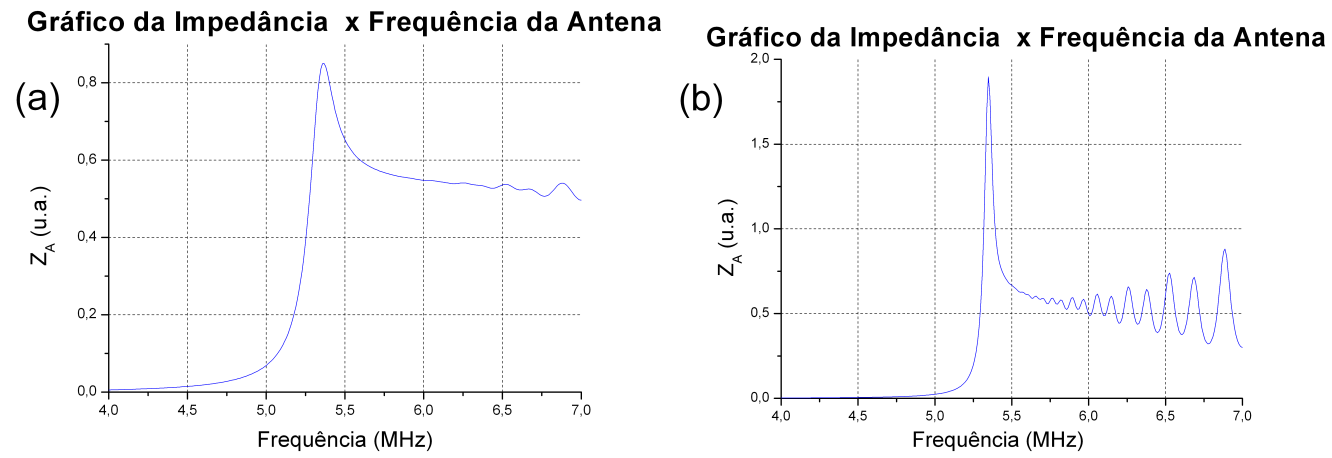

Figura 3.1: Impedância da antena para o modo $N=-4$ e $m=-1$, foram usados parâmetros do TCABR, o gráfico (a) tem um parâmetro de colisão uma ordem de grandeza maior que o gráfico (b), o pico é um modo global de Alfvén

Podemos simular os campos eletromagnéticos para uma dada frequência da antena. Vamos tomar o caso $N=-3$ e $m=-1$ e simular com a frequência do pico da impedância $(4,39 \mathrm{MHz})$, que é análogo ao da figura 3.1. Assim obtemos o perfil para os campos $B_{z}$ e $E_{r}$ 3.2. As oscilações presentes na borda do plasma no gráfico de $E_{r}$ não é instabilidade da simulação, mas uma oscilação no plasma.

Constatamos que os campos se concentram na parte central do plasma, como comentado. Sendo assim temos um modo global que deposita energia no 

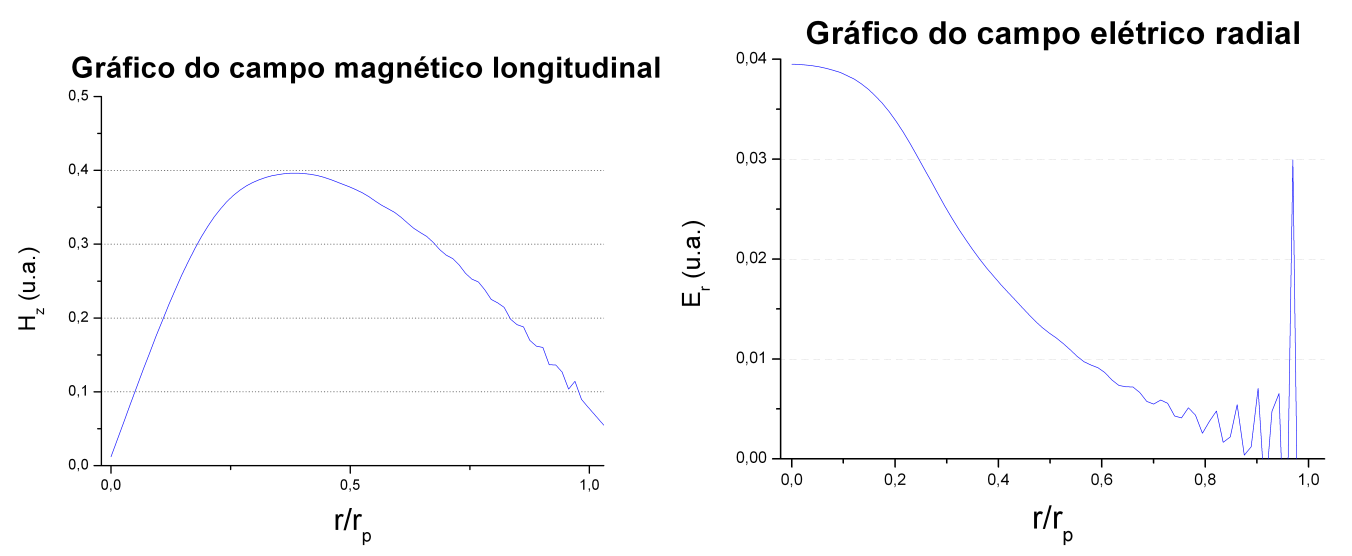

Figura 3.2: Campo $H_{z}$ (que é a perturbação de $B_{z}$ ) e $E_{r}$ para $N=-3$ e $m=-1$ para $f=4,39 \mathrm{MHz}$, que é a frequência identificada como um modo global. É possível ver semelhanças destes gráficos com o gráfico 2.2.

centro do plasma. Utilizamos este método para diferentes modos $N$, sempre negativos, e mantendo $m=-1$. Assim foi possível obter alguns pontos para se comparar com a figura 2.1 .

Vemos que há certas diferenças entre os gráficos, que são esperadas devido ao perfil de densidade e corrente presentes no código. Mas vemos que temos um resultado semelhante. E pelo ramo em que os pontos se concentram temos uma coincidência com as ondas globais de Alfvén calculadas.

Também é possível simular os campos eletromagnéticos para diferentes frequências. Para frequências menores que a ressonância global não há interesse, pois a energia depositada no plasma é praticamente nula pois a impedância é próxima de zero. Já para frequências um pouco acima da frequência da onda global temos uma energia depositada e seria interessante para aquecimento saber em qual região do plasma essa energia é depositada e como são os campos elétrico e magnético. As figuras 3.4 é para $N=-3$ e $m=-1$ com a frequência de $4,8 \mathrm{MHz}$.

É possível notar que há uma mudança na posição do máximo dos campos, que se desviam para a borda. Por isso não depositam tanta energia apesar de serem mais intensos, o perfil de corrente é quadrático, sendo assim a corrente é máxima no centro do plasma. O ponto onde os campos se anulam dentro do plasma é uma zona de conversão de modos, onde temos um tipo de onda de um lado do campo nulo e outra do outro, mas que tem comportamento semelhante para a densidade na região onde se anulam os campos eletromagnéticos. Tratar deste assunto no entanto foge do objetivo desta dissertação, mais informações podem ser encontradas na referência [17]. Conforme a frequência aumenta os campos ficam mais intensos na borda, formando uma 


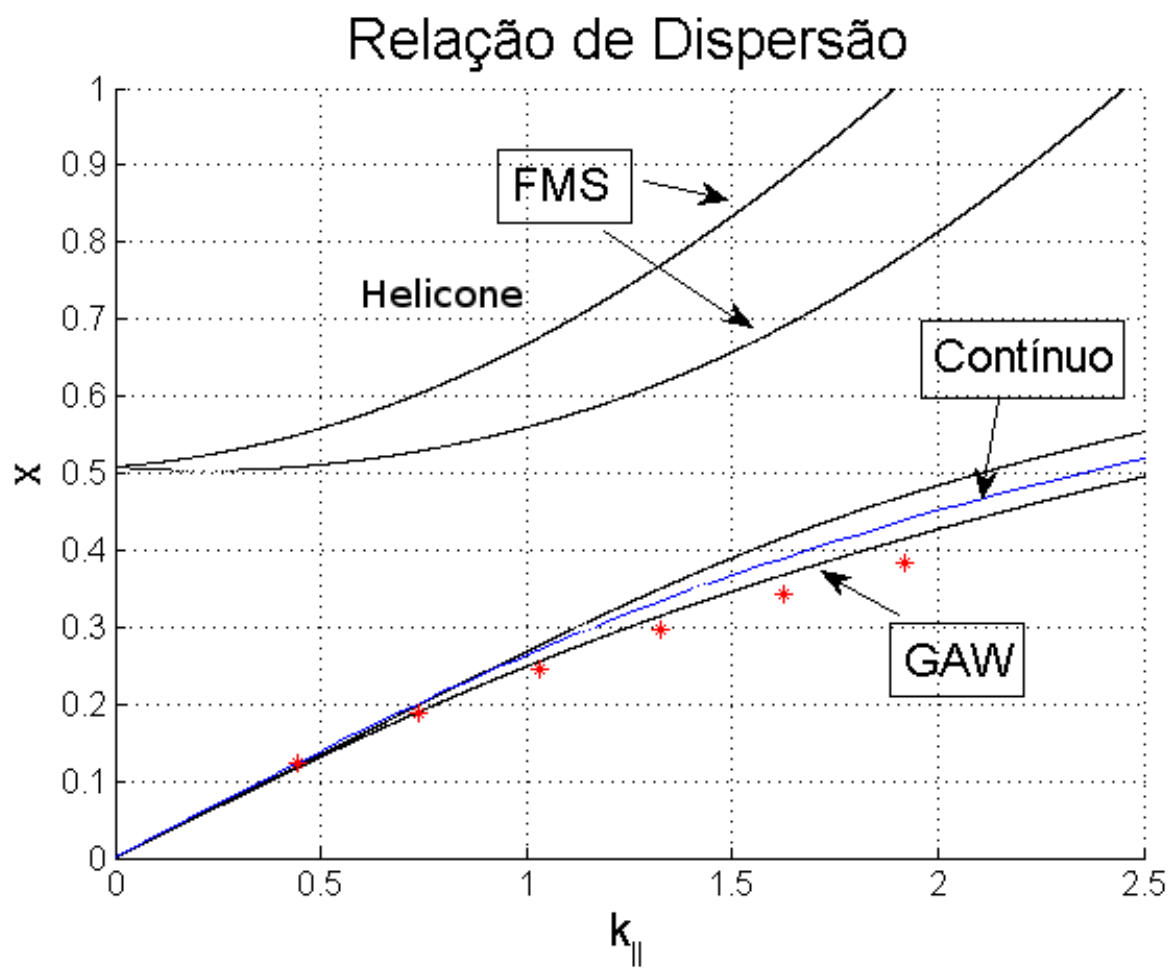

Figura 3.3: Relação de dispersão para as ondas de Alfvén como calculado no capitulo anterior, Figura 2.1. A simulação com o código são os pontos em vermelho. Foram usados valores de $N=-6$, frequência máxima, até -1 , frequência mínima

onda de superfície.

Conclui-se que com a antena é possível excitar ondas globais de Alfvén para podermos aquecer o plasma e fazer análises com varredura de frequência.

Há a possibilidades de aquecer o plasma para a frequência do modo global, ou acima desta na zona de conversão de modos, desde que a energia depositada fique próxima da região central do plasma. 

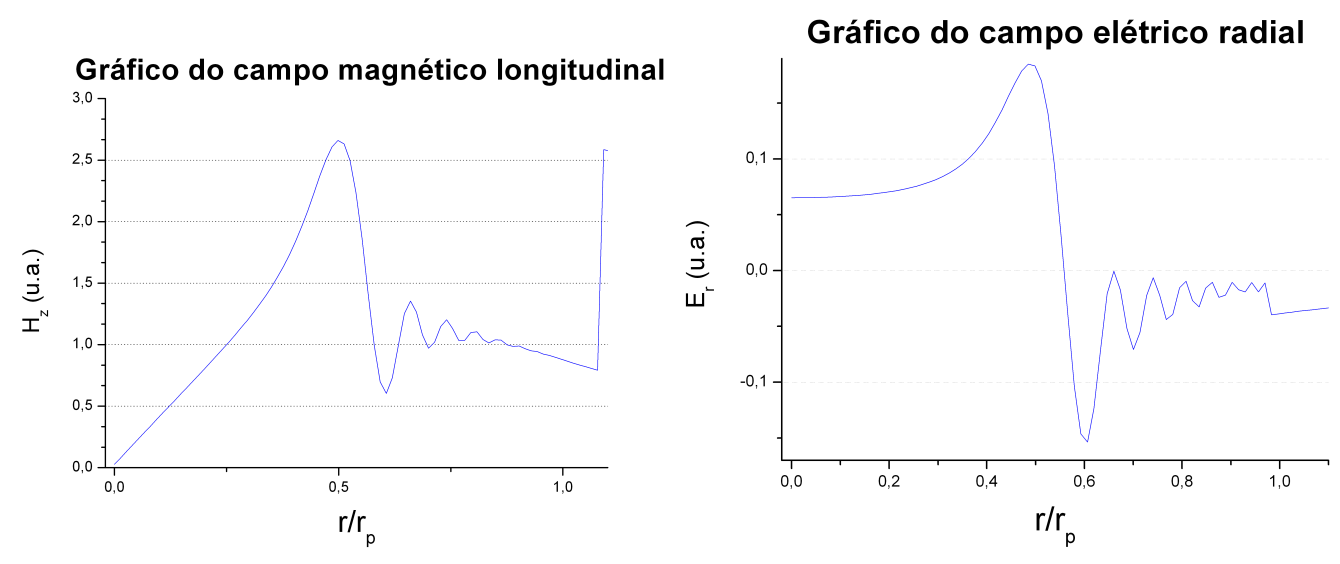

Figura 3.4: Campos $H_{z}$ (que é a perturbação de $B_{z}$ ) e $E_{r}$ para o modo $N=$ -3 e $m=-1$ com a frequência de $4,8 \mathrm{MHz}$, que é maior que a frequência de ressonância da onda global 


\section{Capítulo 4}

\section{Descrição dos equipamentos}

Neste capítulo fazemos descrição e testes do arranjo experimental do TCABR utilizado para as medidas de ondas no plasma. O arranjo experimental consiste de um gerador de frequência variável [43] e um gerador mais potente com frequência fixa, antenas de Alfvén, sondas magnéticas [44] e eletrostáticas para a detecção das ondas e um circuito demodulador de sinais [45], além de um osciloscópio com alta taxa de amostragem. O esquema geral de aquisição de dados apresentado na Figura 4.1.

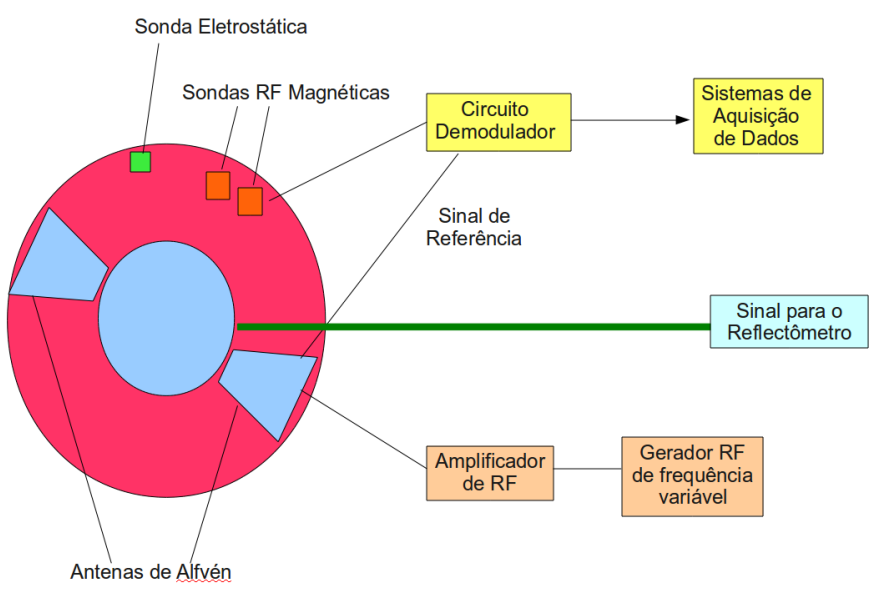

Figura 4.1: Esquema das antenas e da aquisição de dados com o circuito demodulador, as sondas magnéticas e eletrostáticas e o reflectômetro. 


\subsection{Antenas e sondas magnéticas}

No TCABR, antenas instaladas que operam na faixa de rádio frequência (RF), na banda de $2-5 M H z$, o intuito destas antenas é excitar ondas de Alfvén no plasma, que podem ser medidas pelas sondas magnéticas [44], eletrostáticas e reflectômetro.

Há 2 módulos de antena instalados no TCABR, colocados em posições diametralmente opostas, a $180^{\circ}$ uma antena da outra, conforme figura 4.1. Somente com um módulo já foram feitos diversos experimentos, com o segundo módulo é possível excitar novos modos e colocar 4 vezes mais energia no plasma. Um módulo consiste de 4 straps, cada strap é uma alça metálica, conforme figura 4.2.

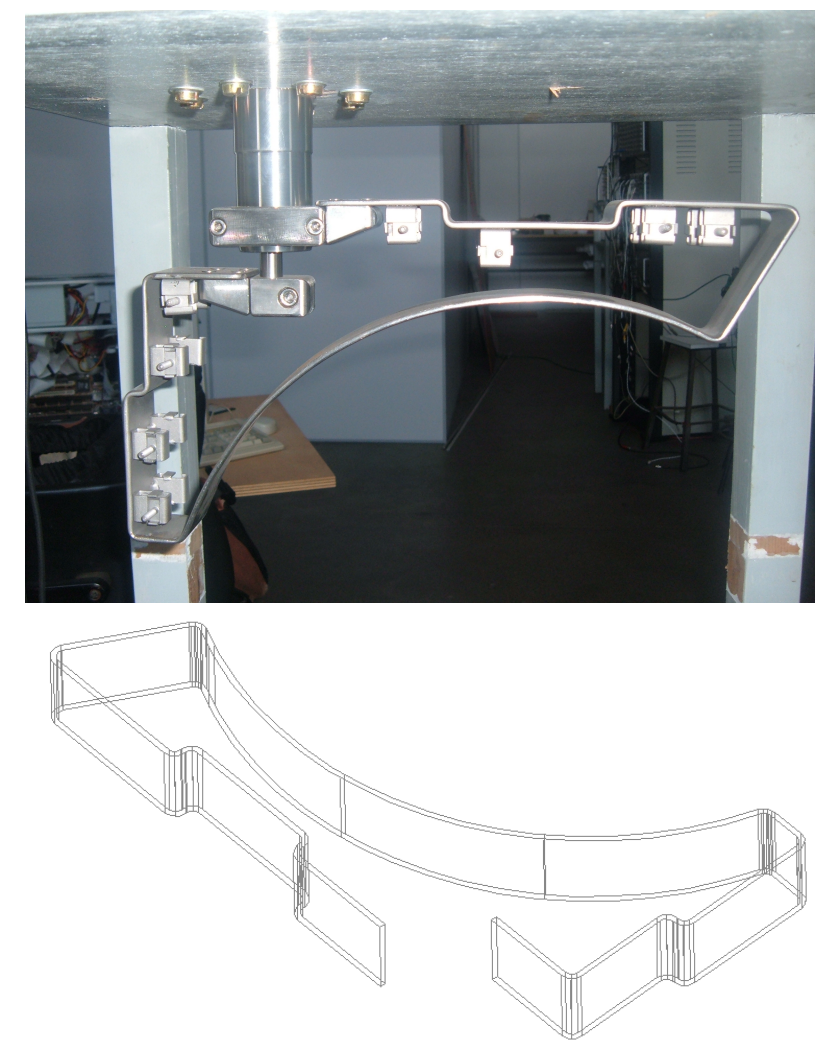

Figura 4.2: Detalhe de um strap da antena de aço inox.

Cada strap é ligado ao gerador de forma independente, sendo possível usar uma defasagem de $\pi$ entre diferentes straps, sendo conveniente para excitar um modo específico. Na figura 4.4 há o esquema de como estão ligados cada straps do módulo da antena. Nas antenas foram instalados capacitores variáveis em paralelo para que todas tivessem a mesma ressonância, que foi 


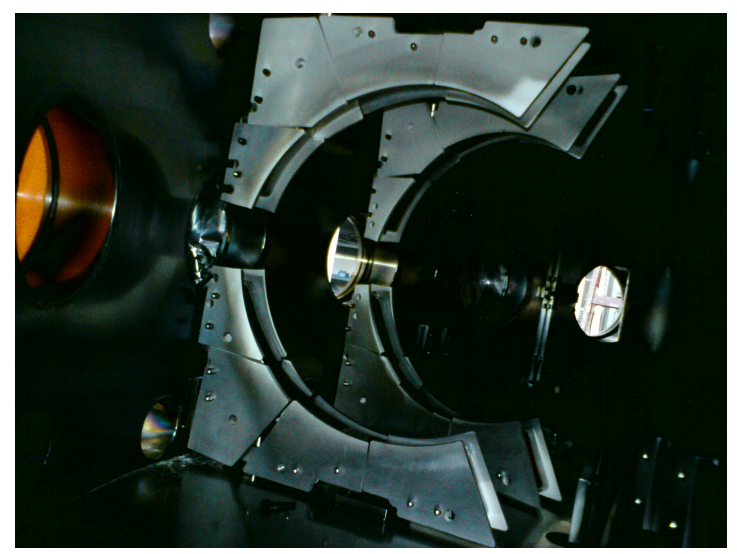

Figura 4.3: Foto da antena dentro do vaso, com a proteção de nitreto de boro.

calibrada em 4915K Hz. Mas quando se usa o gerador de frequência variável, este usa uma caixa amplificadora e é ligado diretamente na antena.

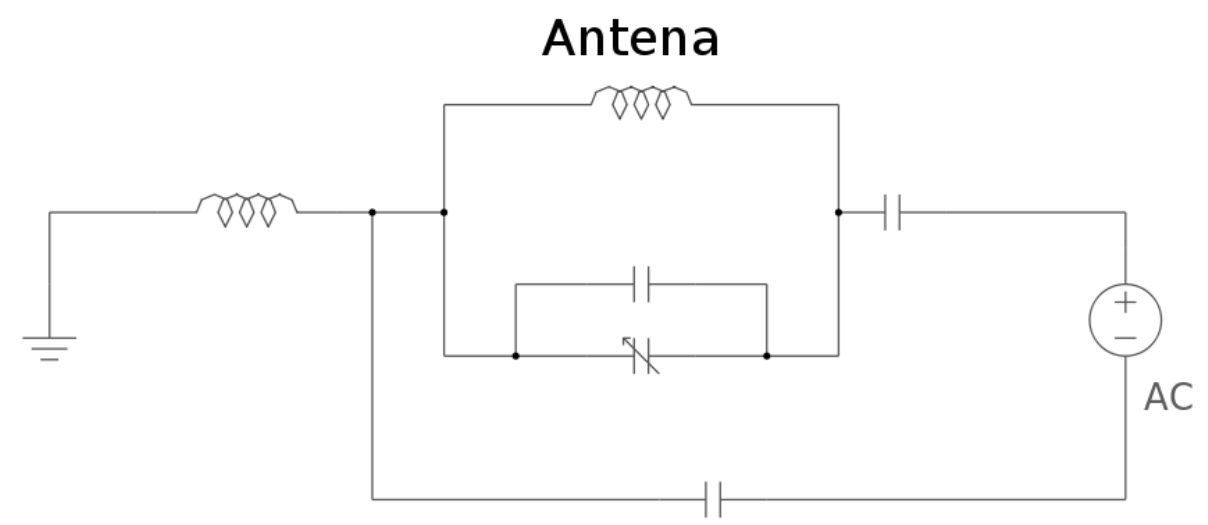

Figura 4.4: Esquema do circuito em que está ligado cada strap da antena, é possivel ligar as antenas com defasagem de $\pi$

Há um módulo de antena mais antigo, que é de cobre e foi instalado em 1998 [44]. Há um outro módulo mais recente, que é feito de aço inox que foi instalado no TCABR em 2008.

As sondas magnéticas estão instaladas na distância de $\sim 1 \mathrm{~m}$ da antena, deslocadas na direção toroidal (fig. 4.1), distribuídas na direção radial, a uma distância de $23 \mathrm{~cm}$ do centro geométrico da câmara de vácuo. Neste caso é possível medir tanto o campo magnético toroidal como o poloidal. Há 2 sondas que o esquema esta mostrado na figura 4.5. A bobina (A) mede o campo poloidal e tem seção de de $11 \times 36 \mathrm{~mm}$, a (B) mede o campo toroidal 
e tem seção de $10 \times 20 \mathrm{~mm}$.

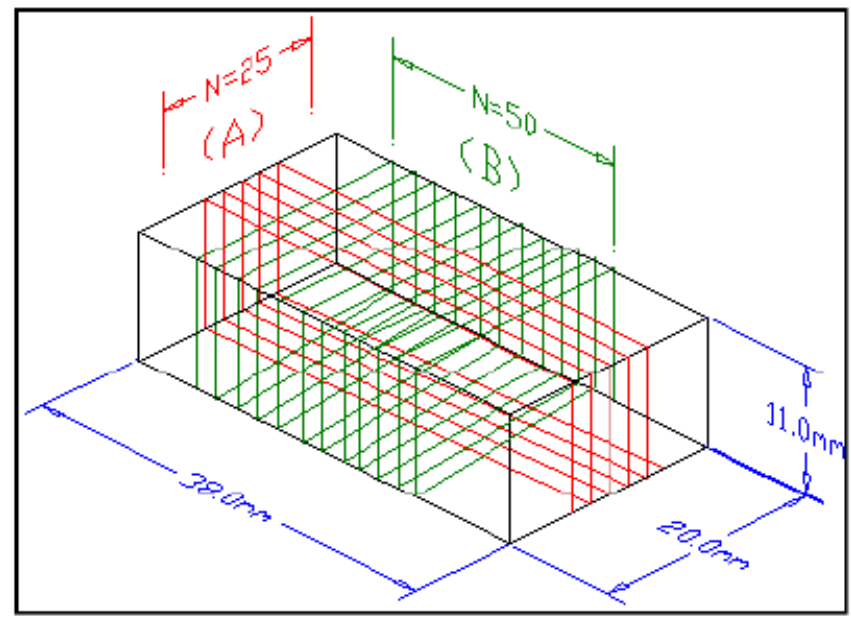

Figura 4.5: Esquema das bobinas ortogonais da sonda magnética usada para fazer as medidas do campo magnético [44]

Para se determinar os campos e os modos excitados havia um método[44], que apresentou muitos ruídos, assim, foi necessário desenvolver o circuito demodulador apresentado na próxima seção. Porém não há informação direta do modo excitado usando o circuito demodulador como apresentado, algo que era possível no esquema anterior.

O método anterior consistia em medir um sinal proveniente da antena com uma bobina de Rogowski e causar um atraso, sendo assim teríamos 2 sinais iguais defasados em $90^{\circ}$.

$$
S=A_{1} \operatorname{sen}(\omega t) \quad, \quad C=A_{2} \cos (\omega t)
$$

O sinal da sonda magnética tem uma amplitude diferente e uma defasagem diferente destes outros 2 sinais

$$
X=I \cos (\omega t+\phi) .
$$

Pode-se multiplicar ambos os sinais e temos

$$
X S=\frac{A_{1} I}{2} \operatorname{sen}(\phi)+O(2 \omega t) \quad, \quad X C=\frac{A_{2} I}{2} \cos (\phi)+O(2 \omega t) .
$$

Podemos escrever $I$ e $\phi$ em função de $X C$ e $X S$, podendo assim achar a defasagem entre os sinais e a sua amplitude, além de determinar o modo 
excitado através da diferença de fase entre as duas sondas magnéticas. Mas não houve sucesso com esse método devido a ruídos eletromagnéticos, então optou-se em desenvolver um circuito demodulador [45].

\subsection{Sonda de Langmuir}

Para se realizar as medidas de densidade do plasma de limpeza [13] foi usada uma sonda eletrostática [46]. As medidas estão apresentadas no capítulo seguinte. Houve o uso do plasma de limpeza pois devido a um problema no TCABR, o plasma do disparo típico do TCABR não estava disponível. No TCABR há diversas sondas disponíveis para as medidas, no caso se usou uma sonda de 4 pinos, mas as medidas feitas usaram apenas um dos pinos, ou seja, é como uma sonda de Langmuir simples. A voltagem aplicada na sonda é de $100-200 \mathrm{~V}$, da ordem do potencial flutuante.

A corrente na sonda pode ser descrita por [13]

$$
I=j_{i}\left(1-\exp \left(\frac{e\left(V-V_{f}\right)}{T_{e}}\right)\right) A,
$$

onde $A$ é a área projetada da sonda ponderada pelo campo magnético, $V_{f}$ é o potencial flutuante, que é o valor aplicado da voltagem para se ter uma corrente nula na sonda, $T_{e}$ a temperatura eletrônica, $j_{i}$ é a corrente iônica.

Primeiramente foram feitas medidas para se estimar a densidade do plasma do disparo de limpeza do TCABR, dados que foram usados na simulação da figura 5.4a. Para se determinar estes parâmetros é necessário fazer uma varredura da voltagem aplicada na sonda e medir a corrente. Pode-se fazer um ajuste dos dados para a equação 4.4, e assim, determinar aproximadamente a temperatura eletrônica do plasma e calcular a densidade utilizando

$$
n_{0}=\frac{J_{i}}{e}\left(\frac{m_{i}}{2 T_{e}}\right)
$$

onde $n_{0}$ é a densidade dos elétrons, que no caso podemos tomar como igual a dos íons, considerando que há poucas impurezas no plasma e o plasma é neutro, $J_{i}$ é a densidade de corrente medida na sonda e $m_{i}$ a massa dos íons. Como podemos ver a densidade varia linearmente com a corrente, sendo assim, se medirmos as oscilações da corrente na sonda, essas oscilações serão diretamente proporcionais as oscilações da densidade.

Em conjunto com as antenas apenas foram medidas essas oscilações na densidade. Sendo assim não se tem conhecimento do valor absoluto da densidade, mas sim das oscilações de densidade quando passa um sinal do gerador pela antena. 


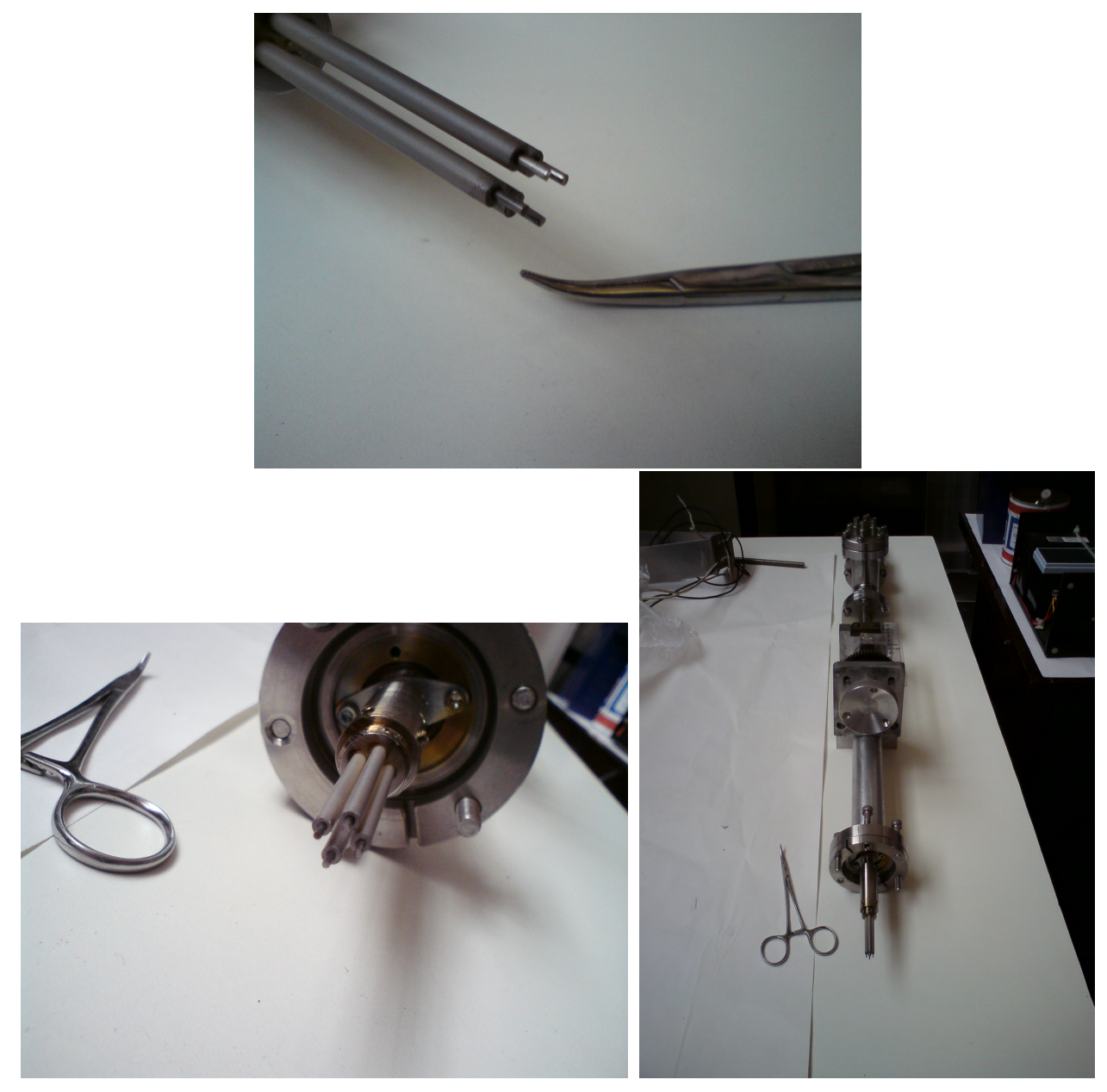

Figura 4.6: Fotos da sonda usada para se realizar as medidas de oscilação de densidade, apesar de ter 4 pinos, apenas 1 foi usado nas medidas.

\subsection{Circuito demodulador}

A frequência das ondas de Alfvén excitadas no TCABR está na banda de $2-5 M H z$. O sistema de aquisição de dados no TCABR é limitado a $1,5 \mathrm{MHz}$, esta é a razão da necessidade de um circuito demodulador, pois não é possível fazer diretamente as medidas das sondas magnéticas com o sistema de aquisição [47]. O papel do circuito é mudar a frequência dos sinais, amplificar e modular o sinal, além de diminuir os ruídos.

O circuito demodulador multiplica os sinais das sondas magnéticas por um sinal de referência, que no caso é sinal da corrente que passa pela antena obtido com uma bobina de Rogowski, que passa pelo amplificador AD811 [48]. Os sinais são multiplicados pelo componente MS1496 [49] Filtros e 
amplificadores diferenciais foram usados para diminuir o ruído do sinal de entrada e um filtro passa baixa foi usado no sinal de saída (Figura 4.8), pois, como já mencionado, temos interesse no sinal de baixa frequência.

A multiplicação dos sinais de referência e da sonda magnética é como a multiplicação de dois cossenos.

$A(t) \cos \left(\omega_{\text {sonda }} t\right) \cos \left(\omega_{\text {ref }} t\right)=\frac{A(t)}{2}\left(\cos \left(\omega_{\text {sonda }} t+\omega_{\text {ref }} t\right)+\cos \left(\omega_{\text {sonda }} t-\omega_{\text {ref }} t\right)\right)$

O interesse é no sinal que é a subtração das duas frequências, que é um sinal de baixa frequência, como $\omega_{\text {sonda }} t \approx \omega_{\text {ref }} t$. A outra componente é eliminada pelos filtro passa baixa e o amplificador operacional. $A(t)$ representa a amplitude do sinal vindo da bobina, que é $A(t) \cos \left(\omega_{\text {sonda }} t\right)$. Se usarmos o gerador no modo de varredura de frequência, o intuito é ter como resposta este sinal, para vermos em que frequência esta o máximo, que pode indicar uma ressonância.

Não podemos obter informação em relação a diferença de fase entre os sinais, neste caso tal diferença apenas mudaria o valor na saída do circuito demodulador. E não há duas equações como mostrado no começo do capítulo para o método desenvolvido anteriormente.

Há 4 canais de entrada no circuito demodulador, para serem usados juntos com as sondas magnéticas apresentadas na seção anterior. O objetivo é ter como sinal de saída um sinal de baixa frequência que carregue a amplitude do sinal de entrada.

Nas figuras 4.7 e 4.8 estão os esquemas do circuito demodulador retirados da referência [45]. 


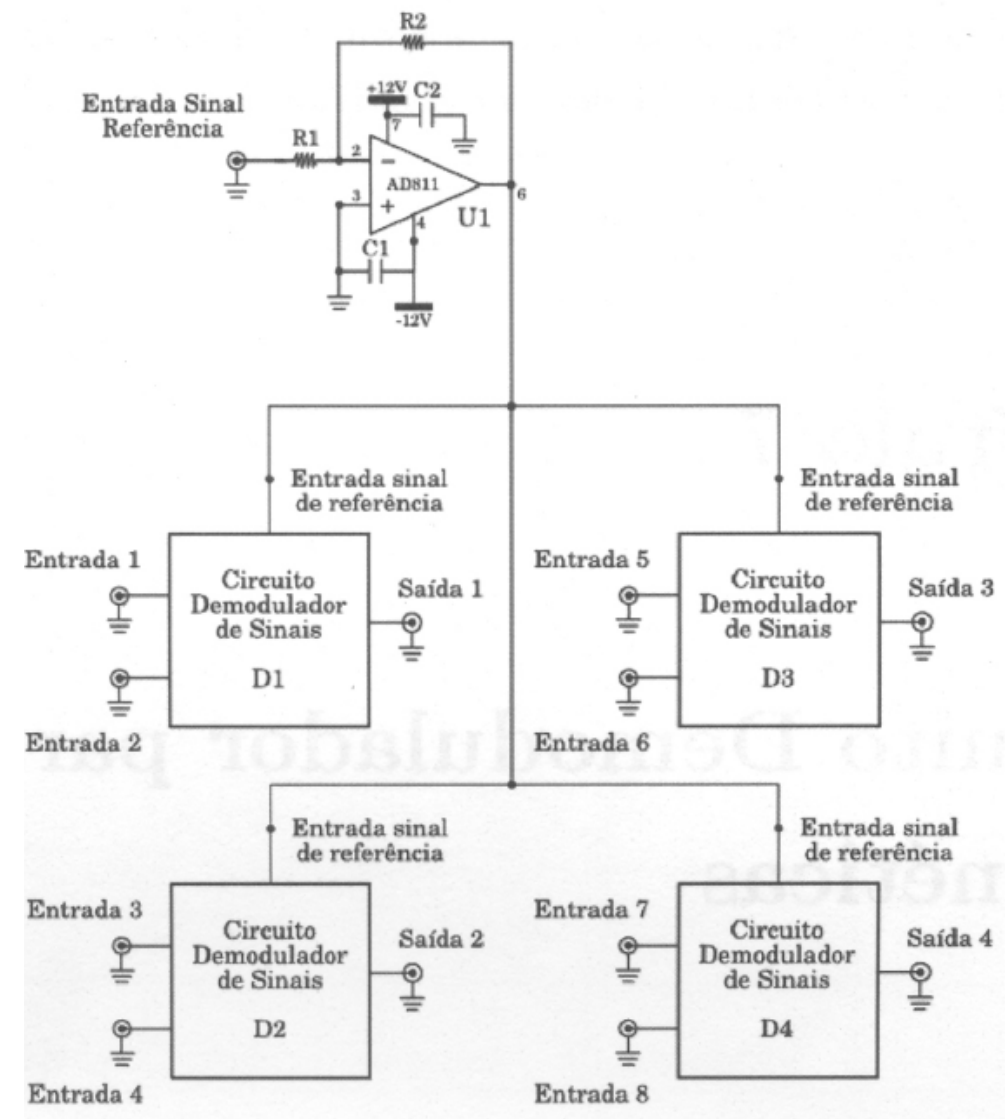

Figura 4.7: Esquema de blocos do circuito demodulador, conforme [45]

Para a calibração foram feitas curvas características do circuito demodulador analisando a resposta do circuito demodulador para diferentes amplitudes do sinal de entrada e para diferentes amplitudes do sinal de referência. Também foi analisado a mudança de frequência no sinal de entrada e como isso afetava a amplitude na saída 4.9 .

Na calibração o sinal de entrada para cada um dos 4 canais era colocado em apenas uma das entradas, enquanto a outra era aterrada. Como se tem um amplificador instrumental [50], que é um tipo de amplificador diferencial, no caso formado por 3 amplificadores AD847 [51], se colocarmos o mesmo sinal em ambas as entradas o sinal de saída deve ser nulo, é necessário que haja alguma diferença entre os sinais. Após passar pelo transformador, os sinais originários das sondas magnéticas apresentam defasagem de $180^{\circ}$, sendo assim cada saída do transformador é conectada a uma entrada do amplificador de instrumentação. Os sinais vindo da sonda magnética tem uma diferença 


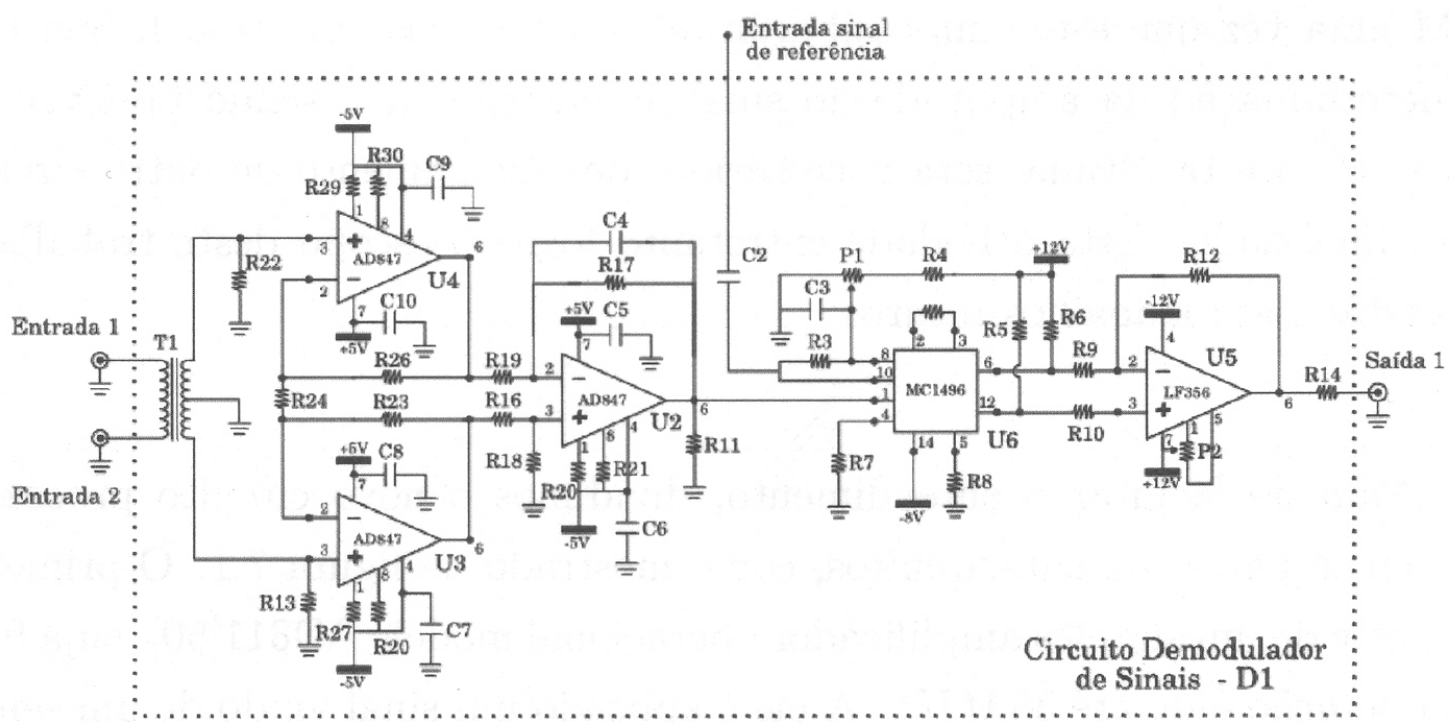

Figura 4.8: Esquema do circuito demodulador de sinais, D1, D2, D3 e D4 da figura 4.7, conforme [45]

de fase e assim pode ser feita uma medição.

Na figura 4.9 a frequência do sinal de referência foi fixada em $5 M h z(a)$, então é possível perceber que apenas sinais com frequência perto desta terão uma voltagem significativa. Nós mudamos a voltagem do sinal de referência (b) e a voltagem do sinal modulado (c), que corresponde ao sinal da sonda magnética. Agora é possível determinar a região de linearidade do circuito.

Para as medidas os equipamentos foram colocados de um modo que consiste em ligar um gerador com um sinal modulado em uma das entradas do circuito demodulador com o aterramento da outra entrada. Para o sinal de referência foi usado um sinal vindo de outro gerador, mas com a mesma frequência do sinal da onda portadora, com exceção do gráfico (a). Para os outros 2 gráficos foi usada como frequência de referência $2 \mathrm{MHz}$, mas para o (c), foi usada uma frequência de $5 \mathrm{MHz}$, que é mais próxima da frequência tradicional que alimenta as antenas. Todos os canais se comportam de modo igual. Os filtros atuam de forma satisfatória, não permitindo que um sinal de frequência diferente da desejada seja medida. 


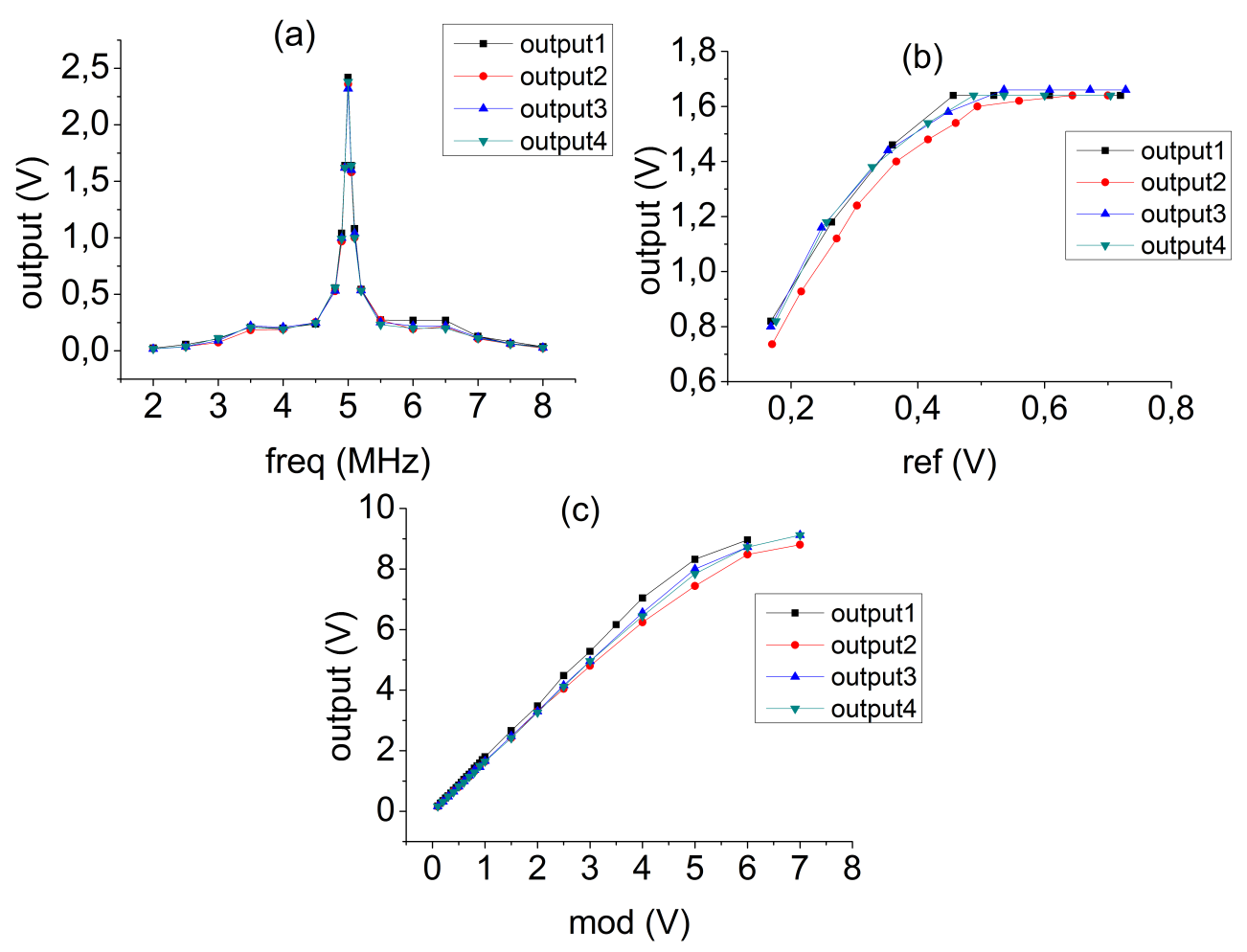

Figura 4.9: (a) saída do circuito demodulador pela frequência do sinal de entrada, a voltagem de ambos era mantida fixa. (b) saída do circuito demodulador pela amplitude do sinal de referência, mantinha-se a mesma frequência para o sinal de entrada e para o sinal de referência que o sinal de entrada. (c) saída do circuito demodulador pela amplitude do sinal de entrada, os outros parâmetros foram mantidos constantes.

\subsection{Reflectômetro}

Para fazer medidas de perfil de densidade o reflectômetro $[52,53]$ usa a banda da frequência eletrônica de plasma, que depende apenas da densidade do plasma. O reflectômetro envia uma onda no plasma com uma frequência, essa onda vai ser refletida no plasma no local onde sua frequência é igual a frequência de plasma, figura 4.10. A distância do ponto de emissão até o ponto de reflexão pode ser determinada pela defasagem apresentada pelo sinal enviado e refletido. Com varredura de frequência, é possível usar um reflectômetro para além de medir o perfil de densidade e também medir perturbações de turbulência.

Para um reflectômetro do tipo O-mode existe reflexão quando a frequência da onda lançada é igual a frequência do plasma [52], pois o campo elétrico 
da onda é paralelo ao campo magnético do plasma. Há também reflectômetros de X-mode, que usa os campos elétricos perpendiculares a linha de campo magnética. Neste caso há uma mudança na frequência de reflexão, que depende também do campo magnético.

Antigamente no TCABR já foram feitas medidas usando um reflectômetro tipo O-mode [27], mas este não esta mais em funcionamento. Agora está substituído por um outro reflectômetro, com uma alta taxa de amostragem. Há proposta de experimentos com este reflectômetro, com ideia de medir tanto o perfil de densidade quanto as oscilações da densidade ao mesmo tempo [27], que é possível devido a alta taxa de amostragem. O reflectômetro opera na banda de frequência de $f=18-40 \mathrm{GHz}$, fazendo a varredura em um tempo de $80 \mu \mathrm{s}$. Há duas bandas de funcionamento do reflectômetro, uma de $18 \mathrm{GHz}$ a $26 \mathrm{GHz}$, que é de baixa frequência e mede apenas a região mais externa da coluna de plasma. A outra banda vai até $40 G H z$ que tem a possibilidade de medir a região mais interna da coluna de plasma, mas esta banda de frequência não estava em operação quando foram feitas as medidas apresentadas no capítulo 6.

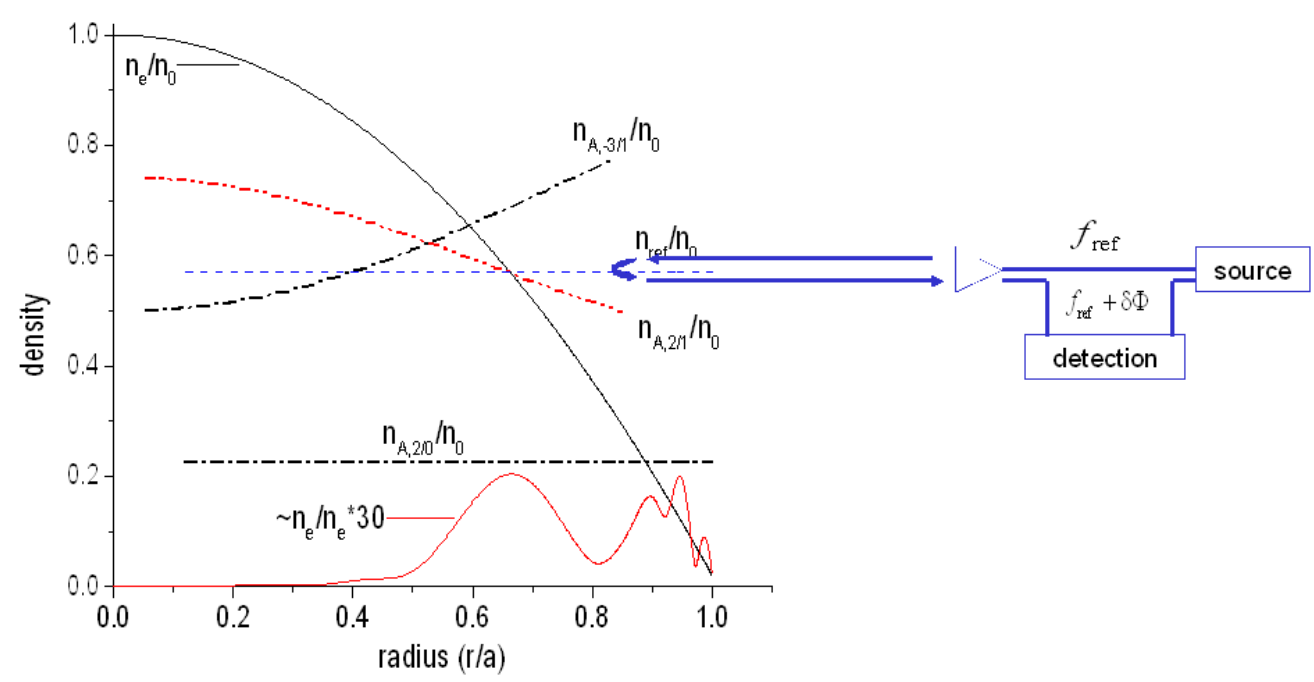

Figura 4.10: Esquema de funcionamento do reflectômetro.[27]

O objetivo no futuro é usar o reflectômetro para se fazer medidas do perfil de densidade com a antena ligada no gerador de frequência fixa, que é mais potente. 


\subsection{Gerador RF com varredura de frequência}

Normalmente geradores RF de potência alimentam as cargas ressonantes, mesmo como as antenas de Alfvén que operam em frequências fixas. Quando se quer fazer varredura de frequência em uma faixa larga é difícil programar o acoplamento efetivo da impedância da saída do gerador com a carga ressonante. Neste caso é necessário um esforço especial para garantir a eficiência do acoplamento da impedância da saída do gerador com a carga adaptada. Por isso, usamos uma técnica que foi desenvolvida para conversores DC-DC para fazer o acoplamento. No nosso caso a técnica de chaveamento é usada no módulo RF de potência com transistores MOSFETs. No amplificador foram usados os componentes básicos de chaveamento. Essa técnica facilita o casamento de impedância de carga e podemos também conseguir a varredura da frequência em uma faixa bastante larga. O módulo do sistema de RF é construído na base de potentes MOSFETs de RF (transistor de campo-efeito de metal - oxide - semicondutor), que podem gerar a potência RF de até $1 \mathrm{~kW}$ com variação de frequências nas bandas de $f=0,05-0,5 \mathrm{MHz}$ e $f=0,5-5 M H z$.

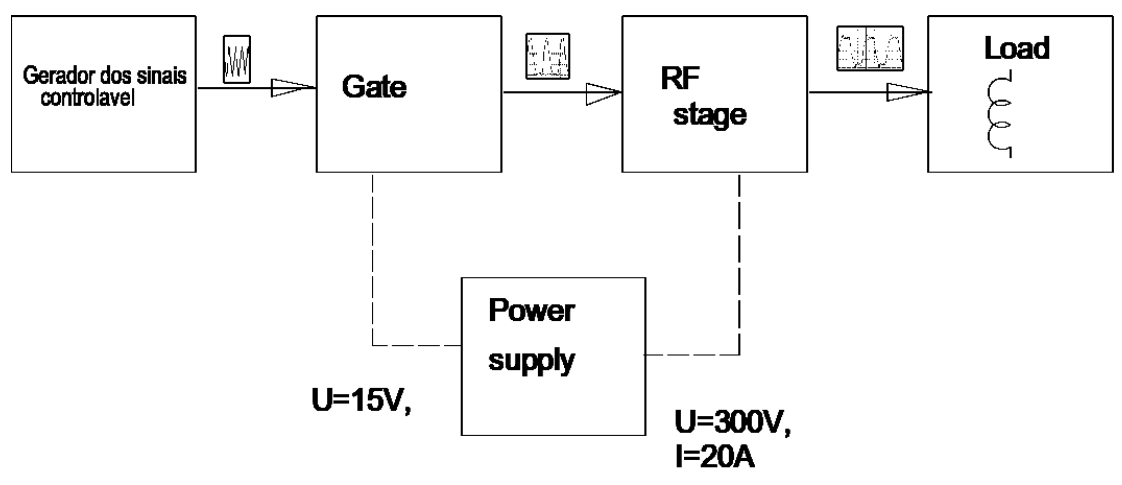

Figura 4.11: Esquema de blocos do gerador de potência com varredura de frequência. [43]

O esquema de blocos do módulo de um canal do gerador da potência RF está mostrada no Figura 4.11. A frequência e a fase do sinal de saída do módulo RF são controladas pelo gerador de sinais comercial "AGILENT 33220A $20 \mathrm{MHz}$ - ARBITRARY WAVEFORM GENERATOR", que fornece o sinal da entrada. 


\section{Capítulo 5}

\section{Teste de excitação de ondas de RF no TCABR no modo de limpeza - Helicon}

Para a realização das medidas da ondas no TCABR foi utilizado o plasma produzido em modo de limpeza [13], pois houve um problema com os diodos de funcionamento do campo magnético principal do TCABR.unciona com descargas na frequência de $5 k H z$. Então, ao invés de excitarmos ondas de Alfvén foram excitadas ondas de helicon [38], que no plasma de menor densidade como o do modo de limpeza, apresentam uma frequência próxima de $3 \mathrm{MHz}$, sendo assim possível testar o equipamento [47]. Ondas de helicon tem dispersão $\omega=c^{2} k_{\|} k \omega_{c e} /\left(\omega_{p e}^{2}+k^{2} c^{2}\right)$ e são usadas para criar plasma de baixa densidade para aplicações tecnológicas [38].

O gerador de frequência variável é utilizado na banda de frequência de $2-5 M H z$. O regime de limpeza do TCABR funciona com descargas na frequência de $5 k \mathrm{~Hz}$, é na mesma frequência que foram feitos os testes do equipamento. O modo de limpeza gera plasma de baixa densidade $1-9 \times$ $10^{16} / \mathrm{m}^{3}$, baixa temperatura eletrônica, estimada em $\mathrm{T}_{e} \approx 25 \mathrm{eV}$ e o campo magnético é de $0,04 T$. Todos os valores muito menores que para o regime normal do TCABR. Com estes parâmetros não é possível excitar ondas de Alfvén, mas sim ondas de helicon [54, 35].

O modo de limpeza serve para remover impuridades da parede do tokamak, fazendo alguma reação que forme uma substância mais volátil, que pode ser bombeada para fora do vaso pela bomba de vácuo. No caso do TCABR se usa disparos pulsados com hidrogênio, que reage com o carbono e hidrogênio que há na parede formando $\mathrm{CO}, \mathrm{CH}_{4}, \mathrm{C}_{2} \mathrm{H}_{4}$ e $\mathrm{H}_{2} \mathrm{O}$, que são gases [13].

Nas medidas usamos um osciloscópio de alta taxa de amostragem para 
Teste de excitação de ondas de RF no TCABR no modo de

adquirir os dados diretamente da sonda magnética. O sinal de referência, que é a corrente na antena, foi registrado com o mesmo osciloscópio. É possível multiplicar os dois sinais digitalmente e comparar com o sinal processado pelo circuito demodulador. A multiplicação dos sinais nos mostra a correlação cruzada entre eles, assim se a multiplicação dos sinais tem um valor alto, que significa uma alta correlação entre os sinais e pode indicar uma frequência de ressonância.

A correlação cruzada calculada digitalmente e o produto feito analogicamente, pelo circuito demodulador, ambos dependem da diferença de fase entre os sinais de entrada. Por isso houve uma preocupação com o tamanho dos cabos, que introduzem um atraso no tempo causando uma diferença de fase entre o sinal que vem da antena para o circuito demodulador e o obtido pela sonda magnética. O tamanho dos cabos foi escolhido de modo a termos uma diferença de fase para maximizar o sinal de saída.

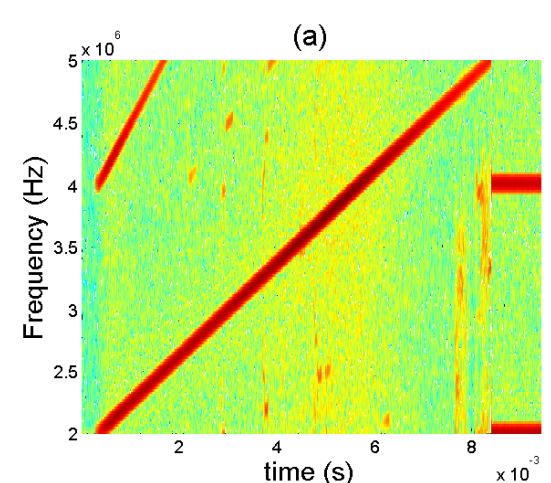

(c)

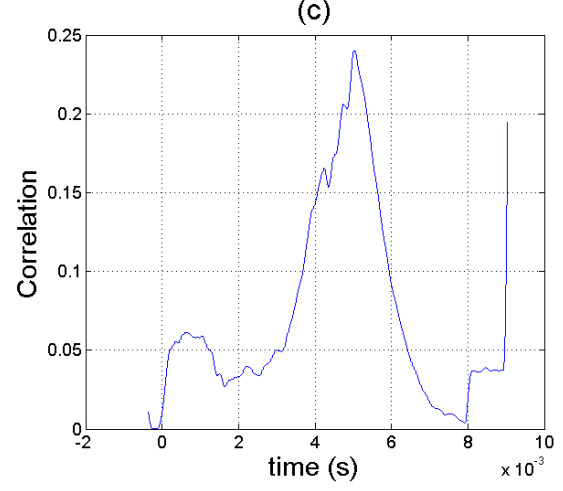

(b)

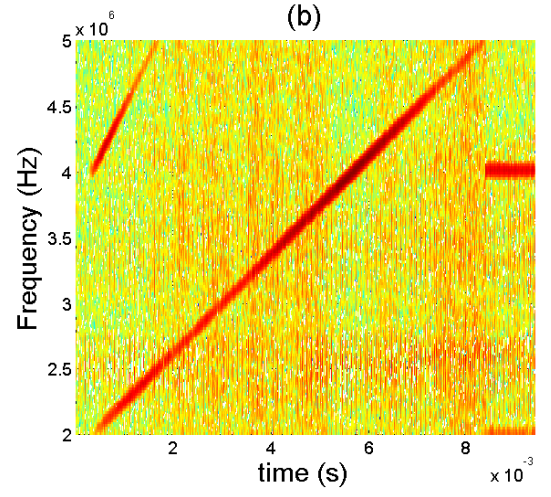

(d)

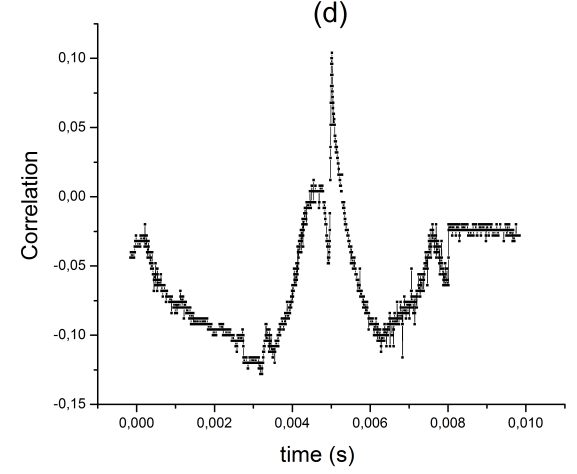

Figura 5.1: Espectrograma (a) da antena e da sonda magnética (b), (c) é a multiplicação digital de (a) e (b). (d) é o sinal de saída do circuito demodulador, para o disparo 1.

Um espectrograma é uma imagem que mostra como a densidade spectral de um sinal varia com o tempo. Ele é calculado a partir de uma transformada 
de Fourier de intervalo de tempo curto (Short-time Fourier transform), ou seja, aplicamos a transformada de Fourier para uma janela de tempo pequena comparada com o sinal, de modo a ter a resolução desejada. E necessário fazer um balanço entre o tamanho da janela e a resolução espectral, uma janela de tempo pequena implica uma boa resolução temporal, mas uma resolução espectral pequena, pois há poucos pontos.

Como é possível ver nas figuras 5.1, 5.2 e 5.3 os sinais do circuito demodulador e o calculado pelos sinais obtidos com o osciloscópio são mais compatíveis com os disparos 1 e 2, no qual o tamanho do cabo era mínimo, no outro disparo a compatibilidade era pior. Para os cálculos nos usamos mais de uma diferença de fase entre os sinais de referência (da antena) e da sonda magnética, para podermos usar o valor de defasagem que maximize a correlação entre os sinais.
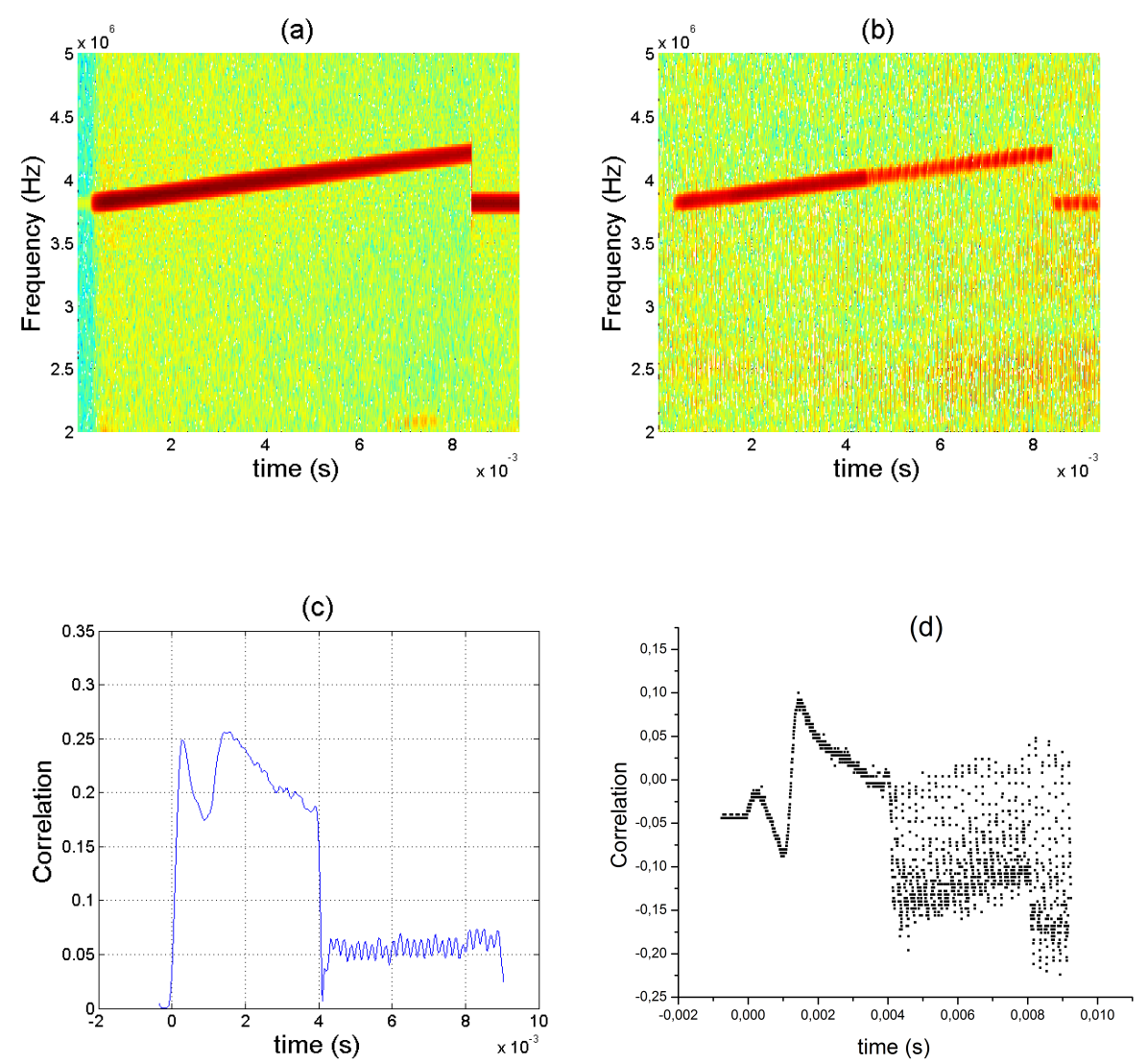

Figura 5.2: Espectrograma (a) da antena e da sonda magnética (b), (c) é a multiplicação digital de (a) e (b). (d) é o sinal de saída do circuito demodulador, para o disparo 2. 


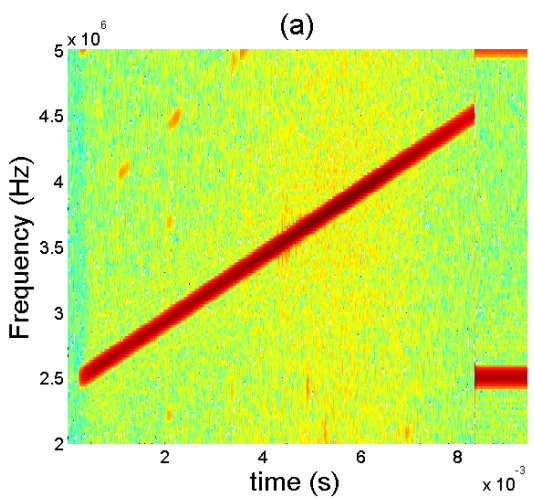

(c)

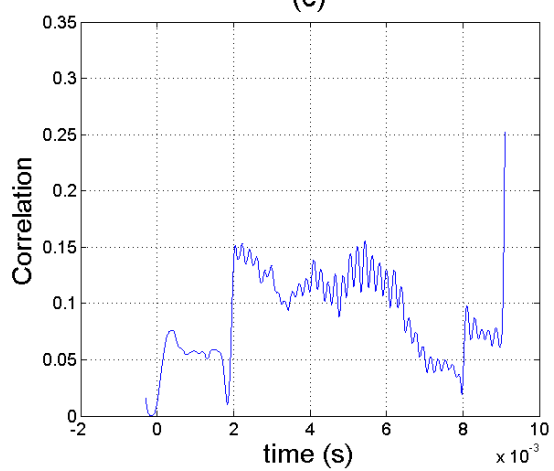

(b)

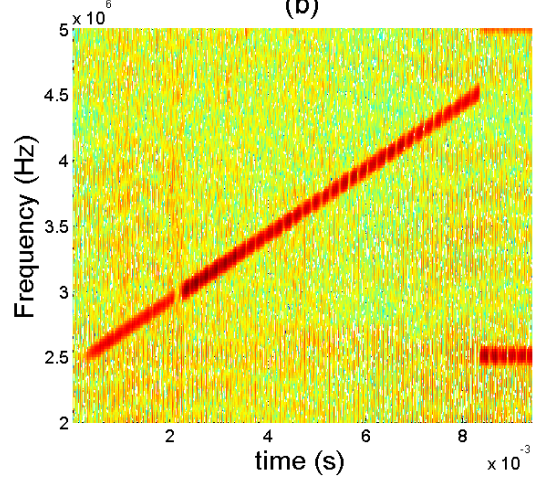

(d)

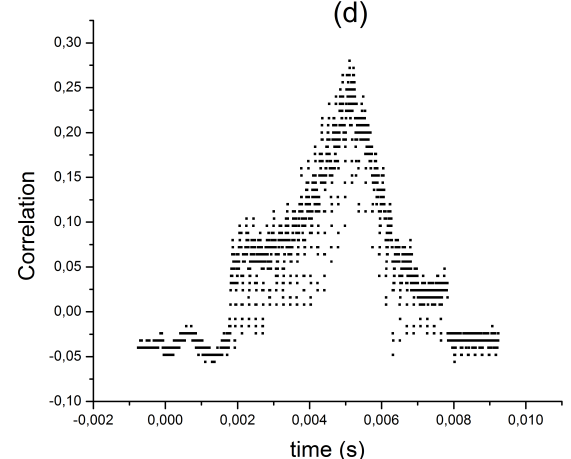

Figura 5.3: Espectrograma (a) da antena e da sonda magnética (b), (c) é a multiplicação digital de (a) e (b). (d) é o sinal de saída do circuito demodulador, para o disparo 3.

Nas figuras 5.1, 5.2 e 5.3 temos o espectrograma da corrente na antena (a) e para os dados da sonda magnética (b).

Como podemos perceber ambas os espectrogramas são semelhantes e podemos afirmar que o sinal do gerador se propaga pelo plasma, já que a bobina magnética que mede as oscilações do plasma está a $1 m$ de distância da antena. Para disparos realizados sem o plasma as bobinas não detectam o sinal que passa pela antena.

As figuras (c) e (d) representam o cálculo feito digitalmente, a multiplicação dos sinais (a) e (b), e o sinal de saída circuito demodulador, respectivamente. É possível notar que há uma frequência de ressonância no disparo 1 (Figura 5.1) em $t \approx 0,005 \mathrm{~s}$, que corresponde a uma frequência de excitação para a onda de $f \sim 4 M H z$. Esta ressonância pode ser identificada como uma onda de helicon, figura 5.4.

Para simulação das medidas foi usado o mesmo código numérico apresentado no capítulo anterior, apenas os parâmetros foram mudados para o 
regime de limpeza do TCABR. Foram escolhidos apenas os menores modos poloidais e toroidais $(M= \pm 1, \pm 2$ e $N= \pm 1)$. Os resultados da simulação estão presentes na Figura 5.4.
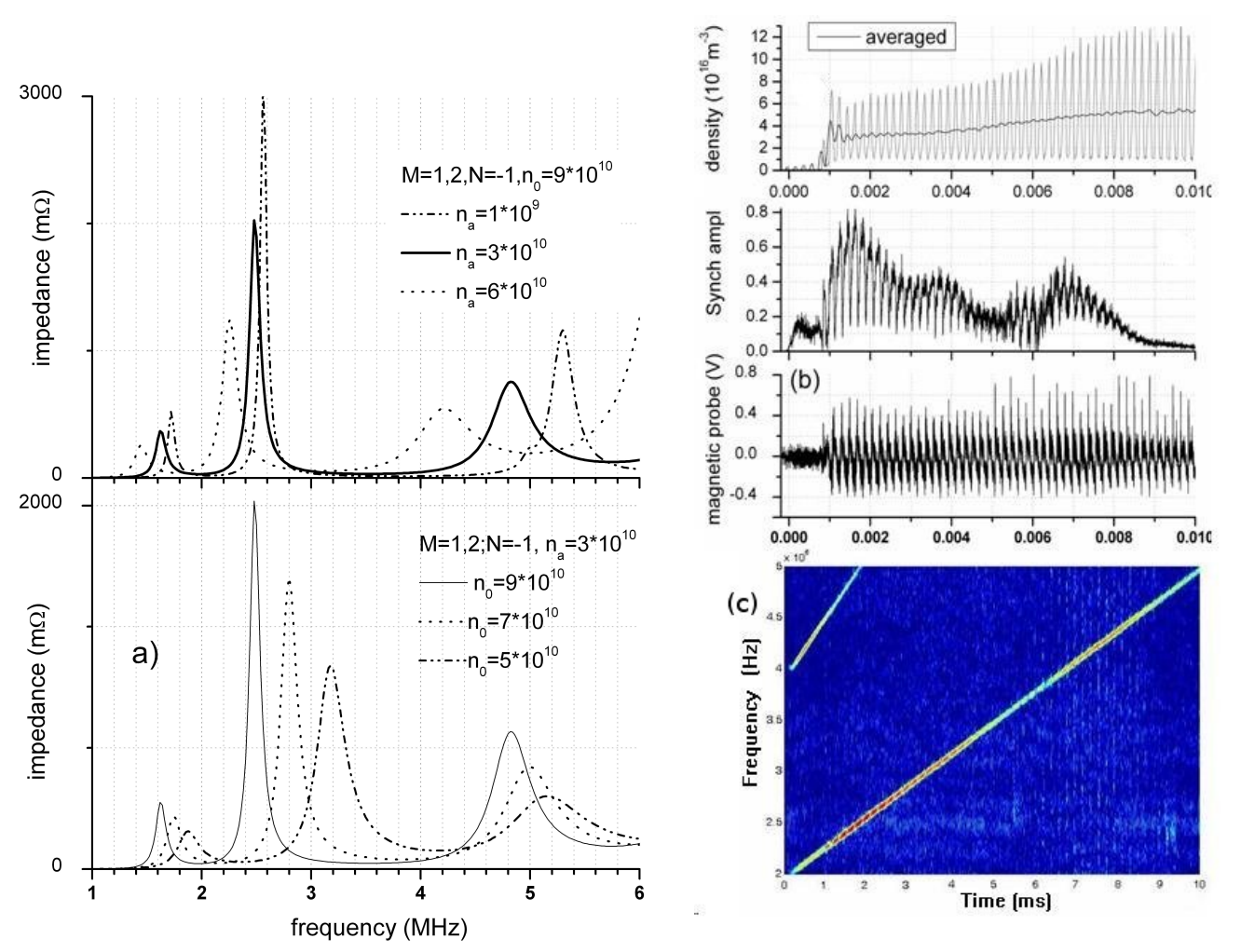

Figura 5.4: Simulação das ondas de helicon(a) para perfil de densidade parabólica de $2-9 \times 10^{10} / \mathrm{cm}^{3}$ no centro, e temperatura de $25 \mathrm{eV}$. (b) disparo que apresenta uma boa cocordância com a simulação de ondas de helicon, (c) espectrograma do mesmo disparo.

A medida da densidade mostrada na figura $5.4 b$ apresenta a variação da densidade que foi medida com a sonda eletrostática, o sinal da sonda magnética, e sinal marcado como synch ampl, que é um processo do mesmo tipo que o usado no circuito demodulador, é um cálculo de correlação cruzada também, entre os outros 2 sinais.

Como podemos ver na figura 5.4 existem ressonâncias para algumas frequências, uma delas em particular esta perto de $4 M H z$ que é semelhante a frequência da figura 5.1. Provavelmente temos um plasma com densidade diferente da simulação e do disparo da figura 5.4.

Podemos observar (Figura 5.4 b e $c$ ) um disparo com uma melhor similaridade com a simulação, infelizmente o circuito demodulador não estava 
Teste de excitação de ondas de RF no TCABR no modo de

operante quando foi feito este disparo.

\subsection{Sumário do capítulo}

No plasma do tokamak em modo de limpeza demonstramos que foi possível excitar ondas de helicon com a antena e fazer medidas das ressonâncias com o circuito demodulador. O esquema de ligação da antena com o gerador de frequência variável funcionou bem, tendo bom desempenho. Também mostramos que foi possível simular as ondas de helicon com o código disponível no laboratório e relacionar a simulação com o experimento.

Os dados obtidos com o circuito demodulador quando comparado com os dados obtidos com o osciloscópio de alta taxa de amostragem são compatíveis. Em casos semelhantes o circuito demodulador pode substituir um sistema de aquisição com alta amostragem, sendo mais barato. Esperamos que seja possível realizar mesmos tipos de medidas com ondas de Alfvén, sendo bom para achar rapidamente as ressonâncias do plasma. Neste estudo confirmamos que nas medidas com as sondas magnéticas as densidades das ressonâncias são identificadas com cálculos numéricos. O método testado de identificação de helicon pode servir para detecção de ressonâncias globais de Alfvén. 


\section{Capítulo 6}

\section{Medidas de perturbações de densidade por ondas de Alfvén com reflectômetro}

\subsection{Metodologia}

O funcionamento básico de um reflectômetro esta explicado no capítulo 4. Nesse capítulo usamos um modo de investigação de frequências de sideband para identificar ressonância de ondas de Alfvén no regime de aquecimento do plasma. Inicialmente o campo de RF esta excitando a ressonância local de Alfvén e no mesmo momento o sinal do reflectômetro é lançado para o plasma e refletido pela camada chamada cuttoff do plasma onde há ressonância de Alfvén, que criam oscilações na densidade, ocorre uma modulação do sinal na frequência da ressonância, criando sidebands (modos vizinhos), que são oscilações em frequências que ficam acima e abaixo da frequência de ressonância, por fenômenos não lineares [28].

$$
\omega_{S}=\left|\omega_{A} \pm \omega_{B}\right|
$$

Sendo $\omega_{A}$ a frequência de ressonância de Alfvén, ou de alguma outra ressonância que há no plasma e $\omega_{B}$ é a frequência de batimento, a frequência da sidebands pode ser encontrada com o uso de um espectrograma do sinal do reflectômetro. As frequências das sidebands são simétricas em relação a frequência da ressonância. No nosso caso, como mantivemos a frequência da antena fixa em $5 \mathrm{MHz}$, se observarmos no espectrograma dois picos em torno da frequência da antena temos um indicativo que há uma ressonância nessa região do plasma. 
Medidas de perturbações de densidade por ondas de Alfvén com 50 reflectômetro

O valor da frequência de batimento depende de alguns fatores próprios do equipamento e também do plasma, sendo dada por [28]:

$$
\omega_{B} t=\phi_{p}(\omega)+\phi_{m}(\omega)-\phi_{r e f}(\omega)
$$

onde $\phi_{p}$ é a diferença de fase causada pelo plasma e como temos um reflectômetro que opera em O-mode (modo ordinário), que tem o campo elétrico da onda eletromagnética enviada ao plasma paralelo ao campo magnético que confina o plasma, temos reflexão quando a frequência de plasma é igual a frequência do reflectômetro e a diferença de fase depende do caminho percorrido pelo sinal que sofre reflexão. $\phi_{m}$ e $\phi_{\text {ref }}$ são as diferenças de fase atribuídas ao sinal refletido e o de referência do reflectômetro respectivamente.

As sidebands aparecem no espectrôgrama quando há oscilações de densidade na região do plasma que recebe o sinal do reflectômetro. Assim, é possível saber a densidade em que ocorrem as ressonâncias. É possível determinar a localização destas ressonâncias se considerarmos um perfil parabólico do plasma e obtivermos medidas de densidade. No caso as medidas de densidade foram feitas com um interferômetro.

Seria possível usar o sinal do próprio reflectômetro para achar a posição das ressonâncias, mas isso não foi feito, pois envolve reconstruir o perfil de densidade do plasma com o sinal do reflectômetro. Isso foge dos objetivos propostos neste trabalho.

Somente o canal de baixa frequência estava em funcionamento, e sendo assim detectamos apenas baixas densidades, o canal de frequência mais alta estava com defeito. Só foram feitas varredura para frequências de $18-26 \mathrm{GHz}$, que correspondem a uma densidade de plasma de $n=4,02-8,38 \times 10^{12} / \mathrm{cm}^{3}$. Se olharmos os parâmetros do TCABR na tabela 1.1, notamos que essa densidade deve se localizar na borda do plasma, sendo até uma ordem de grandeza menor que a densidade no centro do plasma. Nesses experimentos a frequência da onda lançada pela antena era de aproximadamente $5 \mathrm{MHz}$.

O gerador fica em funcionamento durante $5 \mathrm{~ms}$ do disparo do plasma, o tempo é suficiente para o reflectômetro realizar múltiplas varreduras de $80 \mu s$.

\subsection{Resultados e análise}

Os disparos do TCABR analisados foram dos números 24504 - 08, todos tinham condições do plasma parecidas. Como um exemplo do disparo típico os dados de corrente de plasma, densidade e do sinal ECE do disparo 24506 estão mostrados na figura 6.1. Na figura apresentamos também o sinal do raio-X mole que pode ser usado para medir atividade MHD [55] como dentes 
de serra usados para identificar superfícies de $q=1$ no centro do plasma [27]. Não foi possível usar as sondas magnéticas durante estas medidas pois o circuito demodulador ainda não estava operante.
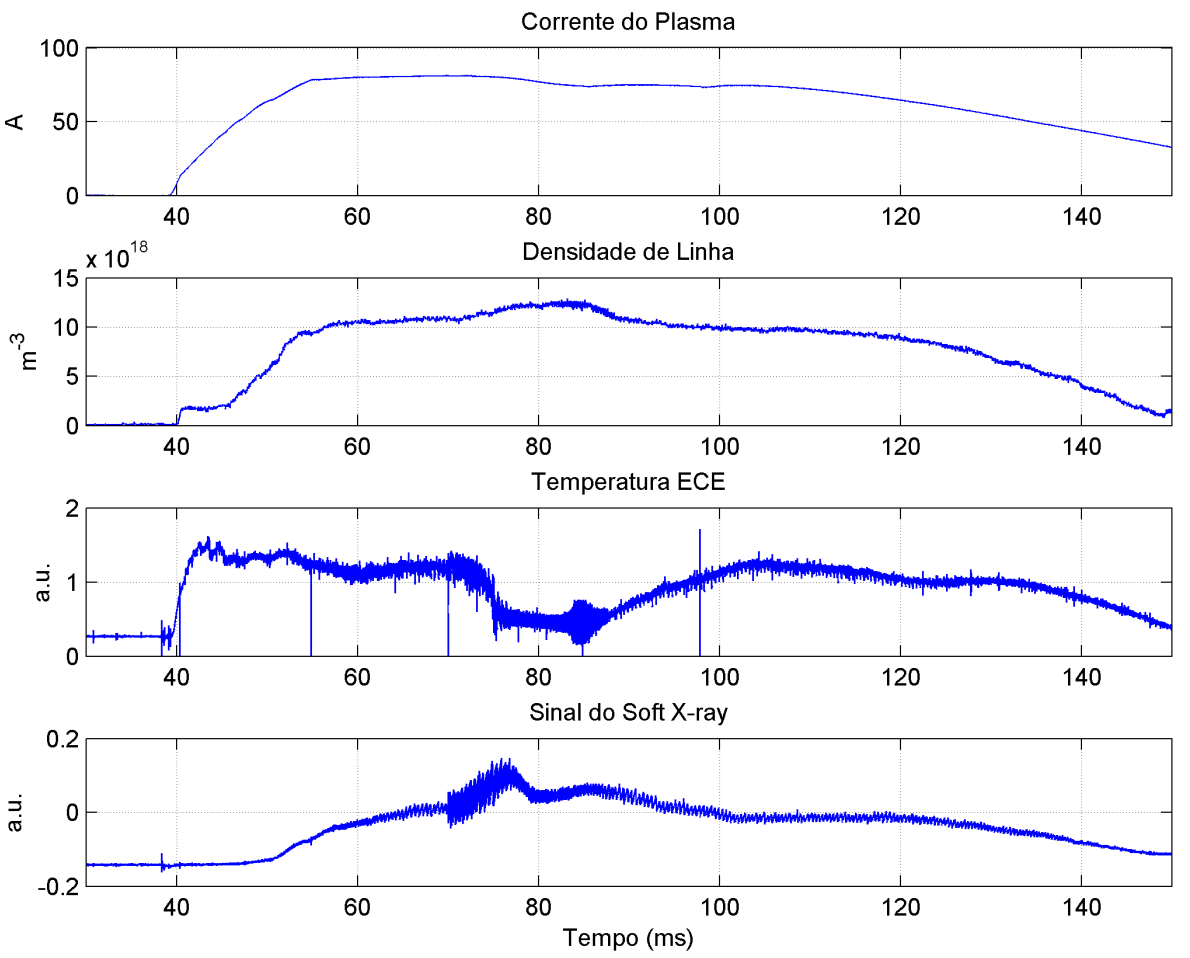

Figura 6.1: Sinais do disparo 24506, mostrando a corrente de plasma, a densidade de linha, o sinal do ECE e raio-X mole.

O gerador foi ligado no tempo $t=70 \mathrm{~ms}$ e fica ligado por $5 \mathrm{~ms}$, é possível notar que perto desse tempo o sinal do ECE diminui, isso se deve a um aumento da densidade do plasma, absorvendo a radiação da banda em que o ECE opera, a frequência de ciclotron dos elétrons é menor que a frequência de plasma, então esta radiação é absorvida. A corrente do plasma permanece inalterada e temos um aumento na densidade. O sinal de emissão de raio $\mathrm{X}$-mole aumenta de atividade quando a antena esta ligada, há mais emissão de raios-X, que podem ser usados para identificar ressonâncias junto ao reflectômetro [56].

Com a densidade de linha podemos estimar a densidade no centro do plasma com um modelo de perfil parabólico e fazer a localização dos pontos de ressonância. Apenas deve-se lembrar que a densidade da linha do interferô- 


\section{Medidas de perturbações de densidade por ondas de Alfvén com 52 reflectômetro}

metro usada não passa pelo centro do plasma, isso tem que ser considerado nos cálculos para se achar a densidade no centro do plasma. A densidade no centro do plasma pode ser calculada pela equação:

$$
n_{0}=\frac{3}{2} \frac{n_{l}}{1-\left(\frac{x}{a}\right)^{2}},
$$

onde $n_{0}$ a densidade no centro do plasma, $n_{l}$ a densidade da linha, medida com o interferômetro, com coordenada $x=R-R_{0}$ que é o deslocamento do centro do plasma ao longo do raio menor. No nosso caso o deslocamento do centro era de $12,5 \mathrm{~mm}$, mas pode ser outro, dependendo da linha usada. Temos que uma linha mais central teria uma medida mais confiável.

Na figura 6.2 vemos que há um aumento da densidade no centro do plasma, mas é pequeno, e dado o perfil parabólico, figura 6.3, pouco muda a densidade na borda do plasma. Região onde foram medidas as possíveis ressonâncias, as medidas foram feitas para densidades de $n=4,02-8,38 \times$ $10^{12} / \mathrm{cm}^{3}$, como podemos ver no gráfico, estas densidades se encontram em $\sim 140-160 \mathrm{~mm}\left(0,78-0,89 r_{p}\right)$.

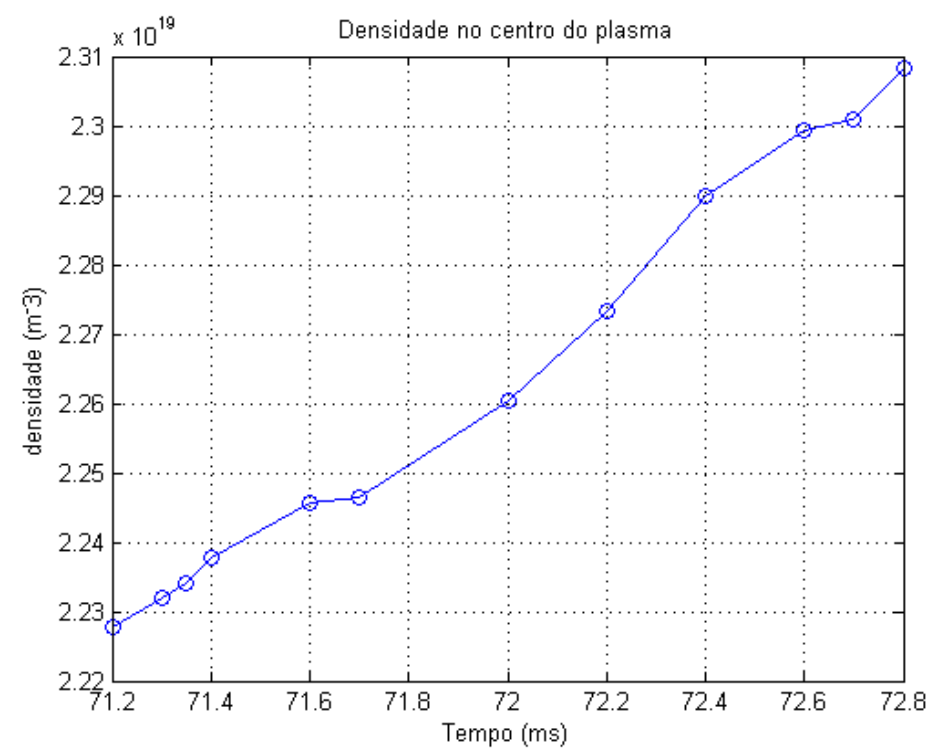

Figura 6.2: Aumento da densidade no centro do plasma durante aplicação de Alfvén do disparo 24506, calculado com a equação 6.3.

Os espetrogramas de alguns dos disparos analisados estão mostrados nas figuras $6.4,6.5,6.6$ e 6.7, as sidebands estão em destaque, elas indicam as ressonâncias no plasma. Nos espectrogramas aparece a frequência em que o gerador esta em operação, próximo de $5 \mathrm{MHz}$. 


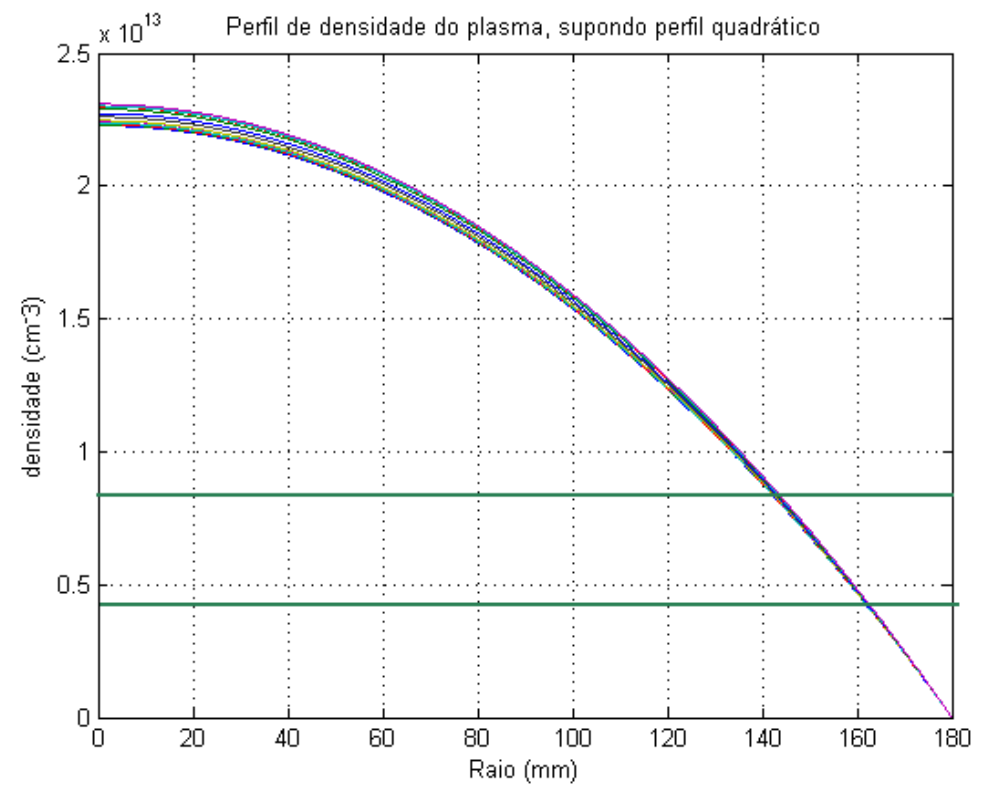

Figura 6.3: Perfil de densidade do disparo 24506, usando os dados do gráfico 6.2. Também mostramos os limites de densidade em que o reflectômetro opera.

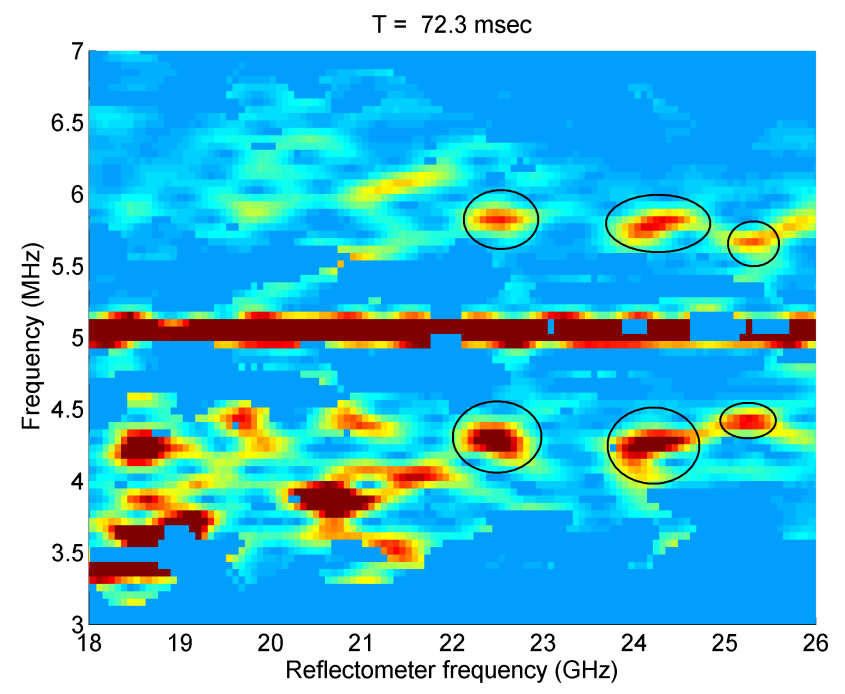

Figura 6.4: Espectrograma do sinal do reflectômetro do disparo 24505, enquanto a antena estava em operação. As ressonâncias estão em destaque. 
Medidas de perturbações de densidade por ondas de Alfvén com 54 reflectômetro

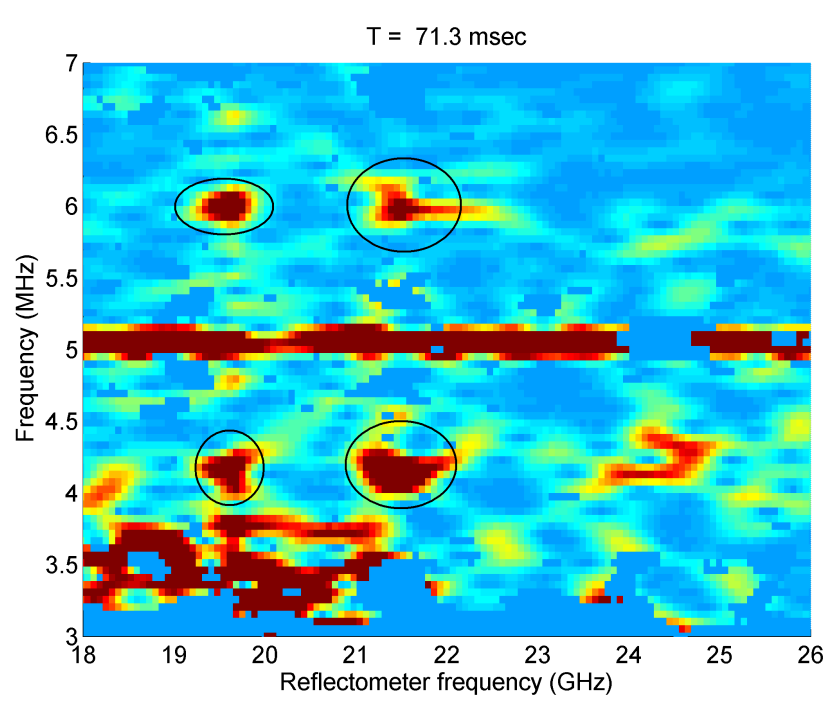

Figura 6.5: Espectrograma do sinal do reflectômetro do disparo 24506, enquanto a antena estava em operação. As ressonâncias estão em destaque.

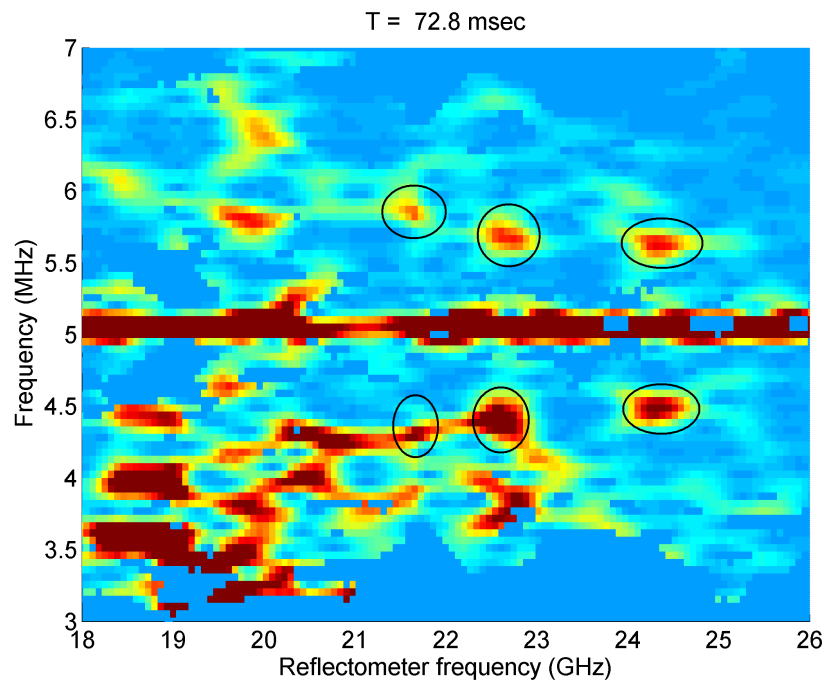

Figura 6.6: Espectrograma do sinal do reflectômetro do disparo 24506, enquanto a antena estava em operação. As ressonâncias estão em destaque. 


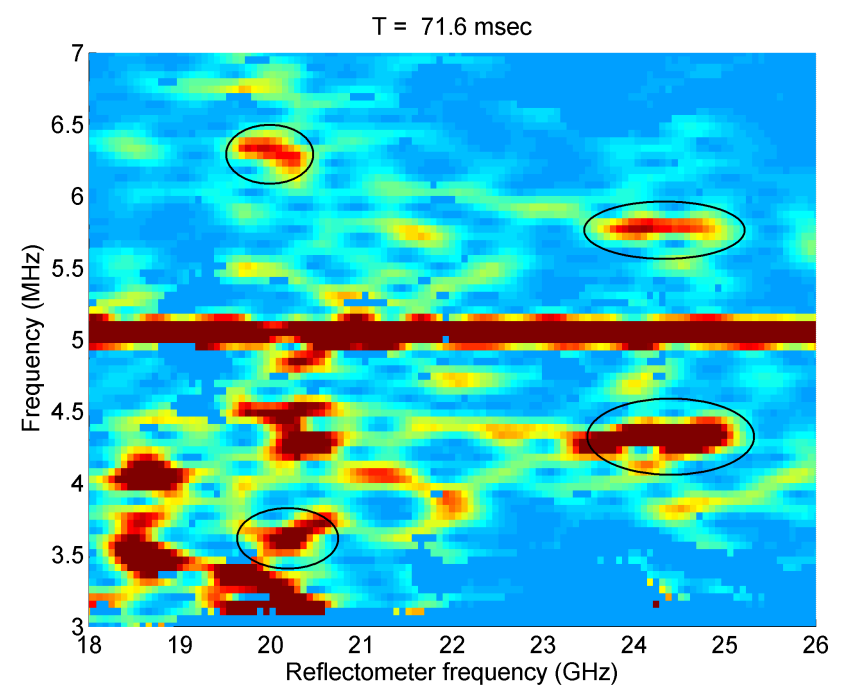

Figura 6.7: Espectrograma do sinal do reflectômetro do disparo 24508, enquanto a antena estava em operação. As ressonâncias estão em destaque.

Para se fazer os espectrogramas foi usada uma rotina do matlab que se encontra no apêndice A, o sinal é filtrado para termos uma melhor resolução na faixa de frequências próxima a frequência da antena. Além disso o sinal com o gerador de Alfvén ligado é normalizado por um sinal do começo do disparo do TCABR, quando ainda não há plasma. O espectrograma recebe um corte de nível, assim não vemos elementos de baixa amplitude e é diminuída a presença no espectrograma de alguma parte do sinal que esta presente antes da antena ser ligada.

Nem todos os espectrogramas feitos mostravam uma imagem clara das ressonâncias, devido a ruídos e a própria resolução do espectrograma. Na figura 6.8 foi feito um gráfico levando em conta todas as ressonâncias encontradas com o valor da densidade das ressonâncias, mas não encontramos algum padrão.

Seria possível estimar a densidade no centro do plasma e assim a posição da ressonância por meio do perfil parabólico. Isso não foi feito pois como temos as medidas na borda do plasma, mudanças de densidade fazem com que haja uma mudança na posição não considerada pelo perfil parabólico. A posição calculada acabaria por ser muito imprecisa.

Como as oscilações induzidas pela antena se encontram perto da borda do plasma, não medimos excitação de ondas de Alfvén, globais ou locais, mas algum outro tipo de onda, veremos na próxima seção que se tratam de ondas eletrostáticas. Observando a figura 6.8 percebemos que não é possível 
Medidas de perturbações de densidade por ondas de Alfvén com 56 reflectômetro

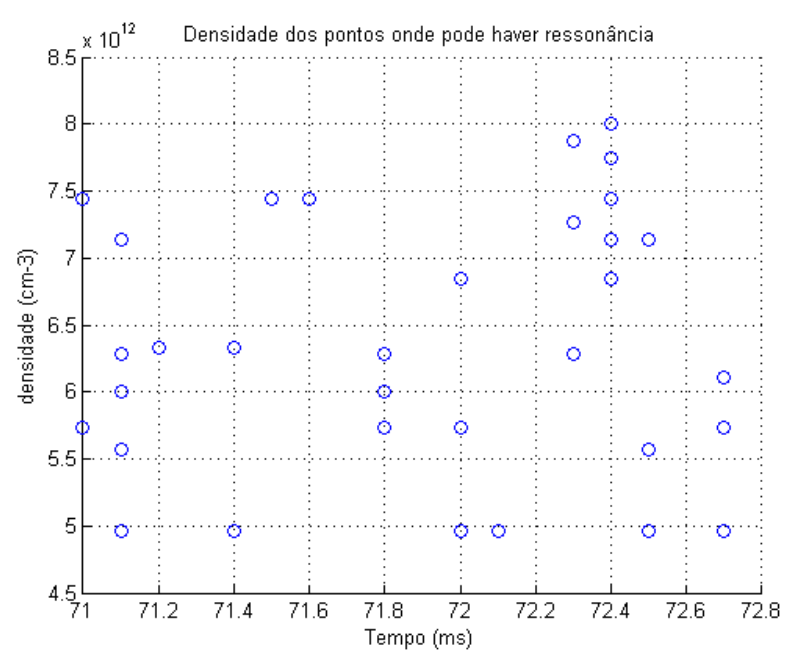

Figura 6.8: Densidade das ressonâncias.

afirmar que se tenha qualquer padrão para a localização das ressonâncias no plasma, isso leva a crer que temos ondas eletrostáticas na borda do plasma.

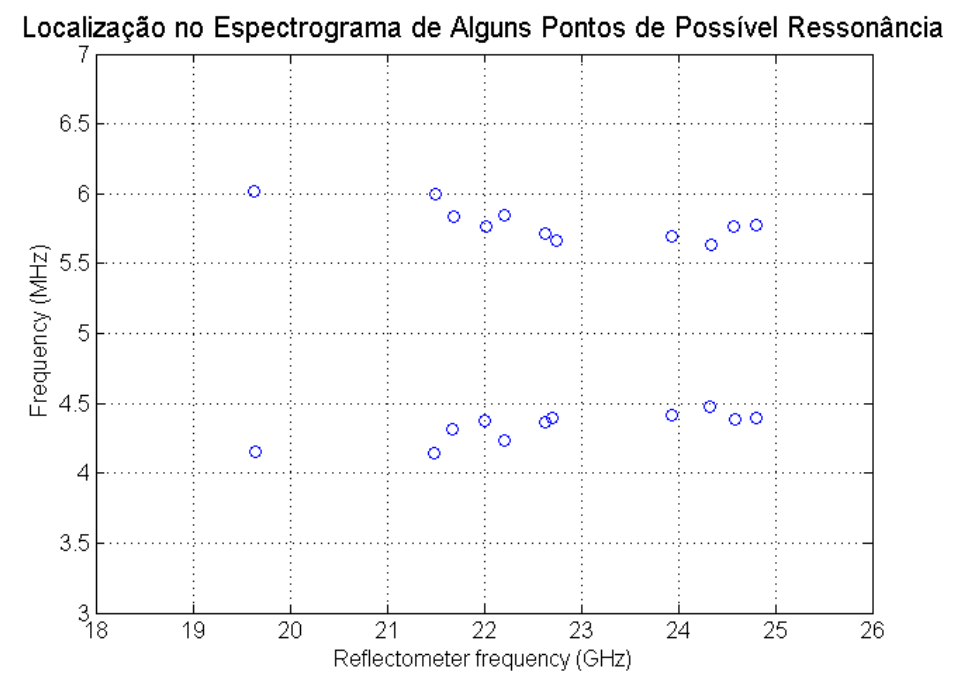

Figura 6.9: Posição das ressonâncias nos espectrogramas.

Porém há um certo padrão na localização das ressonâncias nos espectrogramas, figura 6.9. Para a construção desse gráfico foi utilizado o aplicativo digitize, disponível para o matlab. Foram usados dados de 7 espectrogramas dos disparos para se fazer o gráfico. Vemos que a tendência é a frequência de batimento $\omega_{B}$ diminuir com aumento da frequência do reflectômetro [28]. 
Essa diminuição pode indicar alguma mudança na densidade do plasma, como é possível notar pela equação 6.2, ou simplesmente a dispersão nas guias de onda.

\subsection{Simulações}

Para tentar identificar o tipo de onda que estava sendo excitada foi feita uma simulação com condições semelhantes às usadas para as medidas. Foi usada uma densidade no centro do plasma de $n_{0}=2 \times 10^{13} / \mathrm{cm}^{3}$, a frequência na antena de $f=5 M H z$ e o modo $m=-3$ e $N=-1$. O resultado é apresentado na figura 6.10, que é possível comparar com a figura 3.4, que é semelhante.
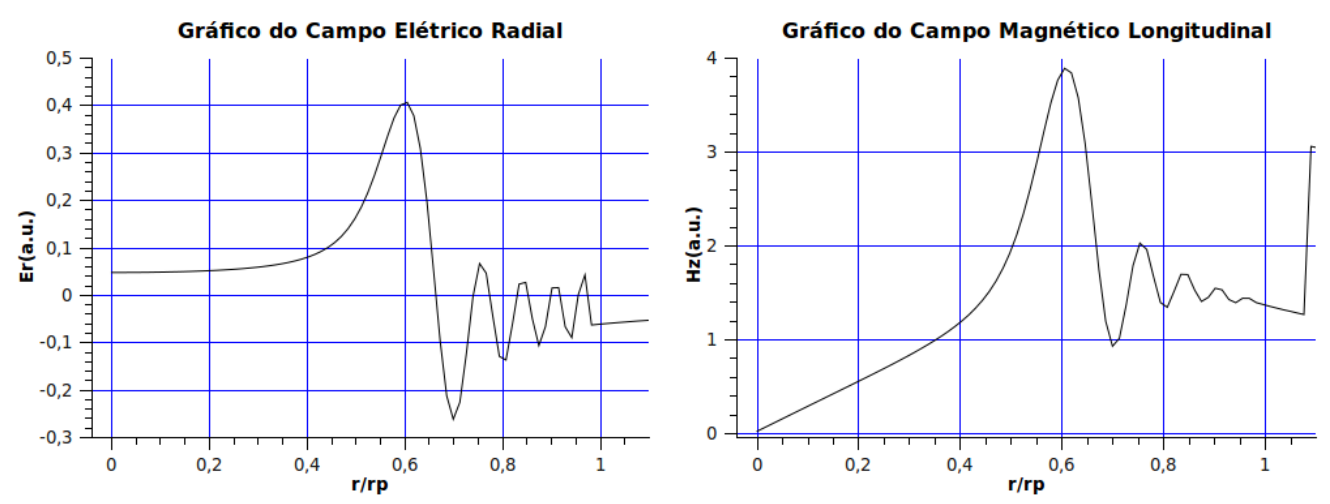

Figura 6.10: Simulação do campo $H_{z}$ (que é a perturbação de $B_{z}$ ) e $E_{r}$ para $m=-3$ e $N=-1$ para $f=5 M H z$.

Com o plasma com a densidade desta simulação e de perfil parabólico o reflectômetro tem uma região de operação de $\sim 0,76-0,89 r_{p}$. Essa região contêm as oscilações que estão na borda do plasma. As oscilações na borda do plasma são oscilações eletrostáticas, que foram excitadas pela antena.Notamos mais uma vez que não foi possível realizar medidas da região mais central do plasma, pois a banda de alta frequência do reflectômetro não estava operante. A ressonância mais intensa, que se encontra na posição $r=0,6 r_{p}$, tem densidade de $n=1,3 \times 10^{13} / \mathrm{cm}^{3}$ e não é acessível ao reflectômetro. 
Medidas de perturbações de densidade por ondas de Alfvén com 58

reflectômetro

\subsection{Sumário do capítulo}

Com o uso do reflectômetro foi possível medir ressonâncias perto da borda do plasma, devido a frequência de operação disponível corresponder a uma densidade do plasma em torno de $n=4,0-8,4 \times 10^{12} / \mathrm{cm}^{3}$. A região mais central do plasma, que tem maior densidade, não estava acessível na banda de baixa frequência do reflectômetro. As ressonâncias medidas são identificadas como ondas eletrostáticas de Alfvén, confirmado por simulações. O método de identificação das ressonâncias pela frequência de batimento funciona e é promissor. Finalmente concluímos que encontrando-se a posição das ressonâncias é possível, com o uso de simulação computacional, identificar os modos de Alfvén e reconstruir algumas propriedades do plasma como massa efetiva dos íons e o perfil do fator de segurança. 


\section{Capítulo 7}

\section{Conclusão}

O estudo mostra que foi possível identificar ressonâncias globais e locais no plasma de limpeza e no plasma de disparo típico do TCABR, usando diagnósticos diferentes. O regime de limpeza foi usado por conta de problemas na ocasião das medidas e apenas este modo era operacional.

No caso do plasma de limpeza, usando as sondas magnéticas, o sinal da antena e de uma sonda de Langmuir foi possível detectar ondas de helicon, as frequências das ondas excitadas foram confirmadas com cálculos usando o código cilíndrico. As ondas foram excitadas com o gerador com varredura de frequência, que tem potência baixa, no plasma de limpeza do TCABR.

Medidas das ressonâncias no plasma típico do tokamak, de maior densidade, foram feitas com o reflectômetro. Devido a apenas a banda de baixa frequência estar operacional foi possível apenas fazer medidas das oscilações na borda da coluna de plasma. Encontramos indicações de ressonâncias induzidas pelo campo eletromagnético no modo de operação de alta potência e com frequência fixa, em torno de $5 \mathrm{MHz}$. A simulação computacional com os parâmetros do plasma, da antena e do gerador mostraram que foi excitada uma onda eletrostática de Alfvén na borda do plasma. Não é possível medir a onda de Alfvén global com o reflectômetro, pois é excitada na região mais central do plasma, na região de maior densidade, inacessível ao reflectômetro na banda de frequências em que foi usado.

Conseguimos medir outros tipos de ressonância, mas há indicativos que com parâmetros de plasma mais adequados podemos medir ondas de Alfvén com os métodos apresentados.

Tanto a análise do sinal das sondas magnéticas obtidas com o circuito demodulador e com o osciloscópio com alta taxa de amostragem, quanto a análise do sinal do reflectômetro, indicam excitação de ondas no plasma e estas foram detectadas. Finalmente concluímos que é possível usar os equipamentos e métodos apresentados para identificar ressonâncias locais e globais 
de ondas no plasma. 


\section{Capítulo 8}

\section{Sugestão para trabalhos futuros}

Usar o sistema de excitação de ondas RF com varredura de frequência com o plasma ôhmico do TCABR e realizar medidas das ressonâncias com o reflectômetro.

Fazer medidas conjuntas com o reflectômetro e as sondas de magnéticas. Sendo possível determinar se medimos realmente uma ressonância.

Fazer pesquisas para frequências mais baixas e tentar encontrar oscilações presentes no plasma, houve uma tentativa mas aparentemente deve-se ajustar o método de análise para encontrar ressonâncias em frequências menores.

Usar os métodos apresentados na dissertação para inferir mais características do plasma e medir o perfil do fator de segurança [27]. Pela equação 1.9, se determinarmos o modo e a posição das ressonâncias é possível determinar o valor do fator de segurança em alguns pontos, com simulação computacional é possível determinar o perfil em todo o plasma. Se for possível medir a ressonância para o modo $\mathrm{M}=0$ podemos determinar a massa efetiva dos íons.

Desenvolver um método para se determinar o modo da onda excitada no plasma com o uso do circuito demodulador, ou fazer modificações neste se for necessário.

Com a banda de alta frequência do reflectômetro detectar ressonâncias de Alfvén mais no centro do plasma. Um outro método é usar uma frequência mais alta, que atravesse o plasma e seja refletido na parede interna do TCABR, assim teriamos o reflectômetro funcionando em modo de interferômetro [57] e observar a modulação do sinal das ressonâncias que estão mais perto do centro do plasma. 


\section{Apêndice A}

\section{Código do Matlab usado para análise dos dados do reflectômetro}

Neste apêndice está apresentado o código desenvolvido no Matlab para analisar e fazer os espectrogramas dos dados obtidos com o reflectômetro no capítulo 6.

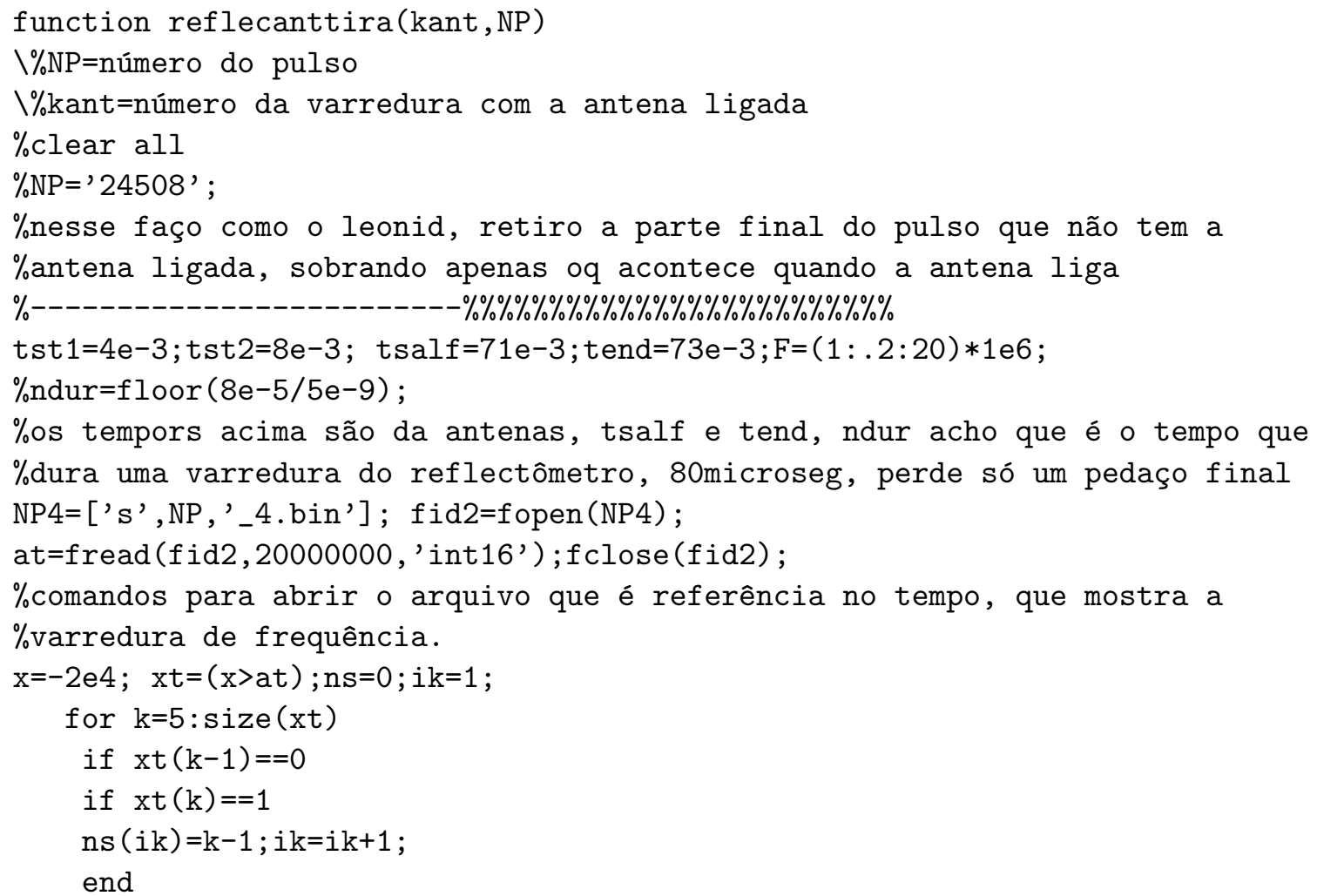


6Código do Matlab usado para análise dos dados do reflectômetro

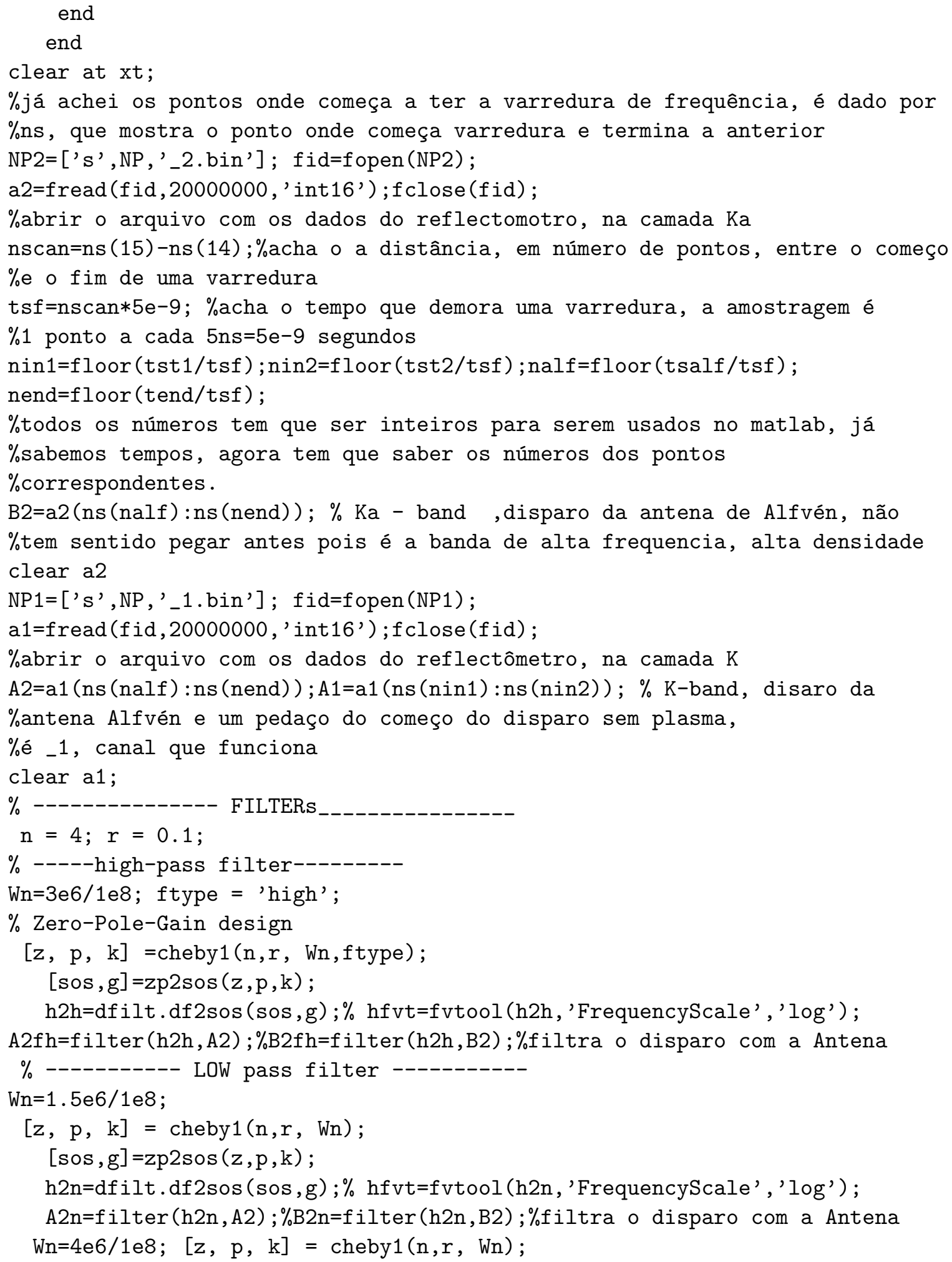


$[\mathrm{sos}, \mathrm{g}]=\mathrm{zp} 2 \mathrm{sos}(\mathrm{z}, \mathrm{p}, \mathrm{k})$;

h2n=dfilt.df2sos (sos,g); \% hfvt=fvtool (h2n, 'FrequencyScale', 'log') ;

A1n=filter (h2n,A1);\%filtra a parte do começo, sem plasma

$\%$ FILTERED REFERENCE signal

$\mathrm{k}=4 ; \mathrm{A} 1 \mathrm{x}=\mathrm{A} 1 \mathrm{n}(1+(\mathrm{k}-1) * \mathrm{nscan}: \mathrm{k} * \mathrm{nscan}) ; \%$ pega a quarta varredura na $\%$ parte $\mathrm{A} 1$, começo, do disparo

$\mathrm{AxF}=a b s(\mathrm{~A} 1 \mathrm{x}(1: \mathrm{ndur})) ; \%$ pega só 80 microseg do disparo, ignora $\circ$ final, $\%$ nscan tem uns 90 microseg, ndur 80 micro seg

$\mathrm{Nf}=500 ; \mathrm{bf}=1 / \mathrm{Nf} *$ ones $(\mathrm{Nf}, 1) ; \mathrm{AxFF}=$ filtfilt (bf, $1, \mathrm{AxF}) ; \%$ clear A1n A1 A1x AxF $\mathrm{t}=(0: 5 \mathrm{e}-9: 2 \mathrm{e}-4) ; \mathrm{t}=\mathrm{t}(1: \mathrm{ndur})$;

AxFF=filtfilt (bf, $1, A x F F)$;

pf=polyfit ( $\left.t^{\prime}, \operatorname{AxFF}, 3\right)$;

AxPF=polyval (pf , $t$ );

$\mathrm{AxFF}=\mathrm{AxPF}{ }^{\prime}$;

\%nessa parte foi filtrado o sinal com o filtfilt, que é um filtro de \%zero-phase, mantem características no mesmo tempo, só passa componente de \%baixa freq.. Depois foi ajustado um polinomio para esse sinal.

$$
\% \% \%
$$

$\mathrm{t}=(0: 5 \mathrm{e}-9: \mathrm{nscan} * 5 \mathrm{e}-9) ; \mathrm{u} 1 \mathrm{~s}=\sin (2 * \mathrm{pi} * 5.05 \mathrm{e} 6 \mathrm{t}(1: \mathrm{ndur})) ;$

$\mathrm{u} 1 \mathrm{c}=\cos (2 * \mathrm{pi} * 5.05 \mathrm{e} 6 \mathrm{t}(1: \mathrm{ndur}))$;

u1s=u1s'; u1c=u1c'; clear t;\%é calculado um seno e cosseno de

\%frequência próxima da antena $5 \mathrm{MHz}$ (Antena) $-5.05 \mathrm{MHz}$ (Seno, Coss)

$\%$ no tempo ndur=80microseg, de uma varredura de freq.

$\%$ do reflec., depois transpõe

deln=nend-nalf\%numero de varreduras que tem a antena ligada, deln=22

$\%$ for $\mathrm{k}=1: \mathrm{deln}-1$;

$k=k a n t \%$ mudei aqui pra fazer a função

$\mathrm{Ax}=\mathrm{A} 2 \mathrm{n}(1+(\mathrm{k}-1) * \mathrm{nscan}: \mathrm{k} * \mathrm{nscan}) ; \%$ Low frequency, menor que $1.5 \mathrm{MHz}$

$\mathrm{Axx}=\mathrm{A} 2 \mathrm{fh}(1+(\mathrm{k}-1) * \mathrm{nscan}: \mathrm{k} * \mathrm{nscan}) ; \%$ High frequency, maior que $3 \mathrm{MHz}$

$\%$ pega a varredura de numero 19 , depois que a antena esta ligada

$t=(0: 5 e-9: 2 e-4) ; t=t(1: n d u r) ; \%$ tempo de $80 \mathrm{microseg}$, espaçado certo

$\operatorname{Axx}=\operatorname{Axx}(1: \mathrm{ndur}) . / \mathrm{AxFF} ; \mathrm{Ax}=\mathrm{Ax}(1: \mathrm{ndur}) . / \mathrm{AxFF} \%$ sinais normalizados pela

\%referência, que é uma parte do disparo sem plasma, bem no começo au1=u1s.*Ax; \%multiplica o sinal de baixa freq pelo seno de $5.05 \mathrm{MHz}$ time $=\operatorname{sprintf}\left({ }^{\prime} \% 5.1 f^{\prime},(\right.$ ns (nalf $)+(\mathrm{k}+0.5) *$ nscan $\left.) * 5 e-6\right) ; \%$ fala $\circ$ tempo

$\%$ em que se esta fazendo a análise, no disparo do tokamak, em miliseg [yx,f ,t,pxs] =spectrogram (au1, 2000, 1900, 3900, 2e8, 'yaxis') ; \%espectrograma

$\%$ do sinal de baixa freq multiplicado pelo seno au1=u1c $*$ Ax ; [yx ,f , t, pxc] =spectrogram (au1 , 2000, 1900, 3900, 2e8, 'yaxis') ;

\%espectrograma do sinal de baixa freq multiplicado pelo seno e pelo cosseno px=(pxs. ${ }^{\wedge}+$ pxc. $\left.{ }^{\wedge} 2\right) \cdot{ }^{\wedge} 0.5 ; \%$ pxs e psc é a potência(power) do sinal

$\%$ multiplicado pelo seno e pelo cosseno e seno, temos a potencia dos 2 somados \%Agora o espectrograma de alta freq. 
66ódigo do Matlab usado para análise dos dados do reflectômetro

[yxx,f,t,pxx]=spectrogram (Axx, 2000,1900,3900,2e8, 'yaxis'); \% HIGH FREQUENCY , \%espectrograma do sinal de alta freq normalizado

$f f=2 *(8.7+(13.5-8.7) /$ length $(t) *((1:$ length $(t))-1)) ; \%$ az a correpondência

$\%$ do sinal do tempo em freq de varredura, em giga-hertz

siz=size $(\mathrm{pxx})$;

for $k \mathrm{k}=1: \operatorname{siz}(2) \%$ normaliza a potência, pela potência máxima

$\%$ em uma dada freq de varredura (tempo)

$\operatorname{pxx}(:, \mathrm{kk})=\operatorname{pxx}(:, \mathrm{kk}) / \max (\operatorname{pxx}(:, \mathrm{kk}))$;

end

$\mathrm{spx}=\mathrm{px}>0.001 * \max (\max (\mathrm{px})) ; \%$ valores apenas maiores que $0.1 \%$ do máximo valor $\%$ do px (potência), apenas as posições, é lógica, apenas 0 e 1

$\%$ px é para baixas freq. com o seno e cosseno com $5 \mathrm{mhz}$

$\mathrm{sp}=\mathrm{spx} . * \mathrm{pxx}+\min (\min (\mathrm{pxx}))+1 \mathrm{e}-2 ; \%$ Agora temos a potência de alta freq. apenas

$\%$ nos locais onde há o máximo para a baixa freq., com um fundo que é

$\%$ mínimo valor de pxx+1e-2, por que fazer isso? aparentemente tira ruídos

$\%$ de baixa freq. e mais \%alguns, onde há ruídos para baixa freq.,

$\%$ spx é zero, sinal fraco, dai é tirado

\%retira as freq., ou parte so sinal, que já existe quando não se tem a

$\%$ antena ligada.

$f=f * 1 e-6$

$\operatorname{surf}(f f, f, a b s(s p)$, 'EdgeColor' , 'none') ;

axis xy; axis tight; $\operatorname{colormap}(j e t)$; view $(0,90)$; ylim([3 7]);

set (gca, 'FontSize', 8);

xlabel('Reflectometer frequency (GHz)', 'fontsize',15); xlim([18 26]);

$\operatorname{caxis}\left(\left[\begin{array}{ll}-.1 & 0.3\end{array}\right]\right)$

ylabel ('Frequency (MHz)', 'fontsize',15);

title(['T = ', time,' msec'], 'fontsize', 15);

set (gca, 'fontSize', 15)

set (gcf, 'PaperUnits', 'inches')

numk $=\operatorname{sprintf}\left({ }^{\prime} \% \mathrm{~d}, \mathrm{k}\right)$; filenam=['shot', NP , ' -',numk, 'tira'];

print (gcf , '-dpng' , '-r300' , '-zbuffer ', filenam); 


\section{Lista de Figuras}

1.1 Esquema representativo de um tokamak, como o JET [11]. . . . . 4

1.2 Esquema das formas de aquecimento auxiliar para o plasma [11]. . 5

2.1 Relação de dispersão para as ondas de Alfvén para o primeiro modo radial. $x=\omega / \omega_{c i}$ e $k_{\|}=N c /\left(\omega_{p} R\right)$ sendo $N$ o número do modo toroidal, no caso foi considerado um contínuo de modo toroidais, para se ter uma imagem da relação de dispersão, mas no caso real, temos valores discretos de $k_{\|}$, para cada valor de $N= \pm 1, \pm 2, \pm 3 \ldots$, foram apresentadas as partes reais das soluções encontradas. . . .

2.2 Perfil radial do campo $B_{z}$ para os dois primeiros modos radiais, estão mostrados os modos com $m=1$, para $m=-1$ só muda o sinal, pois $J_{1}$ é ímpar. $O$ sinal de $k_{\|}$deve influenciar na magnitude do campo, não na forma da função. . . . . . . . . . . . . . . .

3.1 Impedância da antena para o modo $N=-4$ e $m=-1$, foram usados parâmetros do TCABR, o gráfico (a) tem um parâmetro de colisão uma ordem de grandeza maior que o gráfico (b), o pico é um modo global de Alfvén . . . . . . . . . . . . . . . .

3.2 Campo $H_{z}$ (que é a perturbação de $B_{z}$ ) e $E_{r}$ para $N=-3$ e $m=-1$ para $f=4,39 \mathrm{MHz}$, que é a frequência identificada como um modo global. É possivel ver semelhanças destes gráficos com o gráfico 2.2.

3.3 Relação de dispersão para as ondas de Alfvén como calculado no capítulo anterior, Figura 2.1. A simulação com o código são os pontos em vermelho. Foram usados valores de $N=-6$, frequência máxima, até -1 , frequência minima . . . . . . . . . .

3.4 Campos $H_{z}$ (que é a perturbação de $B_{z}$ ) e $E_{r}$ para o modo $N=-3$ e $m=-1$ com a frequência de $4,8 \mathrm{MHz}$, que é maior que a frequência de ressonância da onda global . . . . . . . . . . . . . . . . .

4.1 Esquema das antenas e da aquisição de dados com o circuito demodulador, as sondas magnéticas e eletrostáticas e o reflectômetro. . . 31

4.2 Detalhe de um strap da antena de aço inox. . . . . . . . . . . . . 32

4.3 Foto da antena dentro do vaso, com a proteção de nitreto de boro. 33 
4.4 Esquema do circuito em que está ligado cada strap da antena, é possivel ligar as antenas com defasagem de $\pi \ldots \ldots$. . . . . .

4.5 Esquema das bobinas ortogonais da sonda magnética usada para fazer as medidas do campo magnético [44] . . . . . . . . . . . . .

4.6 Fotos da sonda usada para se realizar as medidas de oscilação de densidade, apesar de ter 4 pinos, apenas 1 foi usado nas medidas. .

4.7 Esquema de blocos do circuito demodulador, conforme [45] . . . .

4.8 Esquema do circuito demodulador de sinais, D1, D2, D3 e D4 da

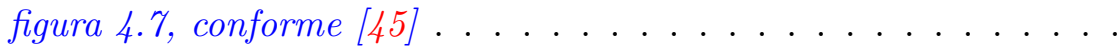

4.9 (a) saída do circuito demodulador pela frequência do sinal de entrada, a voltagem de ambos era mantida fixa. (b) saída do circuito demodulador pela amplitude do sinal de referência, mantinha-se a mesma frequência para o sinal de entrada e para o sinal de referência que o sinal de entrada. (c) saída do circuito demodulador pela amplitude do sinal de entrada, os outros parâmetros foram mantidos constantes. . . . . . . . . . . . . . . . . . . . . .

4.10 Esquema de funcionamento do reflectômetro.[27] . . . . . . . . .

4.11 Esquema de blocos do gerador de potência com varredura de frequên-

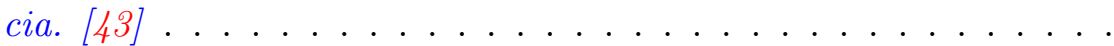

5.1 Espectrograma (a) da antena e da sonda magnética (b), (c) é a multiplicação digital de (a) e (b). (d) é o sinal de saída do circuito demodulador, para o disparo 1. . . . . . . . . . . .

5.2 Espectrograma (a) da antena e da sonda magnética (b), (c) é a multiplicação digital de (a) e (b). (d) é o sinal de saída do circuito demodulador, para o disparo 2. . . . . . . . . . . . . .

5.3 Espectrograma (a) da antena e da sonda magnética (b), (c) é a multiplicação digital de (a) e (b). (d) é o sinal de saída do circuito demodulador, para o disparo 3. . . . . . . . . . . . .

5.4 Simulação das ondas de helicon(a) para perfil de densidade parabólica de $2-9 \times 10^{10} / \mathrm{cm}^{3}$ no centro, e temperatura de $25 \mathrm{eV}$. (b) disparo que apresenta uma boa cocordância com a simulação de ondas de helicon, (c) espectrograma do mesmo disparo. . . . . . . . .

6.1 Sinais do disparo 24506, mostrando a corrente de plasma, a densidade de linha, o sinal do ECE e raio-X mole. . . . . . . . . . . .

6.2 Aumento da densidade no centro do plasma durante aplicação de Alfvén do disparo 24506, calculado com a equação 6.3. . . . . . . .

6.3 Perfil de densidade do disparo 24506, usando os dados do gráfico 6.2. Também mostramos os limites de densidade em que o reflectômetro opera. . . . . . . . . . . . . . . . .

6.4 Espectrograma do sinal do reflectômetro do disparo 24505, enquanto a antena estava em operação. As ressonâncias estão em destaque. 
6.5 Espectrograma do sinal do reflectômetro do disparo 24506, enquanto a antena estava em operação. As ressonâncias estão em destaque.

6.6 Espectrograma do sinal do reflectômetro do disparo 24506, enquanto a antena estava em operação. As ressonâncias estão em destaque.

6.7 Espectrograma do sinal do reflectômetro do disparo 24508, enquanto a antena estava em operação. As ressonâncias estão em destaque. $\quad 55$

6.8 Densidade das ressonâncias. . . . . . . . . . . . . . . . 56

6.9 Posição das ressonâncias nos espectrogramas. . . . . . . . . . . 56

6.10 Simulação do campo $H_{z}$ (que é a perturbação de $B_{z}$ ) e $E_{r}$ para $m=-3$ e $N=-1$ para $f=5 M H z \ldots \ldots \ldots \ldots$. . . . . 57 


\section{Referências Bibliográficas}

[1] Understanding and Responding to Climate Change - United States National Academy of Sciences 2008. http://americasclimatechoices.org/ climate_change_2008_final.pdf, Janeiro 2011.

[2] J. Ongena and G. Van Oost. Energy for Future Centuries: Will fusion be an inexhaustible, safe and clean energy source? 2008. http://www. fusie-energie.nl/artikelen/ongena.pdf, Janeiro 2011.

[3] Chernobyl's Legacy: Health, Environmental and Socia-Economic Impacts and Recommendations to the Governments of Belarus, Russian Federation and Ukraine. http://www.iaea.org/Publications/Booklets/Chernobyl/ chernobyl.pdf, Janeiro 2011.

[4] 20 years after Chernobyl - The ongoing health effects -. http: //www.ippnw-students.org/chernobyl/research.html http://www. ippnw-students . org/chernobyl/IPPNWStudy • pdf, Janeiro 2011.

[5] Chernobyl Sarcophagus. http://www.chernobyl-international.com/ chernobyl-sarcophagus.html, Janeiro 2011.

[6] I. E. Tamm. Theory of magnetic thermonuclear reactor (Part 1). Plasma Physics and the Problem of Controlled Thermonuclear Reactions, v. 1, p. 1, 1961.

[7] A. D. Sakharov. Theory of magnetic thermonuclear reactor (Part 2). Plasma Physics and the Problem of Controlled Thermonuclear Reactions, v. 1, p. 21, 1961.

[8] I. E. Tamm. Theory of magnetic thermonuclear reactor (Part 3). Plasma Physics and the Problem of Controlled Thermonuclear Reactions, v. 1, p. 35, 1961.

[9] S. D. Drell and S. P. Kaptiza. Sakharov Remembered: A tribute by Friends and Coleagues. American Institute of Physics.

[10] J. D. Lawson. Some Criteria for a Useful Thermonuclear Reactor. Atomic Energy Research Estabilishment, GP/R 180\%, 1955. 
[11] http://www.jet.efda.org/, Julho 2010.

[12] F. F. Chen. Introduction to plasma physics and controlled fusion. Springer, 1984 .

[13] J. Wesson. Tokamaks. Claredon Press, Oxford, 2004.

[14] I. N. Golovin and V. D. Shafranov. Sakharov Remembered: A tribute by Friends and Coleagues. 1991.

[15] http://www.iter.org, Julho 2010.

[16] R. Koch. The Ion Cyclotron, Lower Hybrid and Alfvén Wave Heating Methods. Transactions of Fusion Thecnology, v.37, p. 155-162, 2000.

[17] A.G.Kirov A.G.Elfimov and V.P.Sidorov. High-Frequency Plasma Heating. American Institute of Physics, 1992.

[18] King-Lap Wong. A review of Alfvén eingenmode observations on toroidal plasmas. Plasma Phys. and Control. Fusion, v.41, 1999.

[19] W. Grossman and G. Tataronis. Z. Phys 217(261m), 1973.

[20] S.D.Piazza G.G.Borg, J.B.Lister and Y.Martin. Nuclear Fusion, v. 33, p. 841, 1993.

[21] L.F.Ruchko et al. Advanced antenna system for Alfvén wave plasma heating and current drive in TCABR tokamak. Fusion Engineering and Design, v. 43, p. 15, 1998.

[22] E.M.Ozono. Desenvolvimento do sistema de excitação de ondas de Alfvén no TCABR. PhD thesis, IFUSP, 2000.

[23] H.Goedbloed and S.Poedts. Principles of Magnetohydrodynamics. Cambridge University Press, 2004.

[24] H. Alfvén. Nature, v. 150, p. 450.

[25] A.I.Akhiezer. Plasma Electrodynamics vol 1. New York: Pergamon, 1976.

[26] A. A. Rukhadze A. F. Alexandrov, L. S. Bogdankevich. Principles of Plasma Electrodynamics. Springer, 1984.

[27] L.F. Ruchko et al. Identification of Local Alfvén Wave Resonances With Reflectometry as a Diagnostic Tool in Tokamaks. Nucl. Fusion 46, S722, 2006 .

[28] L. Ruchko et al. Registration of Alfvén resonances in TCABR tokamak by the scanning reflectometer at sidebands frequencies. Review of Scientific Instruments, 2011. 
[29] A.G.Elfimov J.A.Tataronis and N.Hershkowitz. Physics of Plasmas,v. 1, p. 2637, 1994.

[30] A.G. Elfimov et al. Brazilian Journal of Physics, v. 25, p. 224, 1995.

[31] G. A. Segundo. Análise numérica do aquecimento de plasmas, geração de corrente e fluxo de onda de Alfvén no Tokamak TCABR. PhD thesis, IFUSP, 1999.

[32] J. Vaclavik e K. Appert. Nuclear Fusion v. 31, p. 1945, 1991.

[33] N. A. Krall e A. W. Trivelpiece. Principles of Plasma Physics. San Francisco Press, Inc., 1986.

[34] Naval Research Laboratory. NRL Plasma Formulary. United States Navy, 2009.

[35] H.G.Booker. Cold Plasma Waves (Developments in Electromagnetic Theory and Applications). Springer, 1984.

[36] J. Vaclavik K. Appert and L. Villard. Introduction to the Theory of Alfvén wave heating. CRPP Report, LRP 238/84, 1984.

[37] J. Vaclavik K. Appert and L. Villard. Spectrum of low-frequency, nonaxisymmetric oscillations in a cold, current-caring plasma column. Phys. Fluids, v. 27, 432-437, 1983.

[38] F. F. Chen. Experiments on helicon plasma sources. J. Vac. Sci. Technol. A 10(4), Jul/Aug 1992.

[39] A.G. Elfimov et al. Physics of plasmas, v. 1, p. 2882, (1994).

[40] R. Sanabria et al. Nucl. Fusion, 46 S154, 2006.

[41] G.A.Pestryakova A.G.Elfimov G.G.Komoshvili M.V.Dimitrieva, S.Yu.Medvedev and V.P.Siderov. Proceedings of 16th EPS Conference on Controlled Fusion and Plasma Physics, Venice, v.3, p. 423, 1989.

[42] G.L.Chen D.W.Ross and S.M.Mahajan. Phys. Fluids, v. 25, p. 652, 1982.

[43] L. Ruchko. Variable Frequency Generator. In Poster presented in Encontro Brasileiro de Física de Plasma, 2009.

[44] E. A. LERCHE. Desenvolvimento e Caracterização dos Sistemas de Alimentação e Diagnóstico para Excitação de Ondas de Alfvén do Tokamak TCABR. Master's thesis, IFUSP, 1998.

[45] L. C. B. M. Guidolin. Determinação da Configuração de Ondas de Alfvén Excitadas no Tokamak TCABR. Master's thesis, IFUSP, 2007. 
[46] R.H. Huddlestone and S.L. Leonard. Plasma Diagnostic Techniques. Academic Press, New York, 1965.

[47] P. G. P. P. Puglia A. G. Elfimov, L. F. Ruchko. Alfvén and Helicon Wave Resonances Measured with Demodulator Circuit in TCABR. referente a trabalho apresentado no ICPP 2010, submetido para publicação para o IOPP Conference Series em 10/2010.

[48] Analog Devices Inc. AD811 High Performance Video Op Amp.

[49] ON Semiconductor. MC1496 Balanced Modulators/Demodulators.

[50] C. Kitchin and L. Counts. A designer's Guide to Instrumentation Amplifiers. Analog Devices, 2nd edition, 2004.

[51] Analog Devices Inc. AD847 High Speed, Low Power Monolithic Op Amp.

[52] M. E. Manso C. Laviron, A. J. H. Donné and J. Sanchez. Plasma Phys. Control. Fusion, v. 38, p. 905,.

[53] G.J.Kramer R.Nazikian and E.Valeo. Phys. Plasma, v. 5, p. 1840, 2001.

[54] A.G.Elfimov and R.M.O.Galvão. Whistler instability driven by relativistic electron tail in tokamaks. Plasma Phys. Control. Fusion, v. 45, L63-L64, 2003.

[55] M.Maraschek P.J. McCarthy M.Sokoll K.Asmussen M.Bessenrodt-Weberpals, H.J. de Blank and the ASDEX Upgrade Team. MHD activity as seen in soft x-ray radiation. Plasma Phys. Control. Fusion, v. 38, 1543-1559, 1996.

[56] A.G.Elfimov R.M.O.Galvão M.Gracia-Munoz V.Igoniche P.Lauber M.Maraschek and ASDEX Upgrade Team. Identification of geodesic chirping Alfvén modes and q-factor estimation in hot core tokamak plasmas in ASDEX Upgrade. Plasma Phys. Control. Fusion, v. 53, 025006, 2011.

[57] S. E. Sharapov et al. Monitoring Alfven Cascades with Interferometry on the JET Tokamak. Physical Review Letters, v. 93, N.16, 165001, 2011.

[58] http://www.nrc.gov/reading-rm/doc-collections/fact-sheets/ 3mile-isle.html, Julho 2010.

[59] J. D. Jackson. Classical Electrodynamics Third Edition. Wiley, 1998. 